University of South Florida

DIGITAL COMMONS

Digital Commons @ University of

@ UNIVERSITY OF SOUTH FLORIDA

South Florida

6-25-2004

\title{
Recycled Materials Relational Database: Design and Implementation Aspects
}

Rory Morgan McDonald

University of South Florida

Follow this and additional works at: https://digitalcommons.usf.edu/etd

Part of the American Studies Commons

\section{Scholar Commons Citation}

McDonald, Rory Morgan, "Recycled Materials Relational Database: Design and Implementation Aspects" (2004). USF Tampa Graduate Theses and Dissertations.

https://digitalcommons.usf.edu/etd/1156

This Thesis is brought to you for free and open access by the USF Graduate Theses and Dissertations at Digital Commons @ University of South Florida. It has been accepted for inclusion in USF Tampa Graduate Theses and Dissertations by an authorized administrator of Digital Commons @ University of South Florida. For more information, please contact digitalcommons@usf.edu. 
Recycled Materials Relational Database: Design and Implementation Aspects

by

Rory Morgan McDonald

A thesis submitted in partial fulfillment

of the requirements for the degree of

Master of Science in Civil Engineering

Department of Civil and Environmental Engineering

College of Engineering

University of South Florida

\author{
Major Professor: Alaa K. Ashmawy, Ph.D. \\ Manjriker Gunaratne, Ph.D. \\ Rajan Sen, Ph.D.
}

Date of Approval:

June 25, 2004

Keywords: waste materials, database management system, industrial byproducts, Microsoft access, compendium

(C) Copyright 2004, Rory Morgan McDonald 


\section{Dedication}

This work is dedicated to my wife, Anne and our newborn son, Dane. Anne has been a tremendous support - sacrificing to stay home with our baby while I was finishing the research in preparation for the defense. During the laborious process of thesis writing, Dane provided much-needed stress relief in the form of father/son playtimes. The support and love of my whole family especially J.P., Jan, PGI, and the President allowed me the unparalleled opportunity of pursuing a graduate degree in geotechnical engineering with Dr. Ashmawy at the University of South Florida. 


\section{Acknowledgement}

Several individuals and organizations made this effort possible. The Florida Department of Transportation funded the recycled materials project through a research grant to the University of South Florida. Newel White, Amr "Sal" Sallam, and Jessica McRory

provided high quality insights on technical issues. Paul Gillrie, Dave Houssian, and Adam Gillrie of the Paul Gillrie Institute shared their knowledge of database management systems. Materials and harassment were graciously provided by Rupert Bodden. Finally, Dr. Ashmawy deserves a special thanks not only for being the best professor with whom I have ever been in contact, but also for being an unexpected mentor and friend. $\mathrm{He}$ requires much from his students but gives them much more in return. 


\section{Table of Contents}

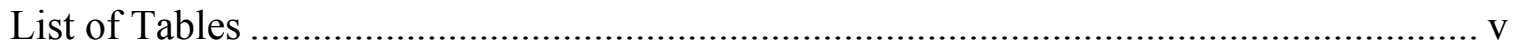

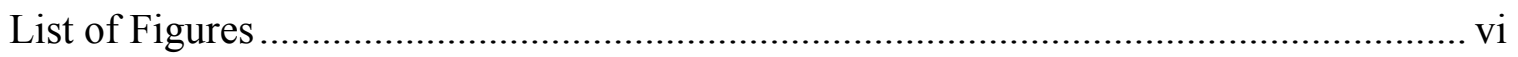

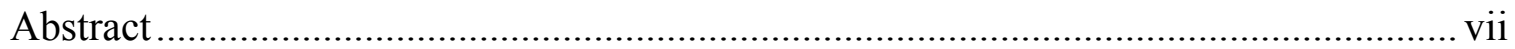

Chapter One: Introduction and General Literature Review ....................................... 1

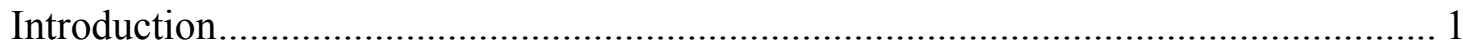

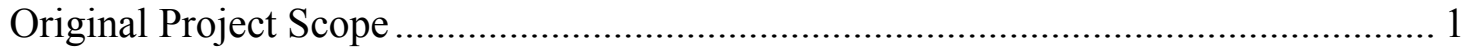

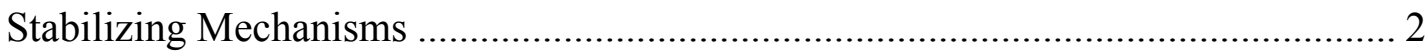

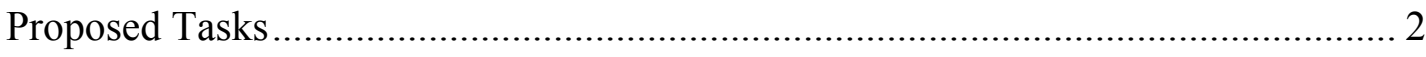

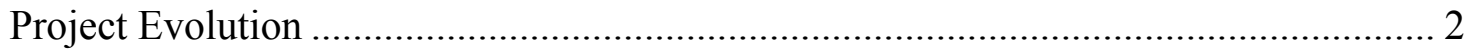

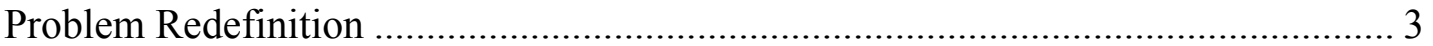

Proposed Solution: Recycled Materials Relational Database ..................................... 4

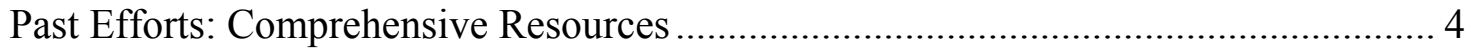

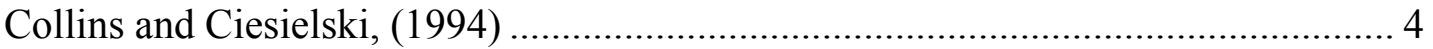

Chesner, Stein, Collins, and MacKay (1998) ........................................................ 5

Chesner, Collins, MacKay, and Emery (2002) ..................................................... 7

Current Effort: Recycled Materials Relational Database ...................................... 9

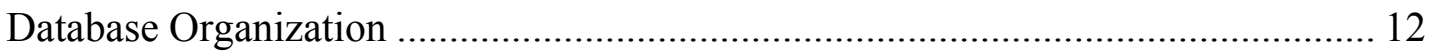

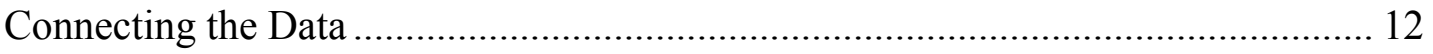

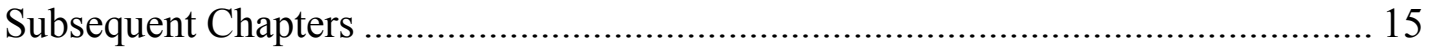

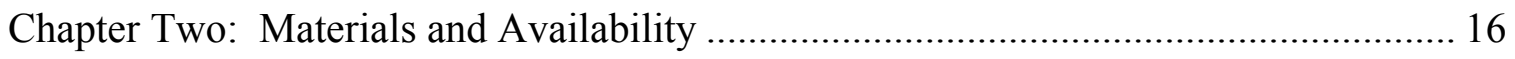

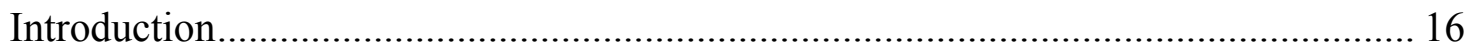

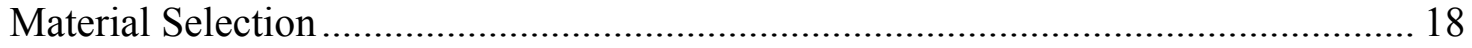

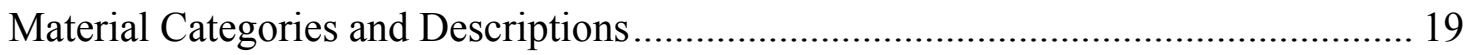

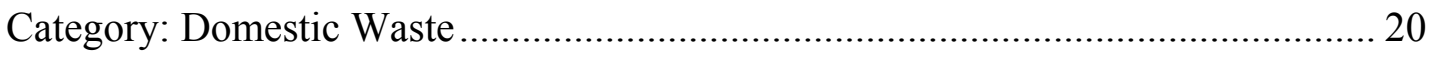

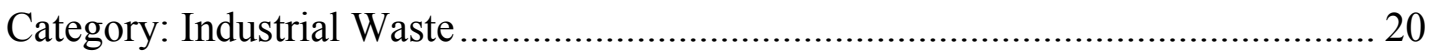




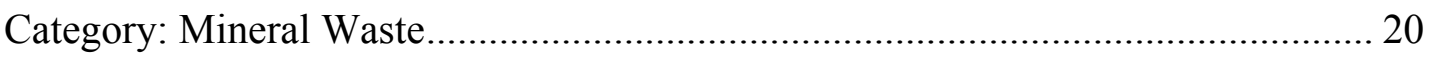

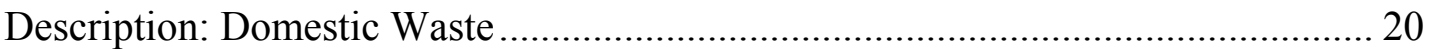

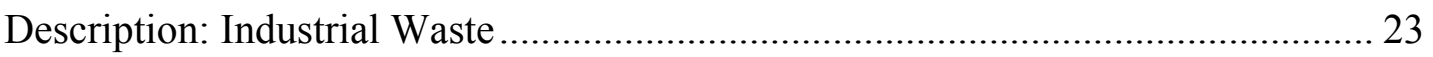

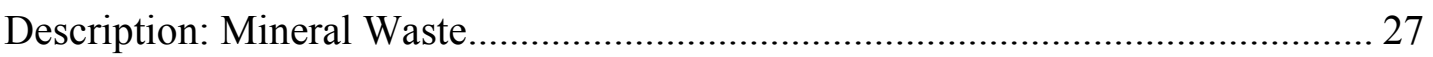

Material Availability ....................................................................................... 28

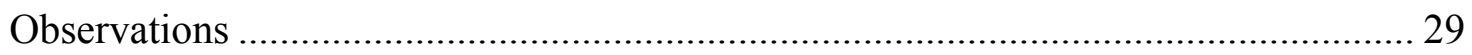

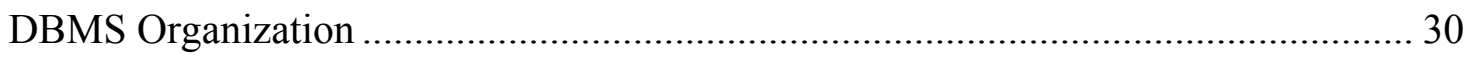

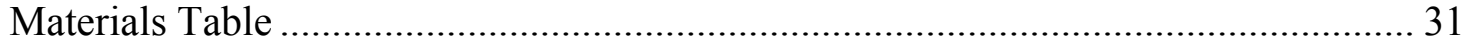

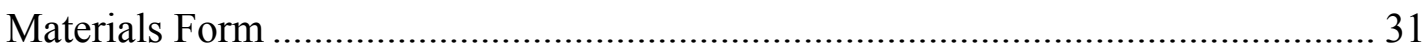

Chapter Three: Processing and Applications .............................................................. 32

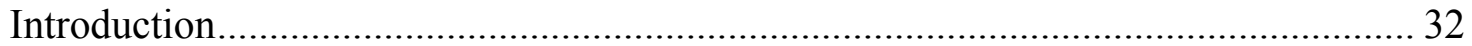

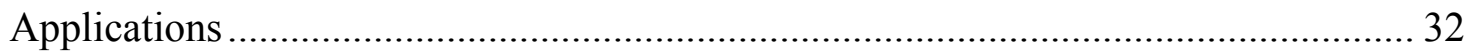

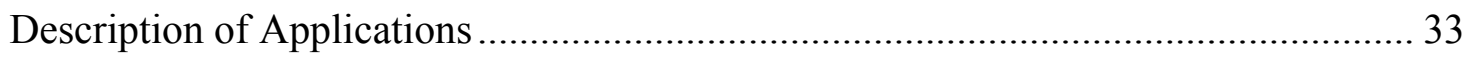

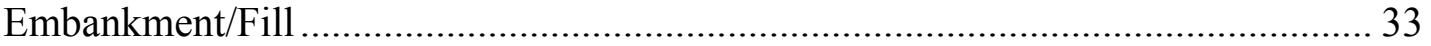

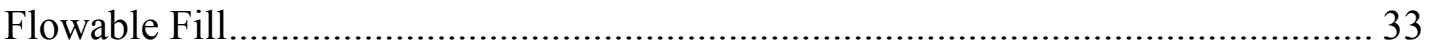

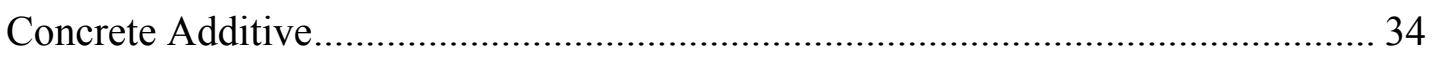

Asphalt Pavement .......................................................................................... 34

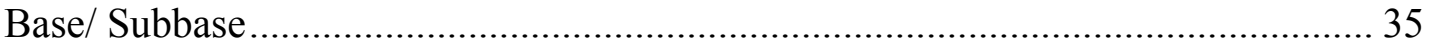

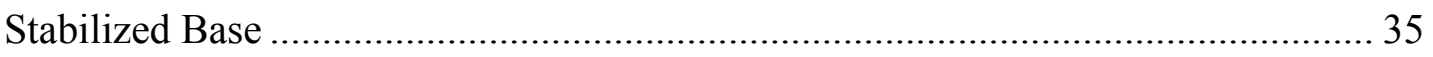

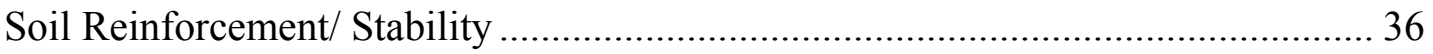

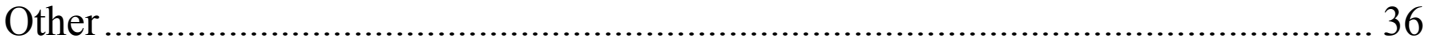

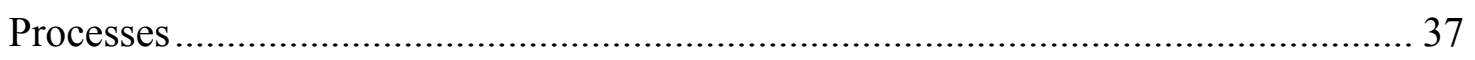

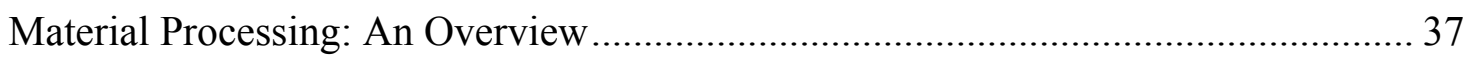

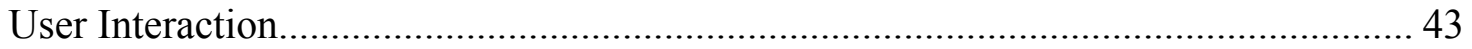

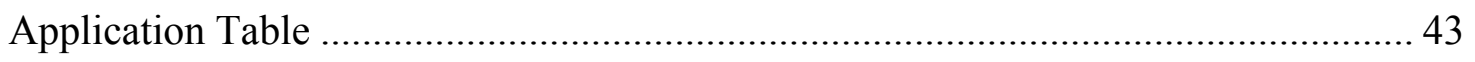

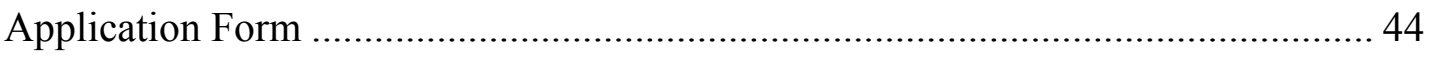

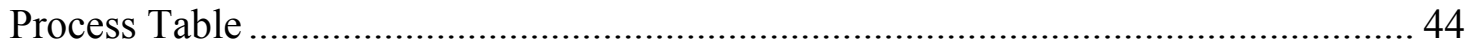

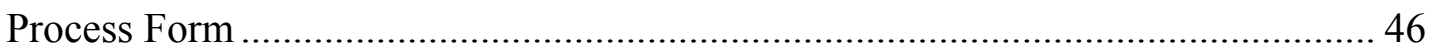

Chapter Four: Engineering and Environmental Properties and Performance.................. 47

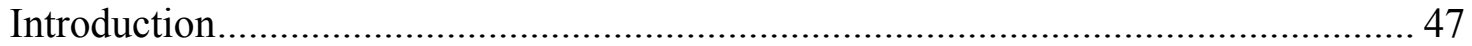




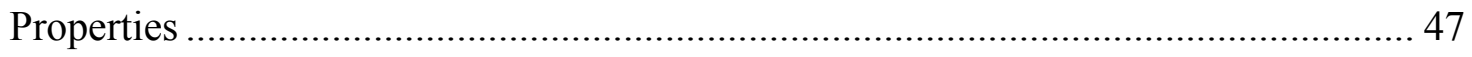

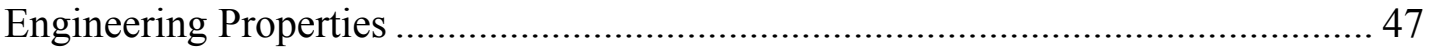

Omitted Engineering Properties .......................................................................... 48

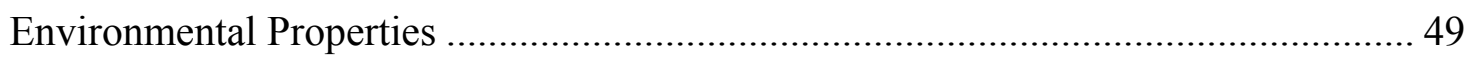

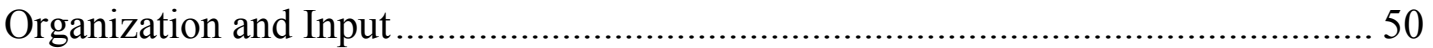

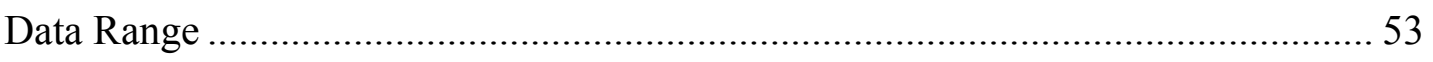

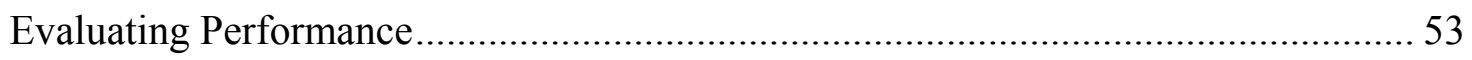

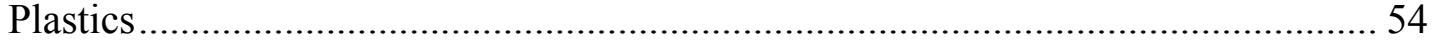

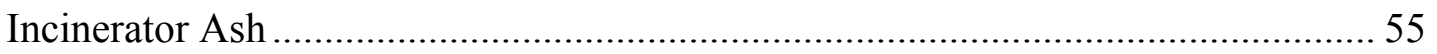

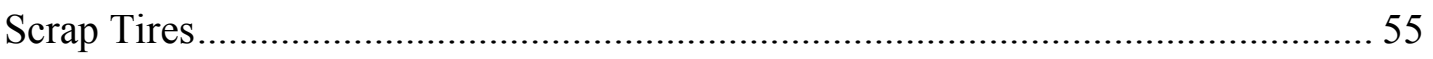

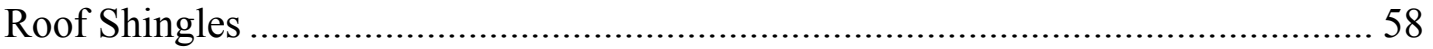

Coal Byproducts (Fly Ash, Bottom Ash, Boiler Slag) ............................................ 58

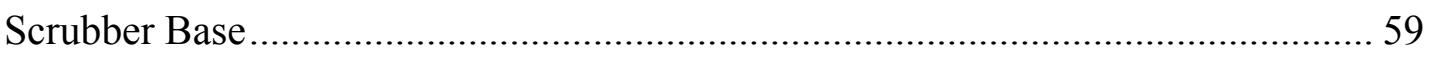

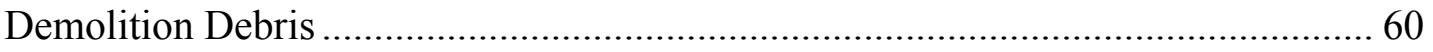

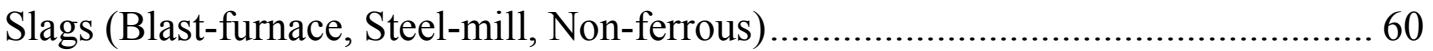

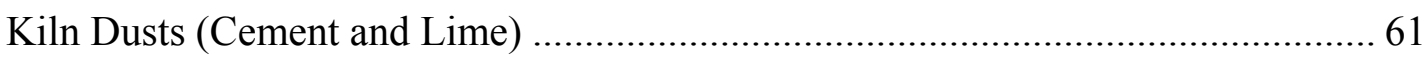

Reclaimed Asphalt Pavement and Reclaimed Concrete Pavement........................... 62

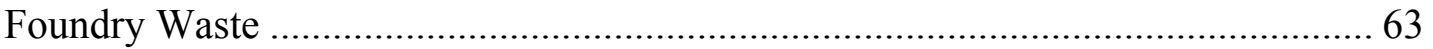

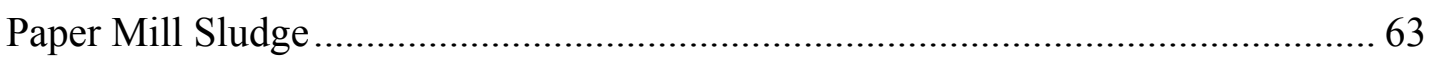

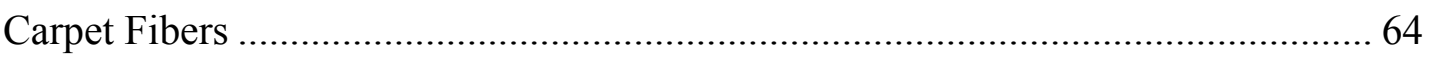

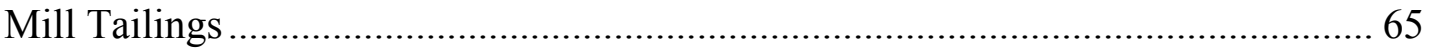

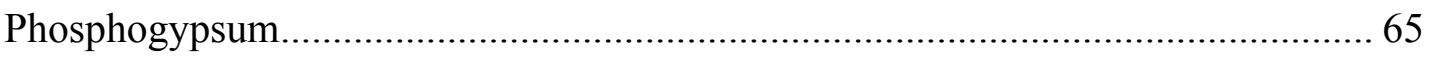

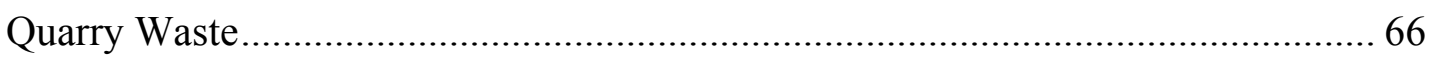

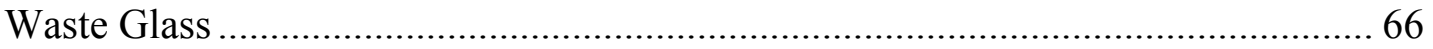

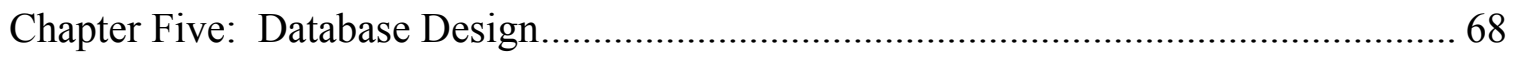

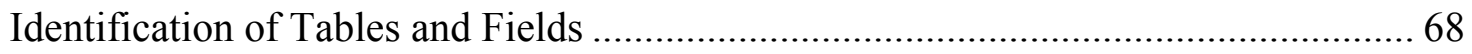

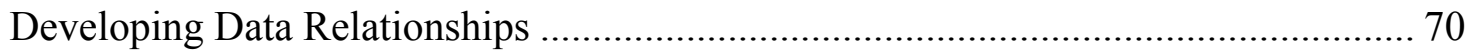

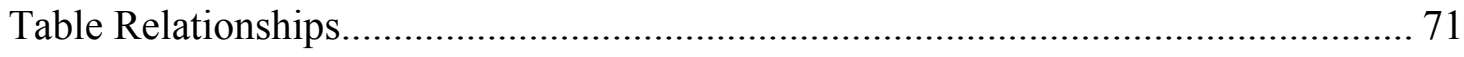

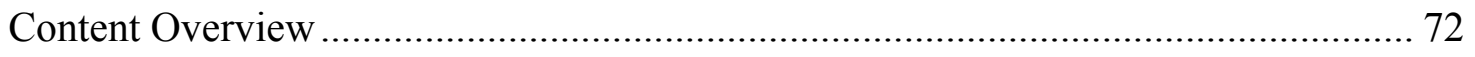

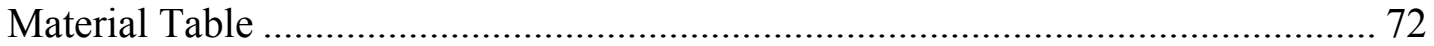




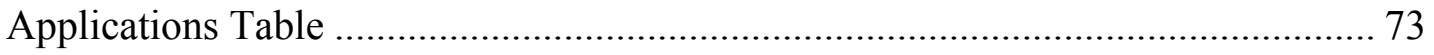

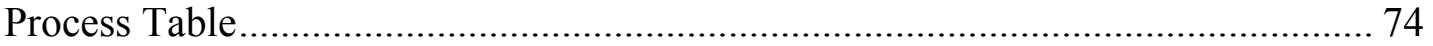

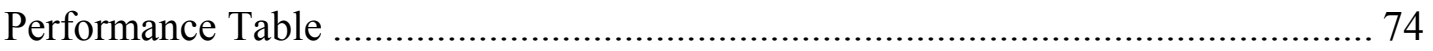

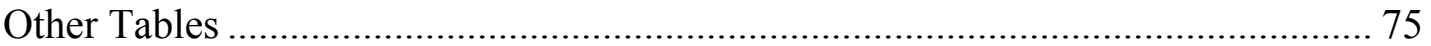

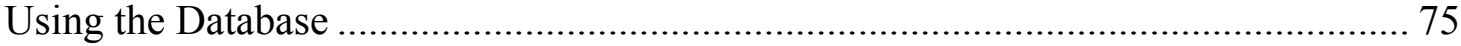

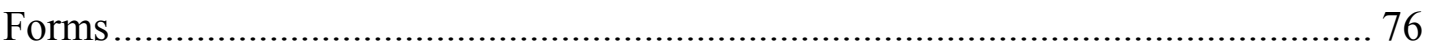

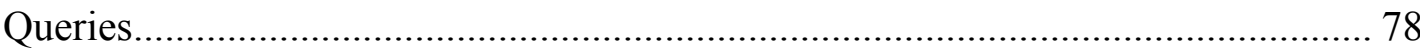

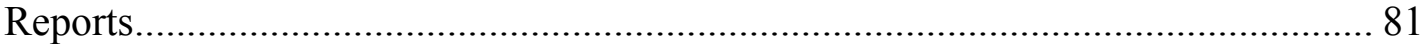

Interface

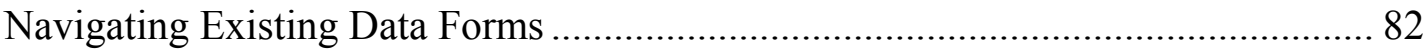

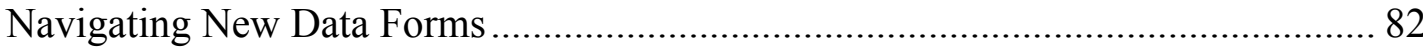

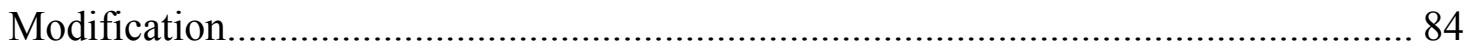

Chapter Six: Cost and Recommendations................................................................ 85

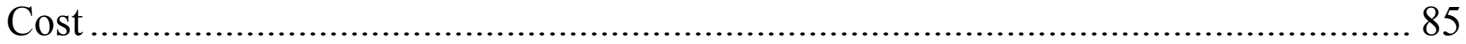

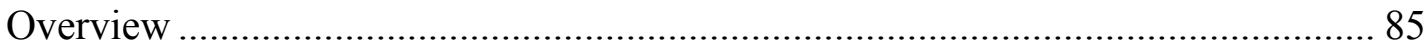

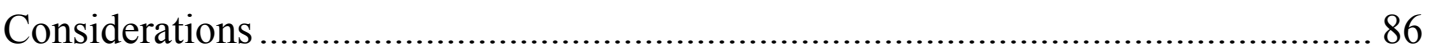

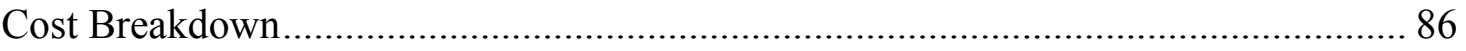

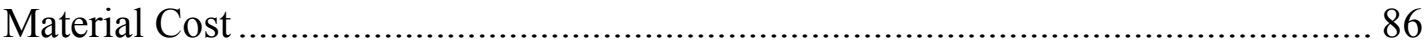

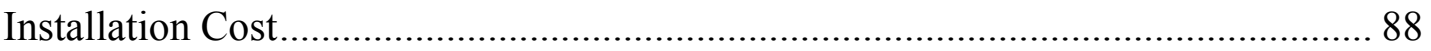

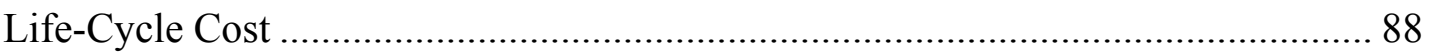

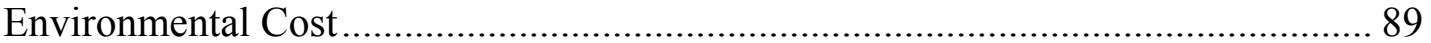

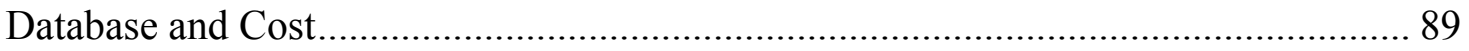

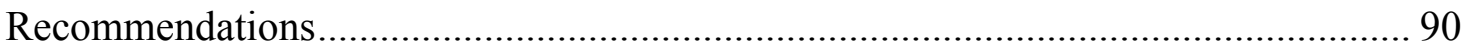

General Recommendations.............................................................................. 90

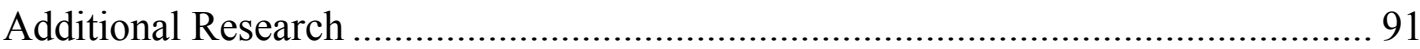

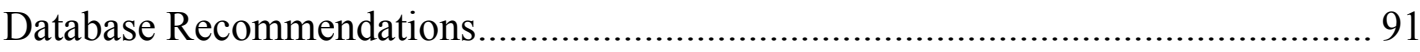

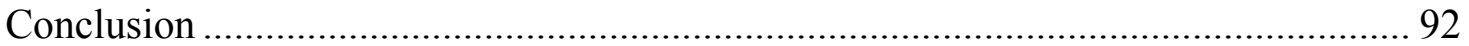

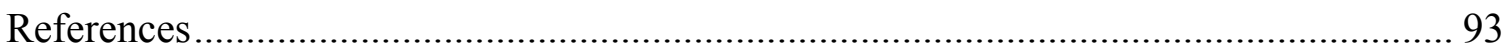




\section{List of Tables}

Table 2-1 Comprehensive Material Studies .......................................................17

Table 2-2 Recycled Materials for Current Research ............................................19

Table 2-3 Material Availability (Million Tons per Year) ......................................29

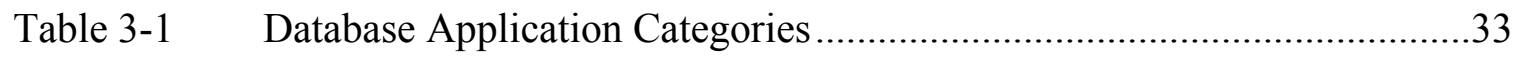

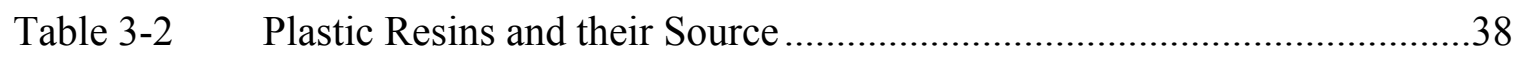

Table 4-1 Database Engineering Properties ..........................................................48

Table 4-2 Environmental Properties Tables ..............................................................50

Table 4-3 Properties of Environmental Concern .................................................51

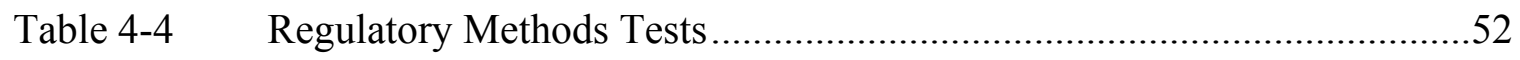

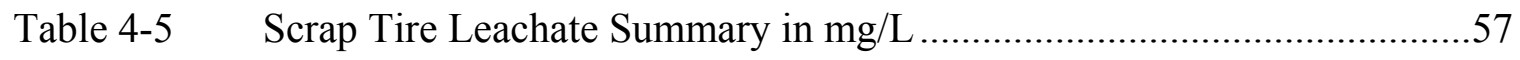

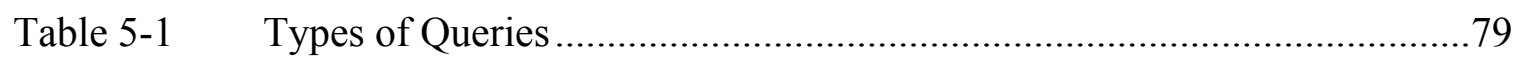




\section{List of Figures}

Figure 1-1 "Recycled Materials Information Database" ".........................................

Figure 1-2 "User Guidelines for Waste Materials in Pavement Construction"............9

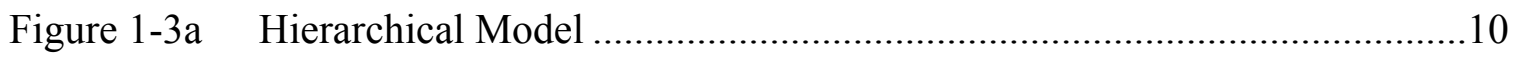

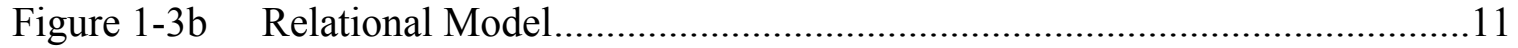

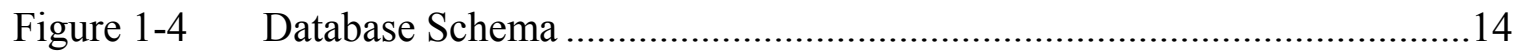

Figure 2-1 Material Availability Bar Graph ...................................................... 30

Figure 3-1 Scrap Tire Use for U.S. and Florida ..............................................40

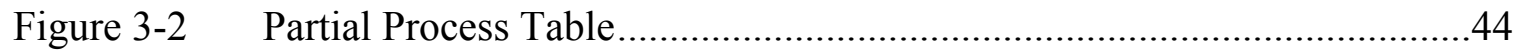

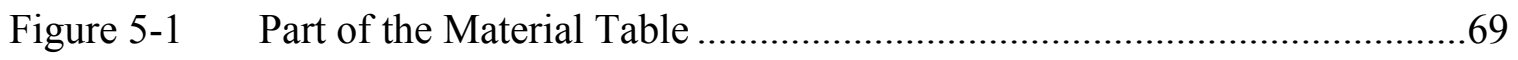

Figure 5-2 Case Process Form ('View Existing Data') ............................................77

Figure 5-3 Process Form ('Add New Data') ...........................................................78

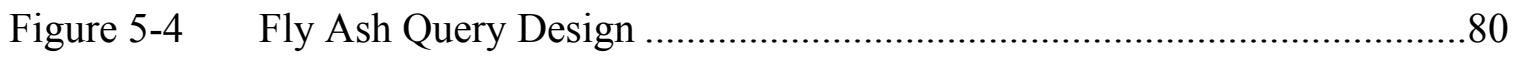

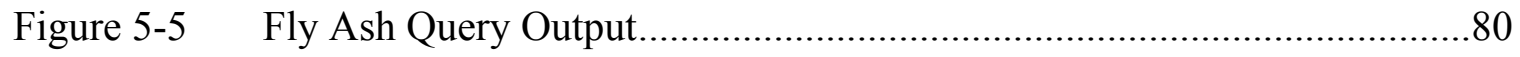

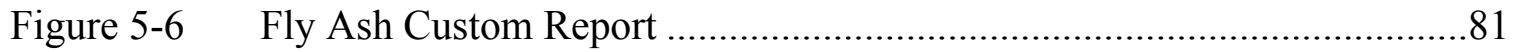

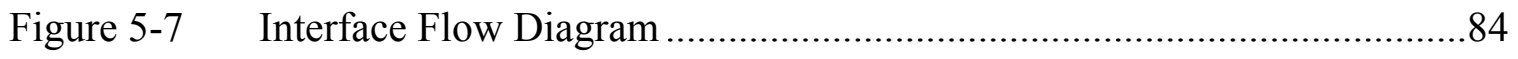




\title{
Recycled Materials Relational Database: Design and Implementation Aspects
}

\section{Rory Morgan McDonald}

\begin{abstract}
Although there has been a rise in the use of recycled materials in highway and geotechnical systems, many tons of potentially useful industrial and domestic byproducts are still being discarded in the United States each year. While extensive research has been conducted to investigate the use of recycled materials in engineering applications, the dissemination of the findings is often limited. The problem is compounded by the lack of a single resource containing relevant engineering and environmental characteristics of each material; the tendency of the researchers to publish their findings in technical reports rather than archived publications; and the wide discrepancies among local and state environmental regulations and acceptability. A relational database is proposed as a method to improve implementation of recycled material research. A comprehensive review is conducted on data available for a wide variety of recycled materials and their usage in highway and geotechnical applications. Mechanical and environmental data and information from case histories are organized into approximately 10 tables in a relational database management system. More than 30 parameters, including engineering properties, availability and cost, are recorded for 23 materials in a highly-organized compendium. Through a simple user interface, a vast amount of data can be sorted to implement a recycled material program based on historic and current data. The DBMS is updatable and the design is amendable to account for future expansion.
\end{abstract}




\section{Chapter One: Introduction and General Literature Review}

Introduction

Recycled materials provide an attractive alternative to traditional engineering construction materials such as asphalt, concrete, natural aggregate and others. This is due in part to their suitable engineering properties, which allow them to be used as substitute materials in several transportation and geotechnical applications. Equally important, recycled materials offer both economic and environmental incentives. In addition to a lower cost in comparison to traditional materials, their use has the potential to alleviate landfill problems as well as avert costs typically associated with their disposal.

\section{Original Project Scope}

Originally, the purpose of this project was to investigate the use of recycled materials in geotechnical and transportation applications. Specifically, it was concerned with marginal soils. Soft clays, muck, organic deposits, and loose sand are often unsuitable for use in construction due to their less-than-desirable engineering properties. Traditional methods of stabilizing these soils through in-situ ground improvement or replacement techniques are costly. Recycled materials such as scrap tires, plastics, ash, slag, and construction debris provide a viable alternative both for their relatively lower cost and desirable engineering properties. Furthermore, use of recycled materials prevents their disposal into landfills, which are approaching capacity across the country. 


\section{Stabilizing Mechanisms}

Initially, it was proposed to investigate different types of marginal soils stabilized with recycled materials. Particularly, the interest was in examining two stabilizing mechanisms: discrete and homogenous. In discrete stabilizing, individual elements such as recycled plastic piles (RPPs) are driven into the soil to prevent slope failure and improve global stability. Homogeneous stabilizing, on the other hand, refers to mixing much smaller particles of recycled materials such as plastics, ash, or carpet fibers with marginal soils to improve their strength. It was envisioned that by classifying these systems and identifying candidate applications, both construction methods and design procedures could be developed.

\section{Proposed Tasks}

Several components of the initial project were proposed. First, a comprehensive literature review was to be conducted in order to gather availability information, technical specifications, and parameter data for several recycled materials. Then, through feedback from the State and District Florida Department of Transportation offices, the procedure would be to categorize the types of marginal soils encountered and current solutions and then classify them according to the appropriate stabilizing mechanism. Next, a laboratory and field experimental program would be setup to investigate both properties of stabilized soils and mixing methods. This would allow for the development of design and construction procedures. Finally, large-scale field evaluations would be carried out as a means of testing design and construction procedures.

\section{Project Evolution}

During the first stage of the project, the literature review, the project began to evolve. Recycled material research was much more developed than originally anticipated - spanning some twenty years. The majority of early studies dealt with new material identification and laboratory testing to determine material properties (Collins and 
Ciesielski, 1994; Edil and Benson, 1998). More recent research has included large-scale field tests, predominantly environmental studies, and processing technique characterization (O’Shaughnessy and Garga, 1999; Liu et al., 2000; Consoli et al., 2002). Perhaps the most surprising finding was the relative lack of documented implementation programs. With so much quality research in recycled materials, it is clear that implementation has not kept pace. This point was tested and reinforced by means of a recycled material survey sent to the seven Florida Department of Transportation district offices. When representatives from each were asked to document use of recycled materials in their district, very few had had any experience to share. This supports a theory that a large gap exists between academic research on recycled materials and engineering practice and implementation.

\section{Problem Redefinition}

Despite current efforts, many tons of potentially useful industrial and domestic by-products are still being discarded each year. Moreover, implementation of recycled material programs at the state level has not kept pace with research. This phenomenon can be explained by several factors. First, the lack of a single resource containing relevant engineering and environmental characteristics of each material limits the dissemination of findings. This makes it difficult to adequately compare several materials before deciding to adopt one into practice. Second, researchers tend to publish data in technical reports, online sources, and special publications as opposed to archived publications. Sorting through and finding pertinent information can be time-consuming and tedious. The wide discrepancies among local and state environmental regulations in terms of material acceptability make it difficult to establish consistent practices among various states and regions. Finally, the rapid generation of new research exacerbates the existing logistics problem of data organization. 
Proposed Solution: Recycled Materials Relational Database

A relational database is proposed as a method to organize current data, simplify the interface that the user encounters, and ultimately improve implementation of recycled material research. If the gap discussed earlier is valid, then there must be a way to mitigate the separation between academic research in recycled materials and engineering practice. The initial effort will be centered on a relational database. Essentially a collection of attributes that describe specific objects, a relational database provides several advantages to traditional methods of organization. For example, such a database stores information in the form of related tables - allowing the same data to be viewed in different ways. It is not necessary for the user to know how the data is related in order to meaningfully interact with it. Through forms, queries, and reports - the fundamental elements of any database management system, the user can rapidly sort through a vast amount of current, relevant data. Furthermore, the database management system is updatable and the design is amendable to account for future expansion. The result is an effective tool to aid in the implementation of recycled material research.

Past Efforts: Comprehensive Resources

Collins and Ciesielski, (1994)

In conjunction with the National Cooperative Highway Research Program (NCHRP) and the American Association of State Highway and Transportation Officials (AASHTO), a study was undertaken to synthesize the information available on the use of waste materials in highway construction. The report sought to systematically compile useful information before disseminating it to the public. Primarily targeted at "administrators, policy makers, engineers, and others involved in highway construction," the resource contains useful information regarding everything from design considerations and environmental aspects to the economics, availability, and actual highway construction use of waste materials (Collins and Ciesielski, 1994). Organized according to four source identifications: agricultural, domestic, industrial, and mineral wastes, the 
report addresses the gap theory by admitting that "what has been learned about a problem frequently is not assembled, costly research findings may go unused, valuable experience may be overlooked, and full consideration may not be given to available practices for solving or alleviating the problem" (Collins and Ciesielski, 1994).

Although somewhat lacking in detail, their findings are nonetheless more comprehensive than previous work. Information is provided on at least 38 materials. In addition, several processes and applications as well as environmental issues are mentioned for each material. Actual uses in field construction are documented according to the state in which they took place. In general, the source is a very good summary of research and practice in recycled materials before 1994. Excellent data on material availability and detailed state-by-state use of recycled materials in several applications are perhaps the best contributions. Unfortunately, the report lacks detail. Virtually no specific information is available on engineering and environmental properties. Finally, as a printed report, there is still no relief from having to painstakingly search for the information that is of interest. The only way to update the report is to produce a new one.

Chesner, Stein, Collins, and MacKay (1998)

Sponsored by the American Association of State Highway and Transportation Officials (AASHTO) and in connection with the Federal Highway Administration, the "Recycled Materials Information Database" was designed as a single source. Its stated purpose was to provide "a tool that could be used to access from a database, information on recycled material properties, applications, and testing procedures" (Chesner et al., 2003). The database is organized according to twenty waste materials and six applications. After choosing a material, nine primary tabs provide easily navigable access to 28 subcategories. The primary tabs are: General Information, Production and Use, Engineering Properties, Environmental Properties, Applications, Laboratory Testing, Field Testing, References, and contacts. The subcategories range from availability by region and chemical composition by material to construction procedures and bibliographical references. Figure 1-1 shows one screen from the database. The 
primary tab "Production and Use" and the secondary tab "U.S.A. Production" have been chosen for "Coal Fly Ash." Availability or production data is presented in a state-bystate breakdown. Features also allow users to edit and delete both the text and existing tables or create new data tables and figures as new information becomes available. In short, the "Recycled Materials Information Database" is a valiant effort aimed specifically at the bridging the gap.

Perhaps the most important features of the database are its attention to detail, its rigid organization and its facilitation of moving rapidly from one area of interest to another. With a click of the mouse, a user can browse trace metal concentration data for a particular material or view the availability of a different material state-by-state. Another helpful addition is the ability to update the existing resources. A user can add new data as it becomes available. There are however, several drawbacks to this approach. First, the database has a hierarchical relationship structure. Similar to a pyramid, this type of relationship is top down. A user must start the search by first choosing a material, and then progressing to a subcategory involving that material. In order to compare data, it is necessary to go back to the beginning and choose a different material. A hierarchical model has two main deficiencies: 1) the user has to know something either about the subject or about the way in which the data is organized and related and 2) the user cannot search for specific information in a specific subcategory without first going back to the beginning of the hierarchy. As a result of these limitations, the database can best be used by an individual with intimate knowledge of recycled material research. 


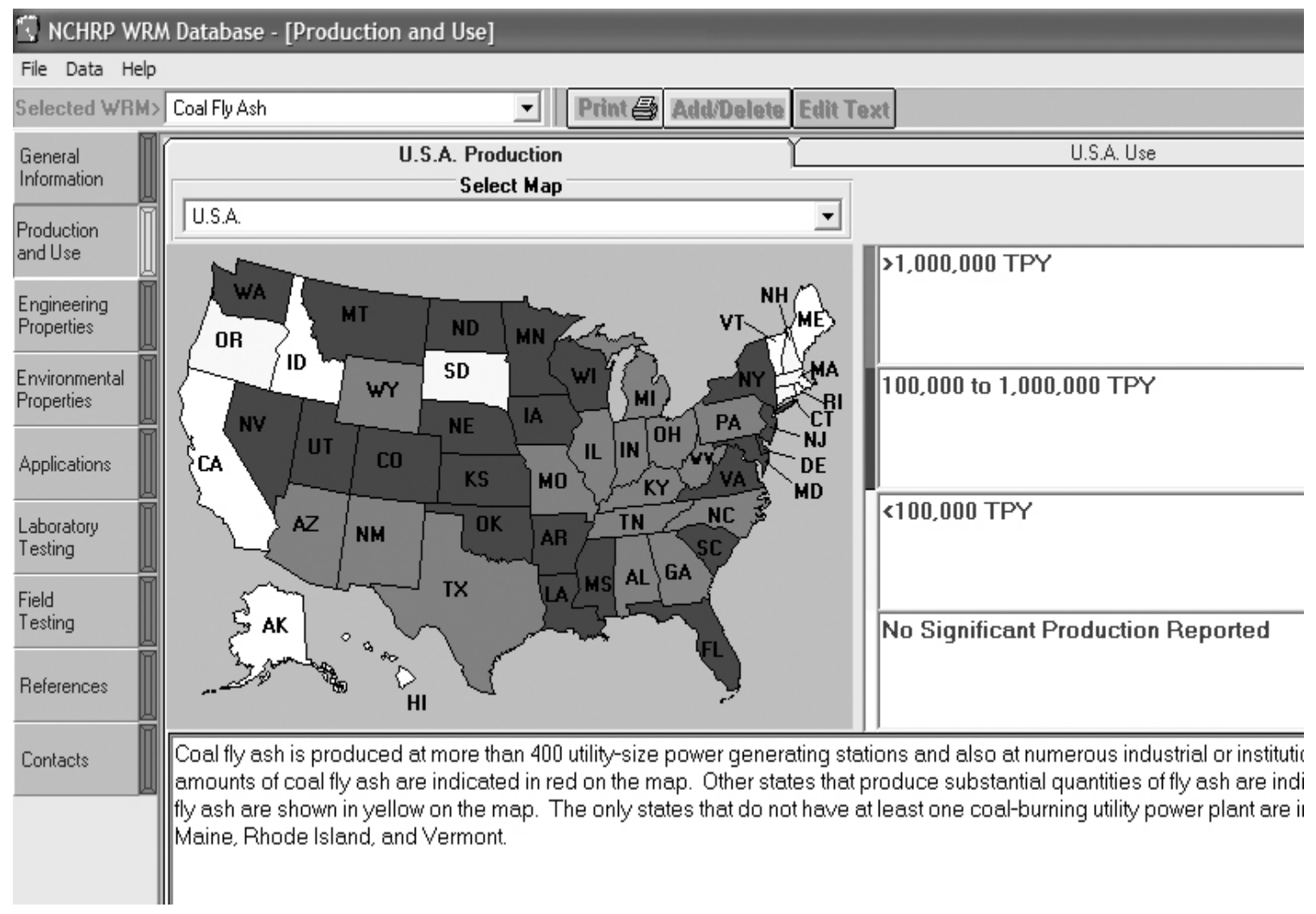

Figure 1-1: "Recycled Materials Information Database" (Chesner et al., 1998)

Chesner, Collins, MacKay, and Emery (2002)

As a result of recent federal initiatives for recycled material use in highway construction in the U.S., a project was undertaken to provide information on waste materials in specific applications. In addition, the project sought to address issues of suitability for relatively unknown materials and identify areas in need of future research (Chesner et al., 2003). The result, "User Guidelines for Waste and Byproduct Materials in Pavement Construction," is an online resource organized through twenty-one recycled materials and six applications. It is primarily an online version of a technical report, providing users with access to information such as material origin, processing requirements, market sources, management options, and material properties (Chesner et al., 2002). Many of the tables and other general information in the user guidelines are borrowed directly from its predecessor, the "Recycled Materials Information Database." 
Currently, no features exist that allow the user to edit or add to existing information. However, the shear volume of information available makes it a valuable single, comprehensive resource.

The advantages of the user guidelines are threefold. First, they are very wellorganized and detailed. Unlike the printed technical report by Collins and Cielieski, material properties are available in the form of data tables. The second advantage is the user interface. It is both seamless and aesthetically pleasing - allowing the user to effortlessly move from one category to the next with a click of the mouse. Finally, by making it available on the web, users are not required to download software or order it in report format. Instead they can simply go to the website and start perusing. However, there are certain drawbacks. Like the database described previously, the user guidelines are set up as a hierarchical model. The user may only choose a material or a material/application combination before viewing the information appertaining to it. This feature requires the user to have some knowledge of recycled materials or at least how the information has been organized. The user cannot search and sort by property, availability, chemical composition or any other subcategory for that matter. Similarly, the user has no ability to add, update, or delete information. This makes the useful life of the user guidelines somewhat limited. In Figure 1-2, the user guidelines page for scrap tires is reproduced. 
CONTACT WEBMASTER

Foreword

User Guidelines

Introduction

Baghouse Fines

Blast Furnace Slag

Coal Bottom Ash/Boiler Slag

Coal Fly Ash

FGD Scrubber Material

Foundry Sand

Kiln Dusts

Mineral Processing Wastes

MSW Combustor Ash

Nonferrous Slags

Quarry Byproducts

Reclaimed Asphalt Pavement

Reclaimed Concrete Material

Roofing Shinqle Scrap

Sewage Sludge Ash

Steel Slag

Sulfate Wastes

Waste Glass

Evaluation Guidance
[ Asphalt Concrete (Wet Process) ] [ Asphalt Concrete (Dry F

\section{SCRAP TIRES}

\author{
ORIGIN
}

Approximately 280 million tires are discarded each year by American motc United States. Around 30 million of these tires are retreaded or reused, le managed annually. About 85 percent of these scrap tires are automobile $t$ need to manage these scrap tires, it has been estimated that there may $b$ accumulated over the years and are contained in numerous stockpiles. ${ }^{(1)}$

Scrap tires can be managed as a whole tire, a slit tire, a shredded or chip product.

Whole Tires

Figure 1-2: "User Guidelines for Waste and Byproduct Materials in Pavement Construction" (Chesner et al., 2002)

Current Effort: Recycled Materials Relational Database

A new thread of recycled materials research has surfaced: compendium development. This research attempts to add to this thread. To be considered truly original and useful, the relational database must continue to build upon the positive advances of past studies and address the limitations of those mentioned here. First, the database must be robust. Studies by Chesner et al. (1998) and Chesner et al. (2002) satisfy this requirement through the large volume of detailed data that they include. In the relational model presented in this thesis, some nine tables composed of more than 60 fields and comprising the work of almost 90 research studies form the skeleton of the 15 mega byte database. By incorporating almost every possible category of information that may be of interest to both academics and engineering professionals, the recycled materials database is a one-stop single source that is comprehensive in nature. 
Further components that must be built upon rather than replaced include data organization, detail, and user interface. The latter especially will be admittedly difficult to duplicate without a professional web designer. However, it is still possible to deliver an aesthetically pleasing, seamless interface, which is user-friendly. The tables and fields are chosen to provide unparalleled organization and maximum detail. The relational database model addresses limitations that are consistent among the other three efforts. First, access to queries improves searchability. By creating a custom query, a user can search for information from any table or any field and combine that information into one table for viewing. The user is not forced to search simply by material type or application. Therefore, the user is not required to have previous knowledge of either recycled materials or the structure of the database. This is one of the advantages of a relational model in which all data is linked together as opposed to a hierarchical model in which initial choices lead to increasingly narrow branches of data. Figure 1-3 and 1-4 provide an example of the hierarchical and relational database model, respectively.

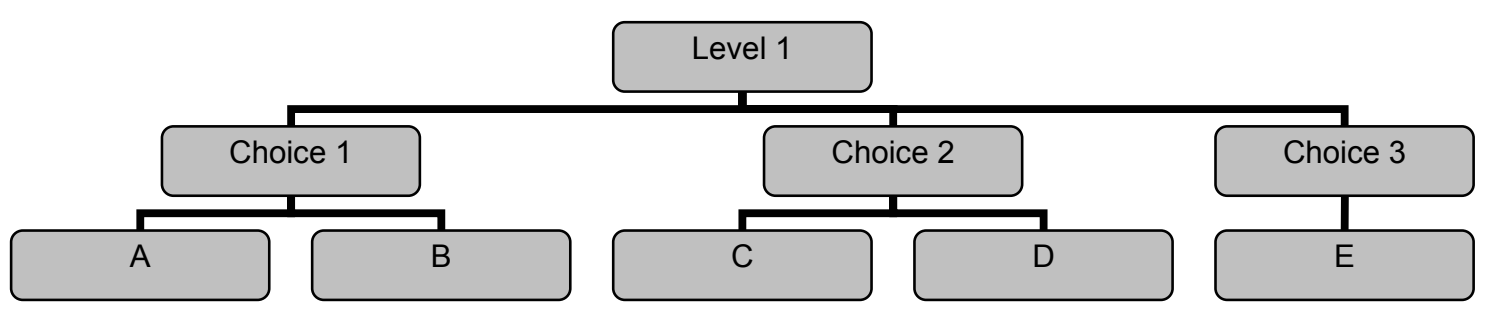

Figure 1-3a: Hierarchical Model 


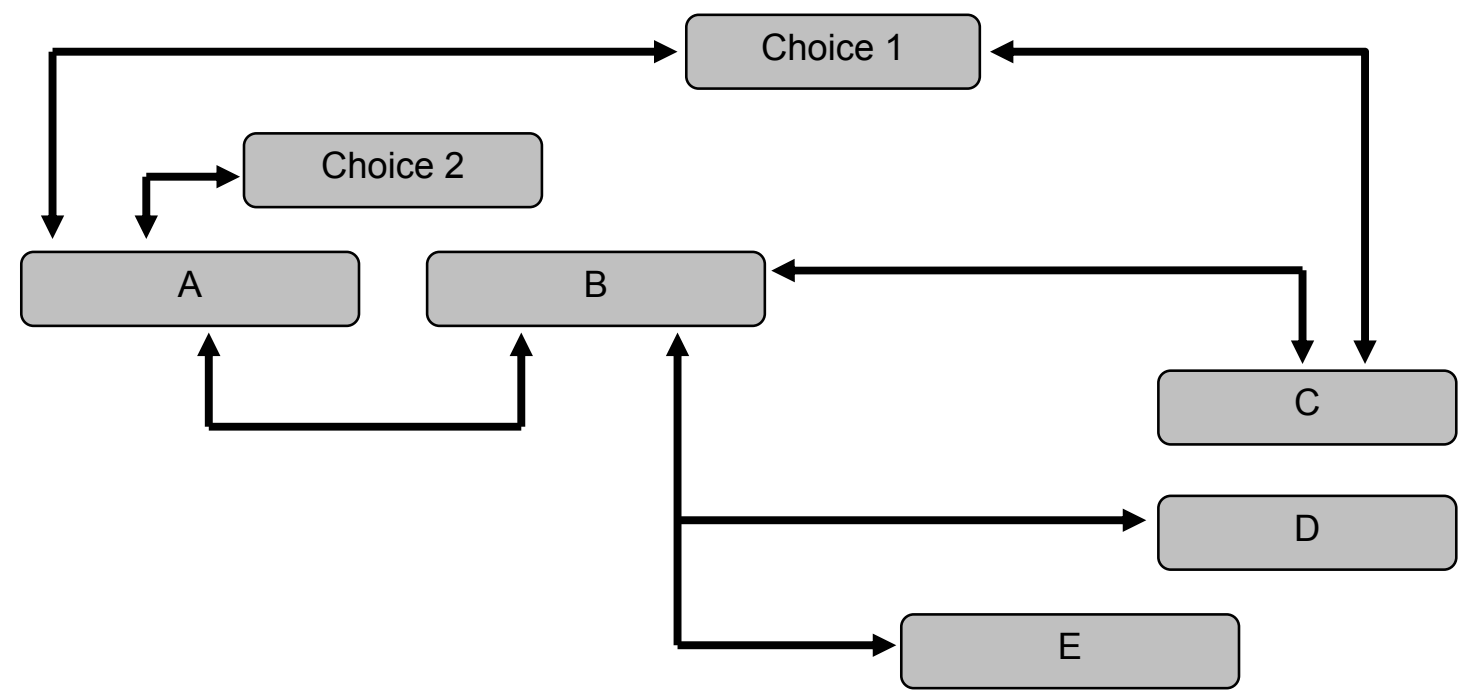

Figure 1-3b: Relational Model

Two more important features are amenability and control of data entry. Only the project by Chesner et al. (1998), allows the user to add, edit, or delete data. However, doing so requires basic knowledge of database design. Also, there is no way to control data entry - to keep a user from inputting duplicate, false, or poorly-formatted data. In the relational model, data is inputted through simple forms that make up one branch of the interface. Field properties and indexing properties are changed so as not to allow duplications in specific data entries. In addition, pull-down boxes and validation rule settings prevent users from entering improperly-formatted data. Finally, forms for viewing data are locked to prevent editing correctly-entered existing data. If any of these controls become burdensome or prove to be inadequate or inappropriate, they can easily be changed by a database designer. 


\section{Database Organization}

The database is organized with nine data tables serving as the framework. These tables are chosen both for their relevant importance as recycled material topics and for their ability to easily link the data together. The nine tables are Material, Application, Process, Performance, Case/Process, Chemical Composition, Metal Concentration, Organic Concentration, and Leachate. The function of most tables is obvious from the name of that table. However, there are a few exceptions. The Process table not only contains descriptions of refining sequences but it also has keeps track of every unique combination of material and application (e.g., fly ash as a concrete additive). The Performance table essentially documents case studies by providing detailed references that correspond to a specific process. So for a study on carpet fibers used in soil reinforcement, the authors of the study, the full bibliographical reference, the year, and the state would be documented. The Case/Process table acts as a matrix of engineering properties. Each record corresponds to a unique combination of case study and process. For example, a record might be kept of a study by a particular researcher to investigate the use of waste roof shingles in asphalt pavement.

\section{Connecting the Data}

Each of the first five tables has an ID field that serves as a primary key. In addition to serving as a unique identifier of the entire record, the primary key links each table to at least one other table through a foreign key. The foreign keys contain the same numbers as the primary keys though they may or may not be unique. The last four tables,

which are the environmental property tables only have primary keys. Because every table is linked to at least one other table and all nine tables are linked to the group, access to one table grants access to all tables. In Figure 1-5, tables and relationships are shown by way of a database organizational chart or schema. Each table name is bolded, and each primary key is underlined. The entries that are not bolded or underlined constitute the subfields within the tables. The lines between the tables indicate relationships that exist. The numbers above and below the lines, ' 1 ' and ' $\infty$ ' refer to one and many 
respectively. They characterize the relationships (one-to-one, one-to-many) that exist between the tables generally and the primary and foreign keys specifically. 


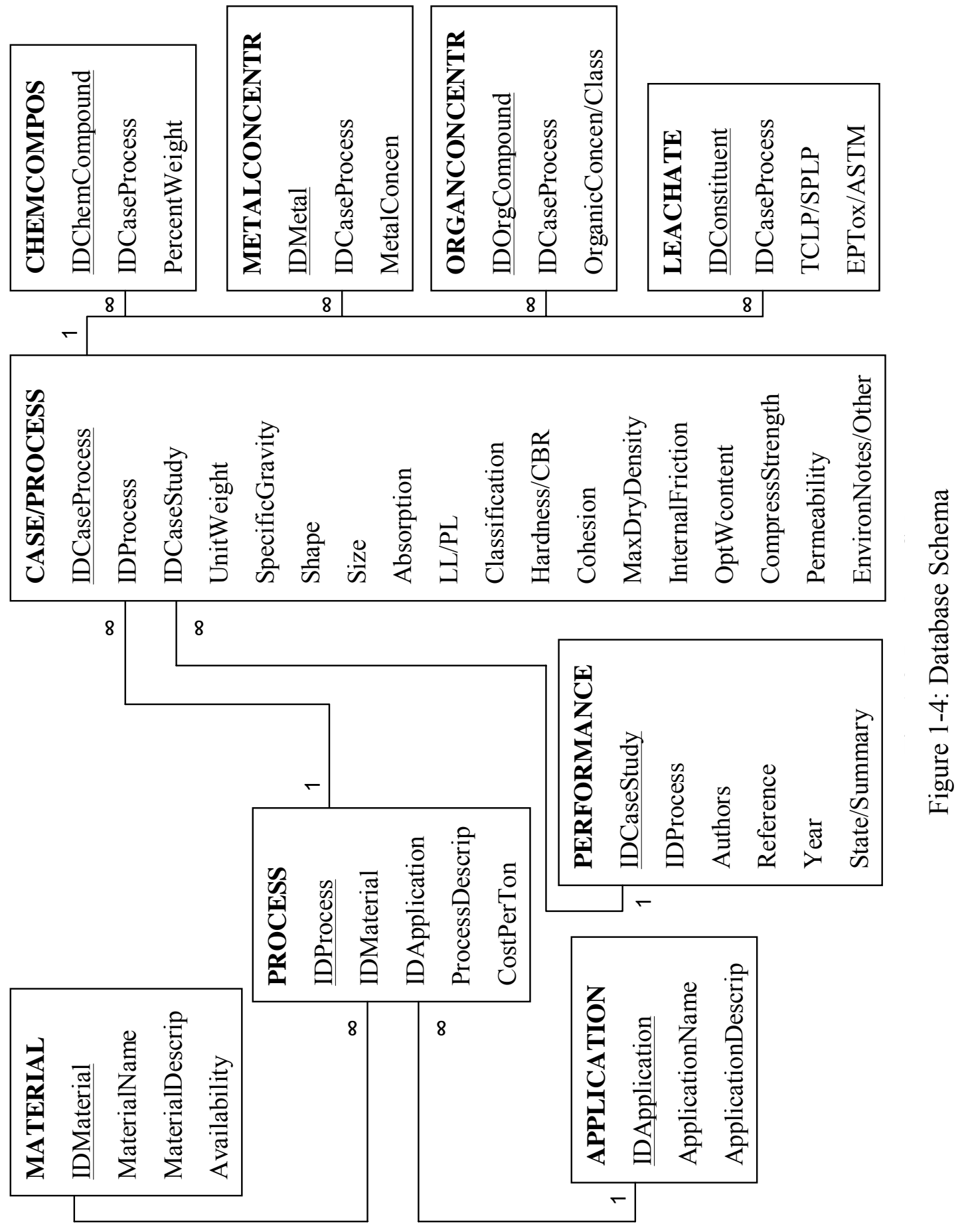




\section{Subsequent Chapters}

Subsequent chapters consider the research that has gone into the creation of the Recycled Materials Relational Database. Many of the components that were chosen for the database came about as a result of this research. However, the format of the database itself warrants additional development of topics such as materials, applications, processes, properties, and performance. The fifth chapter puts it all together and builds on the topics presented in this chapter. Specifically, it details the design of the database. A final chapter is included for recommendations and cost issues. 


\section{Chapter Two: Materials and Availability}

Introduction

Although several additional, equally-important parameters exist in the realm of recycled material research, the majority of studies that have been conducted typically begin with specifying the materials that are to be studied. In most cases, researchers select a material about which research has already been conducted in one form or another and test it to determine its predicted performance for a particular real-world application. Usually, there is some type of laboratory program that includes tests for grain-size distribution, plasticity limits, direct shear, triaxial, and many others. Researchers might also conduct mid-size experiments using testing apparatuses and procedures of their own design. For example, Bosscher et al. (1997) performed tests on model embankments in the laboratory so as to generate deformation response data. Other studies have included full-size field testing programs. When used in conjunction with laboratory procedures, these studies have attempted to quantify the performance of recycled materials in various geotechnical and transportation applications.

Most of the more recent recycled material research has focused on one of two

aspects: 1) new ways of using existing materials and 2) completely new materials or old materials processed in new ways. A study by Reid et al. (1998) examined the use of rubber tire chips as a method to reduce the bumps at the ends of bridges. This illustrates the specialized nature of some of these new ways to use existing recycled materials. Fahoum (1998) capitalized on local conditions by constructing a road-supporting embankment out of lime taken from the lagoon that the road was to cross. Cleary, these two projects are considered original.

Unfortunately, a portion of the recycled material research available is not quite as original. Sometimes, researchers simply rehash previously-performed experiments on 
old materials so as to validate prior findings. Certain widely available materials are clearly given preference over more obscure materials. This is not because the former are more promising. As a result, a vast amount of data is available for materials such as recycled tire shreds and fly ash, while a relatively limited amount exists for mill tailings and phosphogypsum. Unfortunately, research is often repeated because of the difficulty in tracking down previous efforts. The tendency of researchers to publish their findings in technical reports, online sources, and in other special publications rather than archived publications exacerbates the problem.

A new research thread has developed around this third aspect of recycled material research, and it is the subject of the current research as well as that of at least three other studies (Collins and Ciesielski, 1994; Chesner et al., 1998; Chesner et al. 2002). As described earlier, the first summarizes information on 38 recycled materials, the second contains 20 materials, and the third presents 21 materials. The first study is a comprehensive technical report and the other two are online databases. The full extent of these efforts was outlined in Chapter 1. For the purpose of the current study, it is sufficient to present the materials and provide some rationale for selecting those that will be part of this study. In Table 1-1, the materials included in each of the three earlier studies are marked. Notice the close overlap of materials between the second two studies. This is no surprise as both have the same principal author.

Table 2-1: Comprehensive Material Studies

\begin{tabular}{|l|l|l|l|}
\hline Recycled Material & $\begin{array}{c}\text { Collins/Ciesielski } \\
(1994)\end{array}$ & $\begin{array}{c}\text { Chesner et al. } \\
\text { (1998) }\end{array}$ & $\begin{array}{c}\text { Chesner et al. } \\
\text { (2002) }\end{array}$ \\
\hline Crop Wastes & & & \\
\hline Logging/Wood Waste & & & \\
\hline Miscellaneous Organics & & & \\
\hline Paper/Paperboard & & & \\
\hline Yard Waste & & & \\
\hline Plastics & & & \\
\hline Incinerator Ash (MSW) & & & \\
\hline Sewage Sludge & & & \\
\hline Scrap Tires & & & \\
\hline Compost & & &
\end{tabular}


Table 2-1 Continued

\begin{tabular}{|l|l|l|l|}
\hline Boiler Slag & & & \\
\hline Demolition Debris & & & \\
\hline Blast-Furnace Slag & & & \\
\hline Steel Mill Slag & & & \\
\hline Non-Ferrous Slags & & \\
\hline Cement/Lime Kiln Dust & & \\
\hline Reclaimed Asphalt Pavement & & \\
\hline Reclaimed Concrete Pavement & & & \\
\hline Foundry Wastes & & & \\
\hline Silica Fume & & \\
\hline Roofing Shingle Waste & & \\
\hline Sulfate Waste & & \\
\hline Lime Waste & & \\
\hline Ceramic Wastes & & \\
\hline Paper Mill Sludge & & \\
\hline Contaminated Soils & & \\
\hline Quarry Waste & & \\
\hline Mill Tailings & & \\
\hline Coal Refuse & & \\
\hline Washery Rejects & & \\
\hline Phosphogypsum & & \\
\hline Baghouse Fines & & \\
\hline Carpet Waste & & \\
\hline Waste Glass & & \\
\hline Flue Gas Scrubber & & \\
\hline
\end{tabular}

Material Selection

There are several criteria by which materials must be selected for the current research. First, and perhaps most importantly, reliable data must be available about each material selected. With all the parameters used to describe the various materials still to be developed, it is a dubious idea to include an exciting new material about which there is little research available. Second, care must be taken not to duplicate any material. This could be a problem for certain materials, which can be processed in two or more drastically different ways. Another potential material redundancy problem occurs when one material can be referred to by more than one name. As a brief example, consider incinerator ash, which is also referred to as municipal solid waste combustor ash and waste-to-energy ash. With this in mind, care must be taken not only in the selection of materials stage but also during the data collection and entry stage. A final consideration 
for selection is that the data is updatable and the design is amendable. Any omitted materials may be added immediately and the future discovery of new materials may be added as the research becomes available.

Though by no means a comprehensive list, the 24 recycled materials selected for this study provide a robust framework from which to launch the database. Moreover, they are representative of the recycled material research as a whole. Table 2-2 lists these 24 materials.

Table 2-2: Recycled Materials for Current Research

\begin{tabular}{|l|l|l|}
\hline Paper & Demolition Debris & Paper Mill Sludge \\
\hline Plastics & Blast-Furnace Slag & Wood Waste \\
\hline Incinerator Ash (MSW) & Steel Mill Slag & Carpet Fibers \\
\hline Scrap Tires & Non-Ferrous Slag & Mine Tailings \\
\hline Roof Shingles & Cement/Lime Kiln Dust & Phosphogypsum \\
\hline Fly Ash (Coal Ash) & Reclaimed Asphalt Pavement & Quarry Waste \\
\hline Bottom Ash (Coal) & Reclaimed Concrete Pavement & Glass \\
\hline Scrubber Base (Coal) & Foundry Wastes & Boiler Slag \\
\hline
\end{tabular}

Material Categories and Descriptions

This section serves as a background of and companion to the recycled materials database. In this section, a general description of each of the materials is provided. This description includes the various terms used interchangeably that refer to the same material as well as the material's industry origin and other general descriptive characteristics. Collins and Ciesielski (1994) suggest dividing the materials into four categories: agricultural, domestic, industrial, and mineral. However, research of "agricultural" materials is extremely limited, and the one material of interest from that category, wood waste, also fits into the industrial byproducts category.

For the purposes of this study, the 24 recycled materials are divided into three categories based on general origin - domestic waste materials, industrial waste materials, and mineral waste materials. Although the literature suggests adding additional categories and subcategories to allow for a more detailed breakdown, the chosen categories are adequate. Additional categories would only serve to complicate user 
interaction with the database. It is conceivable that several of the materials could fit into multiple categories (i.e. roof shingles, scrap tires, plastic etc.), but they are included in only one here.

\section{Category: Domestic Waste}

Domestic waste materials comprise waste generated in the form of both commercial and household garbage. They are often called post-consumer materials. Domestic waste materials are as follows: paper waste, plastics, incinerator ash, scrap tires, glass/ceramics, and carpet waste (Collins and Ciesielski, 1994).

\section{Category: Industrial Waste}

Industrial waste materials are exactly that - byproducts of industry. Industrial waste materials specified in this study are: roof shingles, fly ash, bottom ash, boiler slag, scrubber base, wood waste, demolition debris, blast-furnace slag, steel mill slag, nonferrous slag, cement and lime kiln dust, reclaimed asphalt pavement, reclaimed concrete pavement, foundry waste, and paper mill sludge.

\section{Category: Mineral Waste}

Finally, mineral wastes result from mining activities or more specifically, the extraction of ores and minerals. Mineral waste materials: quarry waste, mill tailings, and phosphogypsum. Again, it must be emphasized that this list of materials is by no means comprehensive. Other waste materials exist and certainly a range of variations can occur from different processing techniques. However, the list is adequate for the intended use.

\section{Description: Domestic Waste}

Waste paper refers to trash in the form of newspapers, magazines, cardboard, and other miscellaneous paper products. Although the vast majority of this waste paper is 
recycled to produce other paper products, its limited use has been reported in highway applications though mainly in aesthetic applications (Collins and Ciesielski, 1994). Plastics are much more versatile. Trash bags, plastic pipes, milk jugs, battery casings, plastic cups/plates, and plastic soda bottles all are potential sources for waste plastic (Collins and Ciesielski, 1994). These sources are composed of various types of plastic resins among them polyethylene terephthalate (PET) and high-density polyethylene (HDPE). In the past, researchers have taken two very different approaches to using plastics in engineering applications. As a result, they make use of two very different forms of the same material depending on the stabilizing mechanism desired: discrete or homogeneous. Discrete stabilizing incorporates individual elements such as plastic lumber or plastic piles for the purpose of interfering with a failure surface (Loehr and Bowders, 2000). Homogeneous stabilization on the other hand denotes mixing small pieces or strips of the plastic, usually PET fibers from plastic bottles with soil, pavement, or concrete for the purpose of improving engineering properties such as strength or stiffness (Consoli et al. 2002). Stabilizing mechanisms will be described in the application and field performance section of the paper.

Another widely researched domestic waste material is incinerator ash, also referred to as MSW ash. Burning of municipal solid waste produces this type of ash. The residue is divided into two types - bottom ash and fly ash of which the vast majority is bottom ash. The bottom is lighter in color but because it is usually moist, it produces little dust. One the other hand, fly ash is a darker, fine, powdery substance (Chesner et al., 1998). Usually, the two are combined for disposal. Recently, this material attracted negative attention by the EPA due to its tendency to leach high concentrations of heavy metals (Collins and Ciesielski, 1994).

Perhaps the most extensively researched recycled materials currently, scrap tires, are gaining notoriety for their versatility. Potentially usable forms include whole tires, sliced tires, tire chips, tire shreds, and smaller, soil-like particles referred to collectively as crumb rubber. The size of the tire chips is a function the shredding machine itself. To produce a smaller sized chip, it is often necessary to employ more than one processing machine (Bosscher et al., 1997). One tire shred processing company produces a rough 
shred, a $2.5-4 \mathrm{~cm}$ shred, a $1.25-2.5 \mathrm{~cm}$ shred, and a $0.6-1.25 \mathrm{~cm}$ crumb (Chesner et al., 1998). Depending on the processing method and intended application, the size of the crumb rubber can vary dramatically, from a semi-irregular $1.5 \mathrm{~cm}$ crumb all the way down to a graphite-like powdery substance. In addition, the company produces a product it calls "fines." Composed primarily of various types of rubber, recycled tire shreds also contain carbon black, polymers, and fabrics as well as steel wire or belt materials (Chesner et al. 2002).

Waste glass typically refers to any recycled, post-consumer glass products. Such products include soda containers as well as windows and similar materials. The majority of recycled glass is used as feedstock for the production of other glass containers, but it is also used in engineering applications. As a product of supercooling, it is composed primarily of silicon dioxide (sand) and sodium carbonate (Chesner et al., 2002). Further processing of the glass particles yields a product that resembles gravel or sand and exhibits properties similar to those materials. Material recovery efforts have been centered on Material Recover Facilities (Chesner et al., 2002). Ceramic waste, on the other hand, is usually produced in the form of materials rejected by factories such as porcelain and china but could also be waste from the home in the form of toilets and sinks. Similar to glass, ceramics waste is crushed to resemble a fine aggregate.

Carpet waste, also referred to as carpet fibers, consists of waste from industrial production and discarded consumer carpet. Essentially, the material is made up of two layers. Yarn-like fabrics are connected by an adhesive SBR, styrene-butadiene latex rubber (Wang, 1999). Nylon face fibers are clumped into the first layer. Before application of the adhesive, a "soft waste" can be produced, which is usually reused in various non-engineering applications (Wang, 1999). However, the post-adhesive carpet waste, or "hard waste" is of interest in this study. Randomly inserted discrete fibers are mixed with soil in small dosages. An investigation of these mixtures will follow in this thesis. 


\section{Description: Industrial Waste}

Roofing shingle waste consists of both discarded industrial waste shingles and surplus domestic shingles used on houses. Two types of byproducts are normally considered. The first type is "prompt roofing shingle scrap" or "roofing shingle tabs" (Chesner, 1998). This type is generated as new shingles are formed to their specified dimensions. The second type, "tear-off roof shingles," is generated as existing roofs are replaced or removed. Consisting of asphalt, fiberglass, aggregate and other additives in various concentrations, roof shingles waste is non-uniform. Similar to tire shreds, the type and size of roof shingles waste varies dramatically depending on the processing mechanism. The waste can range from a well-graded, irregularly-shaped, coal-like byproduct to poorly-graded, black, sand-sized fines. In either case, questions of contamination arise due to the variation in exposure and age of the recycled shingles.

Fly ash is a byproduct that results from the combustion of coal. Predominantly a fine-grained, powdery material, fly ash boasts a variety of appearances, chemical compositions, and material properties. These variations are due to discrepancies in parent coal properties, burning mechanisms, and material handling (Vipulanandan et al., 1998). Even so, constant constituents include silica, alumina, iron oxide, lime, and carbon (Vipulanandan et al. 1998). Four types of coal are burned to produce fly ash: anthracite, bituminous, lignite, and sub-bituminous. Individually, they produce two types of fly ash, which are characterized by calcium oxide content. Class-F fly ash contains less than 10 percent $\mathrm{CaO}$, and it comes from anthracitic or bituminous coal. Class-C fly ash contains more than 10 percent $\mathrm{CaO}$, and it comes from lignite or sub-bituminous coal (Vipulanandan et al. 1998). For facility of data interaction, this study lumps both types of fly ash into a single material. The sagacity of this decision will be examined during betatesting.

Another coal burning byproduct, bottom ash, consists of a dark gray, coarse, wellgraded material that is produced in combination with fly ash (Chesner et al., 1998 and Chesner et al., 2002). Bottom ash is usually darker in color and consists of slightly larger particles. It is considered both coarser and more porous than fly ash although the 
particles are about the same size as sand. Further differentiation of these materials can be found in the process section of this report.

Boiler slag and bottom ash are very similar materials. First, they both are byproducts of the coal burning process. Second, they exhibit very similar physical and mechanical properties. In fact, the two are often combined by researchers and considered as a single material. However, the production of either bottom ash or boiler slag depends on the type of coal-burning furnace. Moreover, the appearance of boiler slag is "coarse, hard, black, angular, and glassy" (Chesner et al., 2002). It is poorly-graded and smooth in texture, and it is generated in much lower quantities than both fly ash and bottom ash. As an afterthought to initial research efforts, boiler slag and bottom ash were separated and now serve as distinct materials for the purposes of this research.

Scrubber base is the term given to a composite recycled material. Also referred to as general sulfate waste or as FGD scrubber material, it is an equal parts mixture of flue gas desulfurization sludge (FGD) and fly ash (Vipulanandan and Basheer, 1998). The former originated from a method to reduce $\mathrm{SO}_{2}$ emissions during the burning of coal in electric power plants. This scrubber system as it is termed yields a whitish calcium sulfite or calcium sulfate slurry. Calcium sulfite slurries are thixotropic and are generally more difficult to handle and treat than calcium sulfate slurries (Chesner et al., 2002; Collins and Ciesielski, 1994).

Wood waste is a collective term for compost and construction byproducts from wooden structures such as homes, fences, docks etc. It is wasted in the form of "logging residues, wood and bark chips, and sawdust" from sawmills (Collins and Ciesielski, 1994). The few researchers who have examined this waste material have examined it exclusively in mulching applications and some lightweight fill applications. However, it is envisioned that this material will play a significant role in future research efforts.

Demolition debris or C\&D as it is referred to, is the general term for a host of waste materials generated from the construction industry. Consisting of building materials such as concrete, glass, brick, and metal as well as other materials such as wood and plaster, $\mathrm{C} \& \mathrm{D}$ waste must be processed before it can be incorporated into engineering uses (Collins and Ciesielski, 1994). Similar to glass and roofing shingles, C\&D waste is 
essentially a non-uniform material, making its comprehensive characterization difficult. Likewise, sorting poses a problem. Like roof shingles, C\&D waste raises the question of possible contamination from asbestos and other hazardous materials. Some researchers have considered construction and demolition debris as a parent category for both reclaimed asphalt pavement and reclaimed concrete pavement. However, the three materials are separated in this study.

Several materials belong to the general category of industrial waste byproducts collectively referred to as slags. Two varieties exist: iron/steel slags and non-ferrous slags. Blast-furnace slag is a nonmetallic byproduct of producing iron in a blast furnace. Its chemical and physical properties vary according to cooling the molten slag byproduct. The different processes produce four types of blast-furnace slag: air-cooled slag or expanded slag, palletized slag, and granulated slag (Chesner et al., 2002). It is composed mostly of silicates and alumino-silicates of lime (Collins and Ciesielski, 1994). The resultant aggregate materials vary in porosity and unit weight.

Steel slag is a byproduct of the steel-making process. It is initially generated as a molten liquid, but it solidifies as it is cooled. The reaction of lime flux with metal produces steel slag, which is made up mainly of oxides and silicates. There are several grades of steel based on carbon content. Depending on the grade of steel that is produced, steel slag occurs as one of four sub-materials: tap slag, raker slag, synthetic slag, or cleanout slag (Chesner et al., 2002). Steel slag resembles aggregate although the particles are generally harder and heavier.

As the name implies, non-ferrous slags are generated from the recovery and processing of natural ores other than iron. Primarily, this includes copper, phosphate, lead, nickel, and zinc (Chesner et al., 2002). Copper and phosphate slags are the most prevalent. Like steel slags, the initial molten byproduct evolves into a hard, aggregate material as it is cooled. The color and general appearance of non-ferrous slags varies with their parent ores. Non-ferrous slags can be dark black to brown or red and either glassy or dull depending on the metal from which they were processed and the method used. Obviously, non-ferrous slags are really the name given to several different 
materials that exhibit similar albeit unequal properties. Because non-ferrous slag data is limited, the materials will all be included under the non-ferrous slag material heading.

Kiln dusts in general are "fine by-products of Portland cement and lime hightemperature rotary kiln production operations that are captured in the air pollution control dust collection system" (Chesner et al., 2002). Cement and lime kiln dusts are both fine, dry, powdery substances. Although physically similar, the materials exhibit very different chemical properties. While cement kiln dust can contain reactive calcium oxide, lime kiln dust is potentially more reactive due to its free lime composition (Collins and Ciesielski, 1994). Both dusts may contain hazardous wastes.

Although they could potentially fit into the category of construction and demolition debris, both reclaimed asphalt pavement and reclaimed concrete pavement have been researched and used extensively enough to warrant their own citation here. Also known as RAP, reclaimed asphalt pavement is generated as roads are repaired or replaced. RAP consists of asphalt and aggregate and must be processed to become a usable recycled material. Before processing, the material resembles non-uniform oversized aggregate. The composition of reclaimed concrete pavement (also referred to as reclaimed concrete material, recycled concrete pavement, or RCA) varies more than the composition of RAP (Papp et al., 1998). Cement structures such as roads, bridges, sidewalks, buildings, foundations, and retaining walls can generate reclaimed concrete pavement material. Because the method of installation, exposure to environments, and concrete type and quality can all vary dramatically among these structures, uniformity in type and quality of reclaimed concrete pavement is difficult to achieve (Collins and Ciesielski, 1994). The processed material is a well-graded gray aggregate.

Foundry waste is used in metal casting plants, and it is composed of uniform silica sand or furnace dust (Edil and Benson, 1998). The clean sand becomes compromised during casting resulting in a mixture of sand, bentonite, and sea coal collectively referred to as, "green sand" (Abichou et al., 1998). The waste sand's bentonite component varies. There is some question as to the presence of chemicals, trace metals, and stones even in the processed waste material. The final product is poorly-graded. 
Paper mill sludge is a by-product of the pulp and paper industry. Edil and Benson (1998) cite residues from wastewater treatment plants at paper mills as the primary source for this material. The sludge, composed of mineral fines such as kaolinite and calcite, is generally considered an inorganic waste. The material is also mixed with sand to produce a more uniform aggregate-type material. Another by-product of the industry is spent sulfite liquor, a promising material for future geotechnical testing (Collins and Ciesielski, 1994).

\section{Description: Mineral Waste}

Quarry waste is a general term for any material that is generated from the processing of stone at quarries. A series of processes produces different types of quarry waste: screenings, setting pond fines, and baghouse fines. For the current research, they will be treated as one material. Both the consistency and composition of this waste varies with the geographic location of the quarry, but the product is usually characterized by small pieces of chipped rock and fines.

Mill tailings are a byproduct from the ore concentration processes. They are produced initially in slurry form. Typically, the parent ores include iron, copper, lead, zinc, and uranium among others (Collines and Ciesielski, 1994). Mill tailings range in size from sand to silty-clay, but the particles are generally characterized as hard, angular, aggregate-type material composed of significantly large fractions of fines. Like many of the other materials, mill tailings vary greatly in terms of particle size, physical and chemical properties. This is due to a variety of factors such as processing, disposal, type of ore etc.

Phosphogypsum, sometimes included in the more general category, sulfate waste, is another mineral waste material. It is generated from the production of phosphoric acid from phosphate rock (Collines and Ciesielski, 1994). Composed of calcium sulfate hydrate, the final by-product is a wet, gray, silt-sized substance. There are concerns as to its impact on the environment as expressed by the EPA over radon contamination 
(Collines and Ciesielski, 1994). However, the shear volume of phosphogypsum produced, especially locally, makes it an interesting material byproduct to include here.

Material Availability

Availability data is widely scattered and difficult to concretize. This is due mainly to two factors. First, availability of materials changes each year, and there is currently no resource available that tracks these changes. Second, researchers tend to publish their findings on individual materials in technical reports and online sources rather than archived publications. This makes the process of comparing availability data supplied by researchers tedious and time-consuming. The comprehensive relational database approach is envisioned as a way to not only organize availability data from a variety of sources, but also track annual changes in the data. A brief attempt is made here in Table 2-3 to present organized, material availability data to provide a robust framework for the purpose of comparison. 
Table 2-3: Material Availability (Million Tons per Year)

\begin{tabular}{|l|l|l|l|}
\hline Recycled Material Name & $\begin{array}{c}\text { Collines/Ciesielski } \\
(1994)\end{array}$ & $\begin{array}{c}\text { Chesner et al. } \\
(1998)\end{array}$ & $\begin{array}{c}\text { Chesner et al. } \\
(2002)\end{array}$ \\
\hline Paper & 71.8 & & \\
\hline Plastics & 14.4 & 9 & 9 \\
\hline Incinerator Ash (MSW) & 8.6 & 280 & 280 \\
\hline Scrap Tires & 2.5 & & 11 \\
\hline Roof Shingles & 10 & 54.8 & 59.4 \\
\hline Fly Ash (Coal Ash) & 48 & 16.1 & 16.1 \\
\hline Bottom Ash (Coal) & 14 & 23.8 & 23.8 \\
\hline Scrubber Base (Coal) & 18 & & \\
\hline Demolition Debris & 25 & & 15.5 \\
\hline Blast-Furnace Slag & 16 & 8.3 & 8.3 \\
\hline Steel Mill Slag & 8 & 9 & 9 \\
\hline Non-Ferrous Slag & 10 & 18.2 & 18.2 \\
\hline Cement/Lime Kiln Dust & 24 & 45 & 45 \\
\hline Reclaimed Asphalt Pavement & 50 & & \\
\hline Reclaimed Concrete Pavement & 3 & 15 & 15 \\
\hline Foundry Wastes & 10 & & \\
\hline Paper Mill Sludge & & & \\
\hline Wood Waste & 70 & & 500 \\
\hline Carpet Fibers & 2 & 500 & 35 \\
\hline Mine Tailings & 520 & 35 & 175 \\
\hline Phosphogypsum & 35 & 175 & 10.2 \\
\hline Quarry Waste & 175 & 10.1 & 2.6 \\
\hline Glass & 12.5 & 2.6 & \\
\hline Boiler Slag & 4 & & \\
\hline
\end{tabular}

Observations

There are several interpretations that can be made from Table 2-3. The oldest source contains availability data for the greatest number of materials. This fact makes it impossible to do a comprehensive comparison of availability data for all materials over time. Even so, the availability data for materials considered in each of the three sources shows a slight increase, generally speaking. There are however, a few noticeable exceptions and at least one drastic outlier. The availabilities of non-ferrous slags, kiln dusts, reclaimed asphalt pavement, and glass all seem to have decreased slightly in recent years. Perhaps these decreases are a result of increased industrial efficiency and conscious internal reuse of byproducts or perhaps they are a result of less-than-efficient data collection. This latter reason may account for the drastic change in scrap tire 
availability from 2.5 million tons annually in 1994 to 280 million tons annually in 1998 and 2002 (Collins and Ciesielski, 1994; Chesner et al., 1998; Chesner et al., 2002). Figure 2-1 contains a visual representation of material availability.

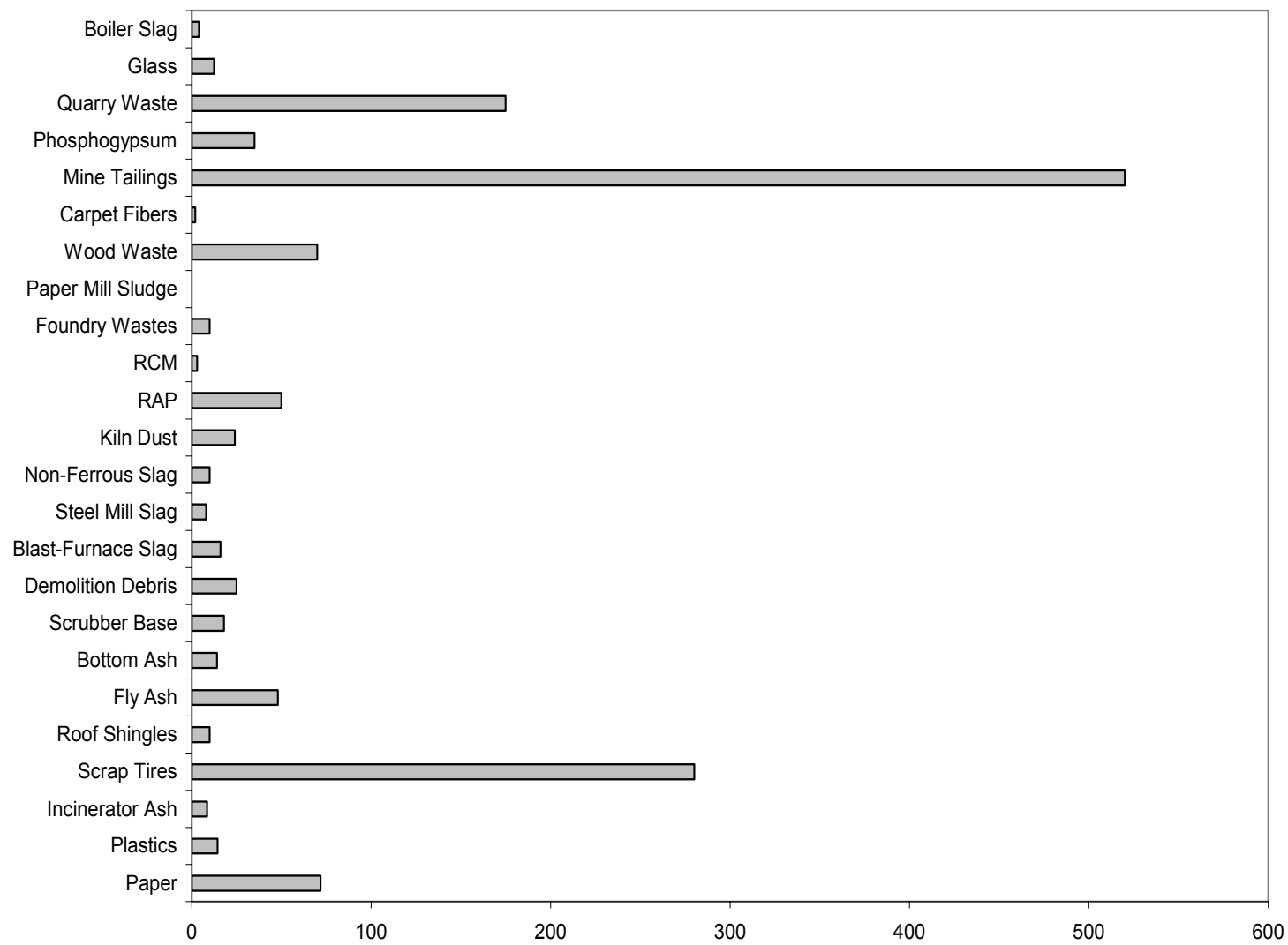

Figure 2-1: Material Availability Bar Graph (Collins and Ciesielski, 1994)

\section{DBMS Organization}

This section describes a relational database model to handle organization and storage of recycled material data. A review of the entire creation and maintenance of the database is available in Chapter 7. The interest here is how the materials themselves and their availability fit into the database and how the user can interact with that data. 
Materials Table

A materials table is generated using the database management system. There are 24 records (rows) corresponding to the 24 materials used in this study. There are also four fields into which the data is stored: MaterialName, IDMaterial, MaterialDescription, and Availability (million tons/year). The data types for these four fields are text, autonumber, memo, and number long integer. The database designer may, of course, add additional materials not found in the original 24-material list. When a new material is added, the autonumber field, IDMaterial automatically increments and assigns a unique number to that new material. For example, as it stands now, if the material fluorogypsum were added to the table, it would be assigned an IDMaterial of 25. IDMaterial serves as a unique record identifier within the Materials table, and functions as the primary key of the table. Its function is to link the Materials table indirectly to the rest of the database and directly to the Process table. The existence of the same field, IDMaterial, in the Process table establishes the link between both tables by serving as the foreign key.

\section{Materials Form}

Two separate forms are based on the Materials table. The first, 'Materials Form,' (green and yellow) is used to view existing data. It opens up directly after the switchboard and launches a sequence of nine forms. The user has the option of scrolling through records of data or moving on to the next form. The data is locked so that no additions or edits can occur. The second form, 'Materials Form (Add Entry),' (red and gray) does not allow the user to view existing data, but instead presents a blank form where the user can enter new data. The same sequence of nine forms is followed. 


\section{Chapter Three: Processing and Applications}

Introduction

Although some researchers skip directly from material selection to laboratory and field testing, they miss out on important parameters that more narrowly define and distinguish the materials. As a result, those who wish to validate existing data or build on previous studies are left to their own intuition and deductive reasoning when it comes to reproducing the same material for testing. Two additional parameters should be specified to rigidly define the materials: processing and application. Processing in this context refers to the preparation, treatment, and conversion of the material from its raw form to a more refined form. Whether the material is processed directly from a parent waste material or collected as a byproduct of external activity, the process spans from origin all the way to use or testing. Application, on the other hand, generically defines how a material will be used in practice or how it is envisioned to be used in practice. A material's envisioned application is very difficult to determine from simply reviewing laboratory material parameter tests. The objective is that the material name, its process, and its application will coalesce to rigidly define each recycled material.

\section{Applications}

Past research efforts have examined actual and envisioned applications that range from the mundane and ordinary to truly innovative and specialized. An example of the latter was described in the previous chapter. Researchers used tire shreds to mitigate the development of "bumps" at the ends of bridges (Reid et al., 1998). Although some of these specialized applications are mentioned here, they are not included directly within the database framework. Instead, eight general geotechnical and transportation 
applications were chosen to characterize some of the more mainstream recycled material research. Table 3-1 presents these applications.

Table 3-1: Database Application Categories

\begin{tabular}{|l|l|}
\hline Embankment/Fill & BaseSubbase \\
\hline Flowable Fill & Stabilized base \\
\hline Concrete Additive & Soil Reinforcement/Stability \\
\hline Asphalt Pavement & Other \\
\hline
\end{tabular}

Description of Applications

\section{Embankment/Fill}

The geotechnical or transportation definition of an embankment is a constructed, raised, earthen mound, composed of soil, aggregate, and other materials. Its purpose is to raise the level of a road relative to the surrounding area (Chesner et al., 2002). Constructed with similar materials, a fill differs in that it is used to cover an area below the surrounding ground surface or to fill in the space behind a retaining wall. Typically, an embankment or fill is composed of several material layers that must simultaneously maximize strength and permeability while minimizing deflection. Because of the large quantities of earthen material required for both embankments and fills, recycled materials offer an attractive, low-cost alternative to expensive borrow material (Vipulanandan and Basheer, 1998). Moreover, recycled materials often exhibit engineering properties that make them more desirable than traditional materials without even accounting for the cost differential. For example, the relatively low unit weight of tire shreds can potentially reduce pressures on retaining walls or lessen the load of an embankment constructed on top of marginal soil.

\section{Flowable Fill}

Consisting primarily of fine aggregate, water, and a cementitious component, flowable fill acts as a rapidly-hardening slurry (Chesner et al., 2002). Its main function is 
to fill in irregular nonuniform excavations, which require only very low bearing strength. There exists some discrepancy in the literature as to its exact constituent components. However, its formal description as a "controlled low-strength material" that exhibits properties of both concrete and soil-cement is unambiguous (Vipulanandan et al., 1998). Alternate names for flowable fill include lean-mix backfill, flowable mortar, and controlled-density fill (Vipulanandan et al., 1998). Recycled materials are sometimes substituted for traditional fine aggregates such as sand. They may also serve as pozzolanic materials - replacing conventional cementitious components. Pozzolanic is the term given to siliceous materials that exhibit cementitious properties when combined with an activator in the presence of water (Chesner et al. 2002).

\section{Concrete Additive}

Portland cement concrete is used in rigid pavements, sidewalks, retaining structures, and bridge components. Made up of coarse and fine aggregate in addition to cement paste, Portland cement concrete also contains cementitious materials and chemical modifiers (Chesner et al., 1998). Recycled materials may be used in place of aggregate or again as pozzolanic cementitious components. The latter is the catalyst through which important physical properties of the concrete can be modified.

\section{Asphalt Pavement}

The layers of asphalt, aggregate, binder and other materials that make up asphalt pavement serve as a mechanism to distribute traffic loadings to underlying base and subbase layers. This application encompasses hot and cold mix asphalt as well as surface treatments. Hot and cold mix asphalt differ in both requisite preparation and expected performance. Hot mix asphalt requires the addition of a mineral filler. It must be mixed at a plant, and can be used anywhere while cold mix asphalt can be mixed on site and is only used in lightly-trafficked rural areas (Chesner et al., 2002). Applied as a liquid, surface treatments improve only existing road surfaces. Besides their potential use as 
substitutes for conventional aggregate in pavements, recycled materials may be used as mineral fillers. The purpose of mineral fillers is to improve stiffening of the hot mix and increase individual particle contact (Chesner et al., 2002). As a result, they establish critical performance characteristics of the asphalt pavement.

\section{Base/ Subbase}

Below the asphalt surface layer lie the base and subbase layers of the pavement. Although both are composed of aggregates, the gradation of these aggregates and the function of the two layers allow them to be treated separately. Base layers consist of higher fines content and their purpose is mainly load-bearing and strengthening in nature (Chesner et al., 2002). Located directly below the pavement surface, it must simultaneously promote drainage and dissipate stress to protect the subgrade. The subbase layer is located below the base, and it functions primarily as a foundation. Opportunities for recycled material substitution exist for this application as well. Highstrength materials can replace sand and gravel as the principal base and subbase aggregates.

\section{Stabilized Base}

Stabilized base is considered a different "class" of base or subbase materials. Similar to the functions of other base layers, its purpose is to improve strength and to more efficiently distribute direct traffic loads to underlying layers (Chesner et al., 2002). The main difference is in composition. A mixture of aggregate, cementitious particles, and water, stabilized base gains strength through compaction. Two terms used interchangeably for stabilized base are soil-cement and roller-compacted concrete. Not surprisingly, recycled materials can be substituted as aggregate or in place of the cementitious particles. 


\section{Soil Reinforcement/ Stability}

Although not included as a separate application in comprehensive recycled material research efforts, significant data exists pertaining to soil reinforcement and stability. In the past, accepted techniques for dealing with reinforcement of marginal soils included the use of synthetic materials such as geotextiles and geofabrics, chemical stabilizers, and advanced albeit expensive soil improvement procedures such as jet grouting, deep dynamic compaction, and vibroflotation. Homogenous stabilization of these problematic soils can be accomplished by using small strips or fibers of various recycled materials (Consoli et al., 2002; Wang, 1999). Slope stability problems have been solved in the past with the use of soil nailing, micropiles, retaining structures, and shotcrete. However, promising alternatives exist such as improving slope stability with discrete stabilization using waste materials (Loehr and Bowders, 2000). In general, this application follows two main stabilizing mechanisms: discrete and homogeneous stabilization. The former has more to do with stability and the latter with soil reinforcement.

\section{Other}

It is difficult and possibly even detrimental to include every possible application for recycled materials either here or as part of the database. Providing an "other" category ensures that even the most obscure and questionable application receives the necessary attention and documentation. Many of these applications are considered specialized applications for specific circumstances and conditions. However, if any one application in this category gains notoriety and becomes the subject of several future research efforts, its status can easily be promoted through the creation of its own category. For current purposes of user access and organization, the "other" category will encompass anything that does not fit into the first seven application categories. 
Processes

Most of the research on recycled materials simply glosses over or completely neglects to mention the material origins and requisite processing. Not only does this practice make duplication of results impossible (since there is no way to ensure that the same material is being tested), but because the process is not described, it is unclear how difficult, expensive, and time-consuming it is to process the material once it has been acquired. Simply put, the breadth of processing techniques is staggering. A process could be as straightforward as stockpiling the material before use or it could be as complicated as a long sequence of treatments requiring several processing machines just to refine it. Furthermore, a process dramatically affects the properties that a material will exhibit. This is why a material such as tire chips must be processed differently for use in an embankment than for use in asphalt pavement.

Material Processing: An Overview

The processing of waste paper and paperboard products is simple. Paper in the form of cardboard boxes, newspapers, magazines, and office paper is recycled through community programs. The paper is collected, sorted, and then shredded before it is used as mulching material and even slick paper hydraulic mulch oversprays (Collins and Ciesielski, 1994).

Unlike paper, plastics originate from a variety of sources and must be processed differently for each application. Table 3-2 shows the six types of plastic resins and their sources. Plastic lumber is formed from reclaimed HDPE, pellets are formed from recycled LDPE and prepared for use as the modifier in asphalt pavement, and a type of polyester is formed from recycled PET to chemically aid in the production of polymer concrete (Collins and Ciesielski, 1994). When used to stabilize cohesionless soils, plastic PET bottles are cleaned, chopped into pieces, and melted in an oven. Afterwards, the filaments are extruded and allowed to cool before they are stretched (Consoli et al., 2002). The mechanism here is homogenous stabilization. Loehr and Bowders (2000) 
combined recycled plastic, saw dust, and other materials to form composite recycled plastic piles (RPPs) used in discrete stabilization.

Table 3-2: Plastic Resins and their Source

\begin{tabular}{|l|l|l|}
\hline Resin & Name & Source \\
\hline Low-density polyethylene & PET & film/trash bags \\
\hline Polyvinyl chloride & PVC & pipes/flooring \\
\hline High-density polyethylene & HDPE & milk jugs \\
\hline Polypropylene & PP & battery casings/luggage \\
\hline Polystyrene & PS & egg cartons/cups \\
\hline Polyethylene terephthalate & PET & soda bottles \\
\hline
\end{tabular}

MSW incinerator or combustor ash is generated from the combustion of municipal solid waste in one of two types of waste combustors: mass burn facilities or refuse derived-fuel (RDF) facilities (Chesner et al., 2002). The former handles raw solid waste while the latter requires shredded and presorted source materials to ensure the absence of deleterious elements. The resulting ash consists of grate ash, siftings, boiler ash, and baghouse ash; the waste stream may be either combined or separated. The ash that sticks to the grate after combustion is bottom ash whereas boiler ash starts in the primary combustion zone but is later carried into both the gas stream and the pollution control system where it is collected (Chesner et al., 2002).

Scrap tire processing has developed as an industry by itself. Used for everything from tire derived fuel (TDF) and playground surfaces to mulch and aggregate replacement, scrap tires are processed in a variety of ways. Humphrey et al. (1998) suggests shredding whole tires before passing them through a sieve to meet gradation requirements. Several machines are required to process the tires into more refined forms. A cutting machine simply splits tires to form slit tires whereas tire shreds require a shredder, a machine with reciprocating knives that move forward and back to both tear and cut the tire (Chesner et al., 1998). Because of their small size, tire chips (13 to 76 $\mathrm{mm}$ ) must go through two rounds of shredders, and the secondary shredder reduces the size and increases uniformity in shape. To produce ground rubber (0.15 to $19 \mathrm{~mm})$, a granulator or grinding machine is first used to reduce size before exposed steel belts are removed through magnetic separation. Fibers are removed by air separation, and the 
resulting material is screened and sized (Chesner et al., 1998; Chesner et al., 2002). Crumb rubber $(0.075$ to $4.75 \mathrm{~mm})$ is generated from one of three processes: the crackermill process uses rotating steel drums, the granulator process uses revolving steel plates, and the micro-mill process produces the finest particles (Chesner et al., 1998). Two distinct processing mechanisms are necessary for pavement applications. If used as a substitute for aggregate, dry ground rubber is added to the hot mix asphalt. The wet process on the other hand, uses crumb rubber as an asphalt modifier to produce rubberized asphalt (Chesner et al., 2002). 

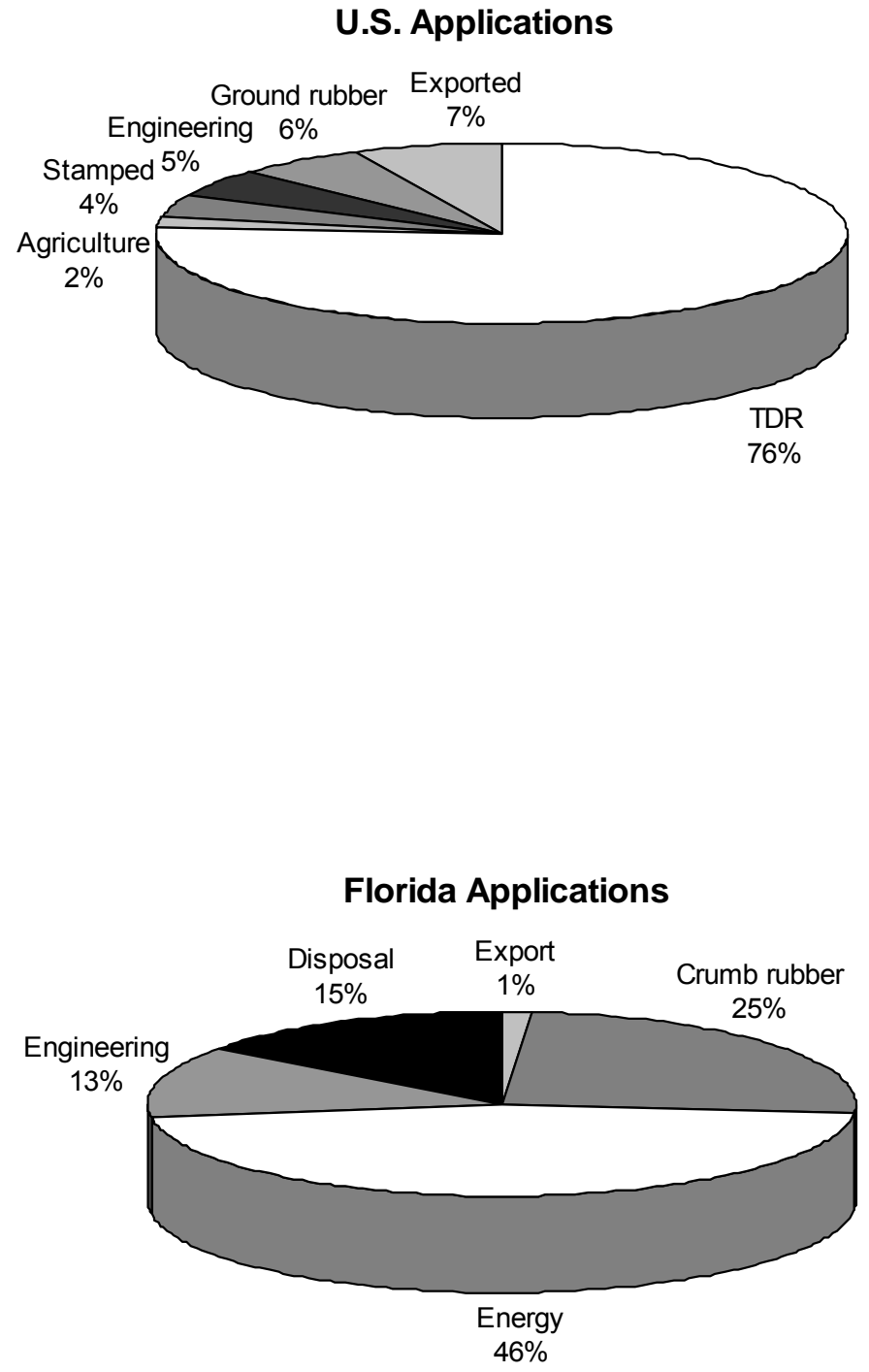

Figure 3-1: Scrap Tire Use for U.S. and Florida (Liu et al., 2000 and DEP, 2003)

Roof shingle waste originates as prompt shingle scrap (tabs) from shingle manufacturers or as tear-off scrap from contractors. Typically, the material is presorted to remove deleterious materials such as nails, other metal, and wood before it is passed 
through a processing machine that reduces its size. The final product may resemble anything from $75 \mathrm{~mm}$ partial shingle pieces to a much finer, black, soil-like material. In either case, it is important to be aware of risks associated with asbestos contamination. Currently, one of the main processing inconsistencies, which results in varying qualities of final product, has to do with the mixing of raw roof shingles from several sources during collection. Future research may address this issue. When used as an asphalt pavement modifier, prompt shingle waste must first pass through a rotary shredder before its size is reduced further with a high-speed hammermill; then it is stockpiled (Chesner et al., 2002).

Because fly ash has so many engineering applications, care must be taken to process the material appropriately. As a concrete additive, fly ash in dry form is used as a mineral admixture where consistent quality is important (Chesner et al., 2002). As a mineral filler in asphalt pavement, fly ash in dry form is collected and stored. Used as cementitious material in stabilized bases, fly ash takes the place of binder although an activator must be mixed with it to serve as a catalyst for pozzolanic activity (Chesner et al., 2002). In flowable fill applications, fly ash is mixed with sand and/or cementitious material whereas embankment applications only require that it be stockpiled and brought to optimum moisture content before compaction (Chesner et al., 2002; Vipulanandan et al., 1998).

Collected from the bottom of coal-burning furnaces, bottom ash is removed by water jets before "dewatering, crushing, and stockpiling" (Chesner et al., 2002). For asphalt pavement uses, bottom ash and boiler slag are screened and blended with conventional aggregates, and pyrites are removed with electromagnets. Screening, grinding, moisture control, and the removal of contaminants round out the processes required for use in base, stabilized base, and embankment applications of these two materials (Chesner et al., 2002).

In the materials section, the desulfurization process required to produce FGD scrubber base was outlined. In addition to this step, the material must undergo forced oxidation or blowing air into the holding tank to convert $\mathrm{CaSO}_{3}$ to $\mathrm{CaSO}_{4}$ (Chesner et al., 2002). Next the material is subjected to either a centrifuge or a belt filter for dewatering 
purposes. A dry material is added to stabilize the scrubber before it can be fixated, or modified chemically with quicklime or fly ash (Chesner et al., 2002).

Demolition debris, reclaimed asphalt pavement, and reclaimed concrete pavement are all processed similarly. After C\&D waste has been sorted to remove wood, drywall, plastic etc., it is reclaimed and crushed to be used in the place of aggregate (Collins and Ciesielski, 1994). Similarly, RAP and RCA are also crushed, screened, and stockpiled although magnetic separators must be used to remove reinforcing steel in RCA (Chesner et al., 2002).

Blast-furnace slag is crushed and screened to meet gradation requirements, but properties must be tested before use because of inconsistencies in the material (Chesner et al., 2002). As a concrete additive, it must be milled very fine. Steel mill slag must also be crushed and screened prior to use, but other criteria such as moisture content, handling, and hydration expansion must be addressed (Chesner et al., 2002). Similarly, non-ferrous slags are crushed, screened, and blended with traditional aggregate.

Mixing small percentages of kiln dust with aggregate and asphalt produces one type of concrete additive. In addition, kiln dusts may be pelletized for use as synthetic aggregate (Chesner et al., 2002).

Waste foundry sand requires crushing, recirculating, and screening to remove large particles. The waste sand is then stockpiled according to particle size (Abichou et al., 1998). Paper mill sludge processing has been the subject of very little research. However, when blended with fly ash, paper mill sludge in the form of bark ash can be fed into coal pulverizers and burned to produce a concrete additive (Collins and Ciesielski, 1994). Wood waste in the form of logging waste and sawdust may be further refined and mixed with other recycled materials to improve their performance. Loehr and Bowders (2000) for example, combined sawdust with plastic to form their recycled plastic piles.

"Hard waste" carpet fibers are added in small doses along with a superplasticizer to improve the toughness of concrete (Wang, 1999). The exact dosage or percentage of fibers to add is still under investigation. In another application, very small dosages of carpet fibers are added to soil to form a homogeneous mixture. 
Mill tailings are processed through crushing and separation of ore from the impurities either by media separation, gravity separation, froth flotation, or magnetic separation (Chesner et al., 2002). The key to processing quarry byproducts is blending when they are to be used in base applications and dewatering when they are used as mineral fillers (Chesner et al., 2002). Another mineral byproduct material, phosphogypsum is generated from a wet process in which phosphate rock is dissolved in phosphoric acid. Phosphogypsum is the byproduct and when used as a binder, it requires the use of a vibrating power screen to create uniformity (Chesner et al., 2002).

Waste glass is crushed and screened to reduce size and densify the final product. This is accomplished primarily by several machines including hammermills, rotating breaker bars, breaker plate, and impact crushers (Chesner et al., 2002). In addition to these steps, the processed material must be inspected for metal and paper.

\section{User Interaction}

In keeping with the relational database model, the remaining sections outline the organization and storage provisions of both application and process data currently available on recycled materials. In addition, the theory behind user interaction with these two data sets is formulated.

\section{Application Table}

An applications table has been created containing eight records corresponding to the eight application categories and three fields: ApplicationName, IDApplication, and ApplicationDescription. The data types for these fields are text, autonumber, and memo. Similar to the Materials table, additional applications may be created in the design view of the Applications table. For example, a user might decide to add a new application called, hydraulic barrier to the table. In this table, IDApplication serves as the automatically incrementing primary key that uniquely identifies each record. Through it, 
the data in the Application table is linked directly to the foreign key of the same name in the Process table and indirectly to the rest of the tables.

\section{Application Form}

The setup of the Application forms is similar to that of the Material forms. There are two distinct forms - one for viewing existing data and one for adding new data. The user can access them by first clicking on the appropriate switchboard button. The user can then navigate from the Materials form to the Application form or he may go directly to the Application (Add Entry) form from the second level switchboard. Locks and allowances prevent data editing in existing forms and allow it in the add entry forms.

\section{Process Table}

The process table contains some 57 records that correspond to 57 different ways of refining a recycled material for its intended application. In the previous section, the processes were described in detail. Although components of different processes sometimes overlap, there exist sufficient distinctive aspects to warrant their separation. An innovative approach was taken to characterize, organize, and store the processes. Each process was assigned a unique Material/Application combination. This serves two purposes: 1) It is practical because materials are processed in certain ways depending on the intended application and 2) It allows the Process table to serve as a linking table for the many-to-many relationship that exists between the Materials table, the Applications table, and the rest of the database tables. Figure 3-2 shows the unique Material/Application combinations that form each of the 57 processes.

\begin{tabular}{|l|l|l|}
\hline IDProcess & MaterialName & ApplicationName \\
\hline 1 & Paper & Other \\
\hline 2 & Plastics & Concrete Additive \\
\hline 3 & Plastics & Asphalt Pavement \\
\hline 4 & Plastics & Soil Reinforcement/Stability \\
\hline
\end{tabular}

Figure 3-2: Partial Process Table 


\begin{tabular}{|c|c|c|}
\hline 5 & Incinerator Ash (MSW) & Asphalt Pavement \\
\hline 6 & Incinerator Ash (MSW) & Base/Subbase \\
\hline 7 & Scrap Tires & Embankment/Fill \\
\hline 8 & Scrap Tires & Asphalt Pavement \\
\hline 9 & Roof Shingles & Asphalt Pavement \\
\hline 10 & Fly Ash (Coal Ash) & Embankment/Fill \\
\hline 11 & Fly Ash (Coal Ash) & Flowable Fill \\
\hline 12 & Fly Ash (Coal Ash) & Concrete Additive \\
\hline 13 & Fly Ash (Coal Ash) & Asphalt Pavement \\
\hline 14 & Fly Ash (Coal Ash) & Stabilized Base \\
\hline 15 & Bottom Ash (Coal) & Asphalt Pavement \\
\hline 16 & Bottom Ash (Coal) & Base/Subbase \\
\hline 17 & Bottom Ash (Coal) & Stabilized Base \\
\hline 18 & Scrubber Base (Coal) & Stabilized Base \\
\hline 19 & Demolition Debris & Embankment/Fill \\
\hline 20 & Demolition Debris & Asphalt Pavement \\
\hline 21 & Demolition Debris & Base/Subbase \\
\hline 22 & Blast-Furnace Slag & Embankment/Fill \\
\hline 23 & Blast-Furnace Slag & Concrete Additive \\
\hline 24 & Blast-Furnace Slag & Asphalt Pavement \\
\hline 25 & Blast-Furnace Slag & Base/Subbase \\
\hline 26 & Steel Mill Slag & Asphalt Pavement \\
\hline 27 & Steel Mill Slag & Base/Subbase \\
\hline 28 & Non-Ferrous Slag & Embankment/Fill \\
\hline 29 & Non-Ferrous Slag & Asphalt Pavement \\
\hline 30 & Non-Ferrous Slag & Base/Subbase \\
\hline 31 & Cement/Lime Kiln Dust & Asphalt Pavement \\
\hline 32 & Cement/Lime Kiln Dust & Stabilized Base \\
\hline 33 & Reclaimed Asphalt Pavement & Embankment/Fill \\
\hline 34 & Reclaimed Asphalt Pavement & Asphalt Pavement \\
\hline 35 & Reclaimed Asphalt Pavement & Base/Subbase \\
\hline 36 & Reclaimed Concrete Pavement & Embankment/Fill \\
\hline 37 & Reclaimed Concrete Pavement & Concrete Additive \\
\hline 38 & Reclaimed Concrete Pavement & Base/Subbase \\
\hline 39 & Foundry Wastes & Flowable Fill \\
\hline 40 & Foundry Wastes & Asphalt Pavement \\
\hline 41 & Paper Mill Sludge & Concrete Additive \\
\hline 42 & Wood Waste & Embankment/Fill \\
\hline 43 & Carpet Fibers & Soil Reinforcement/Stability \\
\hline 44 & Mine Tailings & Embankment/Fill \\
\hline 45 & Mine Tailings & Asphalt Pavement \\
\hline 46 & Mine Tailings & Base/Subbase \\
\hline
\end{tabular}

Figure 3-2 Continued 


\begin{tabular}{|l|l|l|}
\hline 47 & Phosphogypsum & Stabilized Base \\
\hline 48 & Quarry Waste & Flowable Fill \\
\hline 49 & Glass & Asphalt Pavement \\
\hline 50 & Glass & Base/Subbase \\
\hline 51 & Plastics & Other \\
\hline 52 & Paper Mill Sludge & Other \\
\hline 53 & Foundry Wastes & Embankment/Fill \\
\hline 54 & Fly Ash (Coal Ash) & Base/Subbase \\
\hline 55 & Boiler Slag (Coal) & Asphalt Pavement \\
\hline 56 & Boiler Slag (Coal) & Base/Subbase \\
\hline 57 & Boiler Slag (Coal) & Stabilized Base \\
\hline
\end{tabular}

Figure 3-2 Continued

Process Form

The Process forms are similar to both the Material and Application Forms. There are two distinct forms - one for viewing existing data and one for adding new data. The user can access them by first clicking on the appropriate switchboard button. He can then navigate from the Materials form to the Application form and then to the Process form or he may go directly to the Process (Add Entry) form from the second level switchboard. Locks and allowances prevent data editing in existing forms and allow it in the add entry forms. 


\section{Chapter Four: Engineering and Environmental Properties and Performance}

Introduction

Materials, applications, and processes set the tone for much more detailed data. Engineering properties are included in the database for several reasons. First, they more fully characterize how a particular recycled material that is envisioned for a specific application will behave. Obviously the attributes that a material exhibits vary not only with different processing mechanisms but also with different researchers. For this reason, it is essential that the database be replete with as many properties from a breadth of researchers. By considering several different studies of the same material or process, an exhaustive albeit more rigid interpretation of that material's "true" behavior surfaces. Another purpose for including properties is to add another dimension for searching and sorting. For example, a user can search for a material knowing only its intended application and required absorption and strength characteristics. In addition to the previously stated reasons, the inclusion of environmental properties allows the user to instantly locate areas of concern. For example, if a processed material has a relatively large concentration of a particular trace metal, monitoring leachate might be necessary. In addition, quality control as well as source and processing mechanism for that particular material must be emphasized. In short, the properties give the database its detail and robustness.

Properties

Engineering Properties

After reviewing approximately 90 case studies, it was decided that eighteen engineering properties and nine environmental would be selected. The attributes were 
chosen both for their ability to comprehensively characterize the materials and for their consistent appearance throughout the literature. Obviously, the list is not all-inclusive. In fact, a provision is included for inputting important supplementary properties such as $\mathrm{pH}$, corrosivity, and other parameters that appertain only to certain materials. Again, it must be emphasized that tables can be modified by a database designer in order to incorporate more relevant properties. Table 4-1 lists the engineering properties included in the database.

Table 4-1: Database Engineering Properties

\begin{tabular}{|l|l|}
\hline Property & Units \\
\hline Unit weight & $\mathrm{kg} / \mathrm{m}^{2}$ \\
\hline Specific gravity & \\
\hline Shape & \\
\hline Size & \\
\hline Absorption & $\%$ \\
\hline Liquid limit & \\
\hline Plastic limit & \\
\hline Classification & \\
\hline Hardness & $\mathrm{Moh}$ 's \\
\hline CBR & \\
\hline Cohesion & $\mathrm{kPa}$ \\
\hline Maximum dry density & $\mathrm{kg} / \mathrm{m}^{3}$ \\
\hline Internal friction angle & $\mathrm{degrees}$ \\
\hline Optimum water content & $\%$ \\
\hline Compressive strength & $\mathrm{kPa}$ \\
\hline Permeability & $\mathrm{cm} / \mathrm{sec}$ \\
\hline Other properties & \\
\hline
\end{tabular}

\section{Omitted Engineering Properties}

While it is true that these properties accurately characterize the materials, several other properties are appropriate, and they have not been considered here. Property data must be entered in table format using numbers or small phrases of text. Although it is possible that data type 'OLE object' can be inserted into a database for the purpose of viewing a figure, such a practice bogs down the database because of the space the object takes up. Moreover, an OLE object cannot be indexed and is therefore not searchable. 
The inclusion of OLE objects goes against one of the main themes of this relational database: rapid searchability. However, good data in the form of grain-size distribution figures, deformation response, and empirical relationship studies must be sacrificed to achieve it. Perhaps a future effort can build upon the ideas presented in this study and develop a searchable object format that takes up very little of the database space. As it stands though, the user always has the option to look into the data set or case study further by simply accessing its original reference.

\section{Environmental Properties}

Environmental properties also help to characterize recycled materials and determine their eligibility for use in certain applications and regions. Perhaps even more importantly, environmental properties provide useful data for documenting recycled material use and performance - allowing state and federal agencies such as the Department of Environmental Protection (DEP) and the Environmental Protection Agency (EPA) to make informed decisions. Currently, environmental agencies are somewhat reluctant to approve the use of recycled materials without extensive data collection, documented sampling procedures, and an array of quality control measures. Often, the materials are proven to function well from an engineering standpoint, but programs for their implementation become stalled in the environmental approval stage. With this in mind, the database is equipped with ample environmental data from a variety of both laboratory case studies and field case studies. It is organized into the last four of the nine tables. Table 4-2 contains the table names and their corresponding fields (excluding the primary keys since they serve no linking role here but including the foreign keys). 
Table 4-2: Environmental Properties Tables

\begin{tabular}{|l|}
\hline Chemical Composition \\
\hline Chemical composition \\
\hline Weight percentage \\
\hline IDCaseProcess \\
\hline \\
\hline Metal Concentration \\
\hline Metal name \\
\hline Concentration $(\mathrm{mg} / \mathrm{L})$ \\
\hline Concentration $(\mathrm{mg} / \mathrm{kg})$ \\
\hline IDCaseProcess \\
\hline \\
\hline Organic Concentration \\
\hline Organic compound \\
\hline Class \\
\hline Concentration $(\mathrm{mg} / \mathrm{L})$ \\
\hline Concentration $(\mathrm{mg} / \mathrm{kg})$ \\
\hline IDCaseProcess \\
\hline \\
\hline Leachate \\
\hline Constituent \\
\hline TCLP (mg/L) \\
\hline SPLP $(\mathrm{mg} / \mathrm{L})$ \\
\hline EPTox (mg/L) \\
\hline ASTM D-3987 (mg/L) \\
\hline IDCaseProcess \\
\hline
\end{tabular}

\section{Organization and Input}

In the chemical composition table, a unique IDChemical compound, the primary key of the data table, corresponds to a unique case study and process combination. For example, a study by Jenkins that examines the use of reclaimed asphalt pavement in base and subbase applications might have several chemical compounds and weight percentage values associated with it. The importance of linking this table to both the Performance (case study) table and the Process table is apparent. Each time a material goes through a refining process to produce a usable material, both engineering and environmental properties have the potential to change. Also, different researchers have documented varying chemical compounds and weight percentages of those compounds in their case studies. Therefore, each time data is examined from the Chemical Composition table, the 
user is aware that the information is specific to one particular researcher and one particular process. Not surprisingly, over 500 records currently exist in this table.

The Metal Concentration table has one main purpose - to identify and quantify the existence of trace metals within a processed material. Similar to the Chemical Composition table, it is linked to both the Performance table and the Process table. Therefore, data in this table corresponds to a unique case study and processed material. For example, scrap tires envisioned and processed for use as embankment or fill in a study by a particular researcher might include concentrations of aluminum, lead, and any other metal. The presence of certain metals in high concentrations precludes their use in several applications. Both national and state recommended allowable limits (RALs) exist for these materials. In addition, local drinking water standards specify acceptable limits from both health and aesthetics criterion. Table 4-3 summarizes environmental concerns of waste and recycled materials. Many of these concerns are addressed through data collection in the database.

Table 4-3: Properties of Environmental Concern (Kim, 2003)

\begin{tabular}{|l|l|l|}
\hline Parameter & Potential Hazardous Property & Affected \\
\hline Leachable trace metals & As, $\mathrm{Cd}, \mathrm{Cu}, \mathrm{Cr}, \mathrm{Hg}, \mathrm{Pb}, \mathrm{Zn}$ & Ground/surface water \\
\hline Leachable organics & Benzenes, phenols, corrosivity, $\mathrm{pH}$ & Ground/surface water \\
\hline Soluble solids & Soluble and mobile salts & Groundwater \\
\hline Total respirable dust & Respirable fine particles & Air \\
\hline Trace metals in dust & Respirable or deposited trace metals & Air/secondary \\
\hline Trace organics in dust & Respirable or deposited trace organics & Air/secondary \\
\hline Volatile metals & As, Hg, Cd, Pb, Zn released at high temp. & Worker health \\
\hline Volatile organics & Chlorinated hydrocarbons released & Worker health \\
\hline
\end{tabular}

The Organic Concentration table is mainly concerned with the presence of various classes of organic compounds (i.e. volatiles, semi-volatiles, phenols etc.) that are components of processed recycled materials. Special areas of concern include organic compounds such as benzenes, phenols, and vinyl chloride that impact both groundwater and surface water quality (Chesner et al., 2002). Each record in the database corresponds to a specific case study and process. A study by Freeman, which analyzes the suitability of fly ash as flowable fill might have anywhere from ten to thirty entries for organic compounds and their concentration values in $\mathrm{mg} / \mathrm{L}$. 
The final environmental properties table, Leachate, warrants special consideration as there are several different tests used to measure this parameter. Many of these tests developed as a result of the Resource Conservation and Recovery Act (RCRA) that was passed by Congress in 1976. It dealt with hazardous waste disposal and environmental management of waste. These tests fit into one category of leachate tests: regulatory methods. The other two categories are standard methods such as those specified by organizations including ASTM and research methods, developed to measure specific and unique properties (Kim, 2003). Leaching is defined as the removal of materials by dissolving them away from solids. All four tests included as part of the database are batch tests - tests involving a given volume of leachant solution such as water for a given period of exposure time. The four tests are summarized in the Table 4-4.

Table 4-4: Regulatory Methods Tests (Kim, 2003)

\begin{tabular}{|l|l|l|l|l|l|l|}
\hline Method & Leachant & $\begin{array}{l}\text { Sample } \\
\text { size }(\mathrm{g})\end{array}$ & $\mathrm{pH}$ & $\mathrm{L} / \mathrm{S}$ & Units & $\begin{array}{l}\text { Time } \\
(\mathrm{hr})\end{array}$ \\
\hline TCLP & Acetic acid or acetate buffer & 100 & 2.88 & 20 & $\mathrm{mg} / \mathrm{L}$ & 18 \\
\hline SPLP & Water w/ nitric and sulfuric acid & 100 & 4.2 & 20 & $\mathrm{mg} / \mathrm{L}$ & 18 \\
\hline EPTox & Water & 100 & 5.0 & 20 & $\mathrm{mg} / \mathrm{L}$ & 24 \\
\hline ASTM & Water & 70 & & 20 & $\mathrm{mg} / \mathrm{kg}$ & 18 \\
\hline
\end{tabular}

Unrelated to the fundamental questions raised by this thesis, a completely singular research thread has developed around the comparison of these tests in terms of reproducibility and accuracy as compared to some standard "true value." "With exact duplication of regulatory or standard methods, there is a 60 to 80 percent probability that tests conducted by different laboratories with the same protocol will have comparable results" (Kim, 2003). The purpose of the database is to organize and present data rather than interpret or promote particular methodologies.

Table 4-4 also provides the truncated abbreviations of the regulatory leaching batch tests. The full names are as follows: Toxicity Characteristic Leaching Procedure (TCLP), Synthetic Precipitation Leaching Procedure (SPLP), Extraction Procedure Toxicity Test (EPTox), and Standard Test Method for Shake Extraction of Solid Waste with Water (ASTM-D3987). In addition to the differences shown in the table among the tests, TCLP and SPLP warrant further explanation. TCLP is an EPA analytical method 
designed to simulate sanitary landfill contaminant leaching (Aerotech, 2004). Its main purpose is to characterize a waste material as hazardous or non-hazardous. SPLP, on the other hand, is an EPA analytical method designed to simulate acid rain effects. Specifically, it is concerned with toxic organic and inorganic soil contaminants that migrate into the groundwater table (Aerotech, 2004).

\section{Data Range}

Some research studies are numerically and test-intensive. A study may contain data from the testing of twenty materials with only a few samples from each material or it may contain data from testing only one material with twenty samples. In either case, a decision must be made as to which data should be entered into the database. For engineering properties, each parameter is assigned two fields, high and low, so that a high and low value from that particular study can be recorded. Thus, rather than a collection of isolated information from tests, the database contains a data range. Certainly some element of subjectivity must enter into the database design stage and the data entry stage. In both engineering and environmental testing, statistical outliers are discarded. Although it is possible that these outliers represent valid data, in most instances, such data is usually the result of contaminated samples and/or poor testing protocol.

Environmental tests do not include provisions for entering a data range. Instead, an average value is calculated from each testing category after discarding the outliers. For example, a TCLP test performed ten times for one processed material may include one result that is significantly removed from the other nine values. As a result, the average is recorded for the nine values and then entered into the database.

\section{Evaluating Performance}

An exhaustive review of current and past research on recycled materials was conducted in an attempt to fill the database with as much useful information as possible. It is obviously impossible to completely characterize each material in this document. 
However, a limited review of the materials is definitely appropriate. In the sections that follow, some of the materials are examined in detail and a discussion of general performance, field use, limitations, and special considerations are also included. Perhaps this section can be viewed as a sort of comparison and summary of findings.

\section{Plastics}

Surprisingly, out of the three previous efforts at a recycled materials comprehensive compendium, only one included any information on plastics. This is probably due to the fact that it is a relatively new material in the arena of geotechnical and transportation applications. As stated earlier, plastics are used in at least two stabilizing mechanisms: discrete and homogenous. Consoli et al. (2002) examine sand reinforced with strips of recycled, processed, plastic strips. Long, flat strips of varying length are added either alone or in combination with Portland cement in small doses to increase strength and stiffness of loose sand. The plastic strips improved both peak and ultimate strength in both cases (Cosoli et al., 2002). The plastic waste exhibited the following engineering properties: specific gravity of 1.06, internal friction angle between $37^{\circ}$ and $43^{\circ}$, tensile strength between 207 and $230 \mathrm{MN} / \mathrm{m}^{2}$, and elastic modulus of 7 $\mathrm{GN} / \mathrm{m}^{2}$ (Cosoli et al., 2002). Loehr and Bowders (2000) explore weak reinforcement of slopes with recycled plastic piles. In the field study, 317 of the piles are eventually installed with a continuous monitoring system so far proving the plastic piles' efficacy (Loehr and Bowders, 2000). Compressive strengths of $21000 \mathrm{kPa}$ and tensile strengths of $13000 \mathrm{kPa}$ were achieved with a cost of \$42 per square meter of slope face (Loehr and Bowders, 2000). So far, it appears that plastics are used in only a few applications slope stability and soil reinforcement. To be used properly it is important to specify the type of plastic (i.e. PET fibers or HDPE pellets etc.). In addition, very little environmental data is available on this material. 


\section{Incinerator Ash}

Incinerator ash has been used in asphalt concrete and in base and subbase applications. It has been used in Chicago, Houston, Washington, D.C., and Harrisburg, Pennsylvania, and Lynn, Massachusetts - all in asphalt pavement applications and most as a replacement for coarse aggregate in asphalt paving mixes (Collins and Ciesielski, 1994). Concerns have been raised over leaching of heavy metal such as lead and cadmium since past efforts have seen amounts in excess of regulatory limits (Collins and Ciesielski, 1994). In general, EPA has been slow to approve incinerator ash as a construction material, and has even characterized it as a borderline hazardous waste in some instances. Many of these problems stem from the inconsistency of the processed material itself. The material may be processed in a mass burn facility (no presorting) or a refuse derived-fuel facility (requires presorting), and this facility may be new or old. As a result, the quality of the final processed ash is inconsistent and may exhibit varying engineering and environmental properties (Chesner et al., 2002). It is recommended that this material be used under a controlled process and environmental monitoring. Fortunately, engineering properties of incinerator ash are less scattered: unit weight of 965 to $1290 \mathrm{~kg} / \mathrm{m}^{3}$, specific gravity of 1.86 to 2.24 , CBR of 75 to 150 , friction angle of $40^{\circ}$ to $45^{\circ}$, abrasion of 44 to $50 \%$, absorption of 3.6 to $14.8 \%$, and maximum dry density of $1730 \mathrm{~kg} / \mathrm{m}^{3}$.

\section{Scrap Tires}

Scrap tires have easily generated the most recent research interest for their wideavailability, potential applications, consistent engineering properties, and relatively lowimpact environmental properties. Although the use of scrap tires in field projects has been widespread with some 40 state highway agencies conducting some sort of research, its use is still deemed experimental (Collins and Ciesielski, 1994). This is due to several factors including high upfront costs (investment in processing machines, monitoring equipment etc.), the necessity of monitoring performance and maintenance requirements 
over a long period of time, and the evolving mandates and environmental guidelines involving the use of scrap tires. Tire chips have been investigated for use in embankments and fill (Bosscher et al., 1997; Humphrey et al., 1998; Vipulanandan and Basheer, 1998) in asphalt pavement applications (Chesner et al, 2002), in specialty applications (Reid et al, 1998), and their impact on the environment has been assessed (Chesner et al, 1998; O'Shaughnessy and Garga, 2000; Liu et al., 2000). The following range of engineering properties has been observed for scrap tires: unit weight of 390 to $584 \mathrm{~kg} / \mathrm{m}^{3}$ depending on void ratio, specific gravity of 1.1 to 1.3 , absorption of 2 to $3.8 \%$, cohesion of 8 to $12 \mathrm{kPa}$, internal friction of $19^{\circ}$ to $41^{\circ}$ (dependent on whether shreds, chips, or crumb rubber is used), permeability of 1.5 to $15 \mathrm{~cm} / \mathrm{sec}$, heating value of 28000 to $35000 \mathrm{~kJ} / \mathrm{kg}$, and Young's modulus of 770 to $1250 \mathrm{kPa}$. The reasons for the relatively wide ranges of properties stem from the use of varying sizes and shapes of scrap tires. In general, crumb rubber, the smallest processed scrap tire material, has a higher unit weight, higher friction, and lower permeability precisely because there is less void space.

The large variation in processing techniques and machinery has been addressed in a previous section. However, two environmental studies warrant special consideration. O'Shaughnessy and Garga (2000) examined the leaching behavior of an embankment constructed with scrap tires. The research, a combination field and laboratory study, found almost no evidence of either metals or organics exceeding local regulatory limits. Some "anomalies" existed including the presence of selenium in concentrations that slightly exceeded limits and inconsistencies in long-term results associated with concentrations of lead, cadmium, and chromium (O'Shaughnessy and Garga, 2000). However, the difficulty is in sorting and comparing such results to similar studies that cite conflicting data. It appears that more environmental data is required.

A study by Liu et al. (2000) also evaluated the environmental characteristics of scrap tire embankments through an original effort and comparison with previous studies. The study found that the control sample, typical bituminous asphalt actually leached higher concentrations of metals than the sample containing scrap tires (Liu et al., 2000). In addition, none of the laboratory samples containing scrap tires exceeded allowable 
limits for TCLP tests and EPTox tests (Liu et al., 2000). Table 4-5 summarizes their findings.

Table 4-5: Scrap Tire Leachate Summary in mg/L (Liu et al., 2000)

\begin{tabular}{|l|l|l|l|l|l|l|l|}
\hline Metal & $\begin{array}{l}\text { Minn. } \\
\mathrm{pH} 3.5\end{array}$ & $\begin{array}{l}\text { Minn. } \\
\mathrm{pH} 5\end{array}$ & $\begin{array}{l}\text { Minn. } \\
\mathrm{pH} 7\end{array}$ & $\begin{array}{l}\text { Minn. } \\
\mathrm{pH} \mathrm{8}\end{array}$ & $\begin{array}{l}\text { Wisconsin } \\
\text { AFS }\end{array}$ & $\begin{array}{l}\text { Tire Mgmt. } \\
\text { Council }\end{array}$ & $\begin{array}{l}\text { VDOT, } \\
\text { long-term }\end{array}$ \\
\hline $\mathrm{Al}$ & & & & & & & 0.746 \\
\hline $\mathrm{As}$ & & & & & & $\mathrm{ND}$ & \\
\hline $\mathrm{Ba}$ & 0.488 & 0.205 & 0.174 & 0.265 & 0.12 & 0.59 & 2.08 \\
\hline $\mathrm{Cd}$ & 0.125 & 0.007 & 0.005 & 0.005 & & $\mathrm{ND}$ & 0.004 \\
\hline $\mathrm{Cr}$ & 0.235 & 0.002 & 0.005 & 0.002 & 0.003 & 0.05 & 0.082 \\
\hline $\mathrm{Cu}$ & & & & & & & 0.328 \\
\hline $\mathrm{Fe}$ & 500 & 41.2 & 0.531 & 0.718 & 0.23 & & 31.62 \\
\hline $\mathrm{Pd}$ & 0.417 & 0.051 & 0.038 & 0.039 & 0.015 & 0.016 & 0.138 \\
\hline $\mathrm{Mn}$ & & & & & 0.3 & & \\
\hline $\mathrm{Hg}$ & & & & & & 0.0004 & \\
\hline $\mathrm{Ni}$ & & & & & & & 2.46 \\
\hline $\mathrm{Se}$ & 0.203 & 0.054 & 0.045 & 0.028 & 0.005 & $\mathrm{ND}$ & \\
\hline $\mathrm{Ag}$ & & & & & & & 0.005 \\
\hline $\mathrm{Zn}$ & 23.5 & 17.5 & 3.38 & 0.005 & 0.63 & & 0.153 \\
\hline
\end{tabular}

Scrap tire field implementations have gained notoriety for recent failures and therefore warrant special consideration. In 1995, two scrap tire road embankments in Washington State and one in Colorado began to exhibit signs of exothermic reactions heat is released as a result of chemical or biochemical reactions (Liu et al., 2000). This led researchers to examine the causes and propose solutions. All three of the field embankments/fills were constructed exclusively with scrap tires, and the tire shreds had exposed steel belts (O'Shaughnessy and Garga, 2000). According to researchers, "the potential causes of initial exothermic reaction are oxidation of exposed steel wires, oxidation of rubber, microbes consuming exposed steel wires or generating acidic conditions, and microbes consuming liquid petroleum products" (O'Shaughnessy and Garga, 2000). The existence of free oxygen was a result of inadequate soil cover or exposure to fertilizer-rich soil or crumb rubber. As a result of these experiences, guidelines for embankment construction using scrap tires are now available. 


\section{Roof Shingles}

As a material that has been studied much less than some of the others, recycled roof shingles could prove its value if certain limitations can be addressed. As stated in the materials section, two types of roofing shingle byproduct exist: prompt roofing shingle scrap (leftover from the manufacturing of roof shingles) and tear-off roof shingles (leftover from replacement of roofs by contractors). Both the engineering and environmental properties of prompt roofing shingle scrap are fairly consistent, which facilitates their incorporation into civil engineering applications. However, tear-off roof shingles may contain deleterious materials such as "nails, felt underlayment, metal flashings, wood, and water proofing and insulation materials" (Chesner et al., 2002). In addition, the asphalt cement binder component of this type of scrap is usually old and weathered. A final environmental concern comes from the existence of asbestos fibers, which present a serious health risk, in older shingles. The important consideration here is that if recycled roof shingles are to be used, the source must be controlled. Whether this happens through the exclusive use of prompt roofing shingle scrap or if it happens through presorting and control on the part of the material supplier/recycler, the issue must be addressed. Field implementation has occurred mainly in the form of cold-patching of antiquated pavement sections in low traffic areas (Collins and Ciesielski, 1994).

\section{Coal Byproducts (Fly Ash, Bottom Ash, Boiler Slag)}

The various forms of coal ash have been studied extensively: fly ash (Vipulanandan and Basheer, 1998; Vipulanandan et al., 1998; Tandon and Picornell, 1998; Senadheera et al., 1998, Collins and Ciesielski, 1994; Chesner et al, 1998; Chesner et al., 2002). Fly ash can be used as in asphalt pavement, as flowable fill, as a concrete additive, and in stabilized bases or embankments. Due to its pozzolanic properties, or tendency to form cementitious compounds, when combined with calcium and water, it can be adapted to various conditions (Collins and Ciesielski, 1994). Also, it is an abundant recycled material, but only a small percentage is actually put to use. In general, 
fly ash has proven to be a versatile material, and it has performed well is the vast majority of these applications. However, as has been mentioned in a previous section, the class and quality of fly ash varies. Depending on the type of parent coal (bituminous, subbituminous, and lignite) that is burned, the class (Class-C or Class-F), and other processing mechanisms and technology, the properties of fly ash, especially the environmental ones can vary dramatically. The range of both engineering and environmental properties is too great to include here, but it can be accessed using the database.

Bottom ash and boiler slag are generally not investigated individually, but rather they are included as part of comprehensive studies (Collins and Ciesielski, 1994; Chesner et al., 1998; Chesner et al., 2002). Unlike fly ash, these materials do not exhibit pozzolanic properties, but they can still be used in asphalt pavement, base, subbase, and stabilized base applications. Like fly ash, the engineering and environmental properties vary with the type of parent coal as well as the processing technique. An element of concern is the possible corrosive properties of these materials as a result of the salt content and low $\mathrm{pH}$ of both bottom ash and boiler slag (Chesner et al., 2002). Corrosion potential should be investigated prior to use. The following engineering properties were observed: unit weight of 720 to $1620 \mathrm{~kg} / \mathrm{m}^{3}$, specific gravity of 2.1 to 2.89 , absorption of 0.8 to $7.52 \%$, CBR of 36 to 70 , internal friction of $34^{\circ}$ to $55^{\circ}$, permeability of 0.001 to $0.1 \mathrm{~cm} / \mathrm{sec}$, abrasion of 35 to $43 \%$, and void ration of 0.49 to 0.53 . The high range of values suggests the necessity of material testing prior to use or source control.

\section{Scrubber Base}

Flue gas desulfurization (FGD) sludge, or scrubber base, has been investigated for potential use in stabilized base and embankment applications (Chesner et al., 1998; Chesner et al., 2002). Field implementation has taken place in Kentucky and Pennsylvania sites (embankments), Louisiana (road shoulders), and Texas (stabilized base) (Collins and Ciesielski, 1994). It is important to differentiate between different forms of FGD scrubber base. The product may be in an unoxidized calcium sulfite form, 
which can be used for roads or it may be in an oxidized calcium sulfate form, which can be used as a concrete additive (Chesner et al., 2002). In its unoxidized state, FGD scrubber can be further subdivided by whether it has been dewatered, stabilized, or fixated. Not surprisingly, engineering properties are widely scattered.

\section{Demolition Debris}

Investigated for its use in asphalt pavement and base/subbase applications, demolition debris provides another interesting albeit inconsistent recycled material. The material is an amalgamation of wood, plaster, concrete, glass, metal, brick, shingles, and asphalt (Collins and Ciesielski, 1994). Because of the variation in both quality and percentage of these components and because the components themselves were manufactured differently, it is difficult to control the material to meet gradation or construction performance requirements. Again, the quality control responsibility must either lie with the state agency that will be using the material or with the material provider such as the manufacturer or the recycling facility. The existence of both sewage sludge and asbestos is a very real possibility that must be investigated prior to incorporation into road applications (Collins and Ciesielski, 1994).

Slags (Blast-furnace, Steel-mill, Non-ferrous)

Historically, it has been difficult to gather accurate information on the various types of slags. Researchers have often failed to divide the slags into subcategories before summarizing data. In addition, non-ferrous slags are almost always grouped into one category even though they exhibit very different properties based on their parent ore (i.e. copper, nickel, zinc, phosphorus, lead etc.). Blast-furnace slag can be air-cooled, granulated, or expanded, and it can be used in asphalt pavement, base, embankments, or as a concrete additive (Collins and Ciesielski, 1994). Steel slags are produced from one of three types of furnaces: open hearth, basic oxygen, and electric arc and can be used in asphalt or base applications (Chesner et al., 2002; Collins and Ciesielski, 1994). In 
general, these slags are heavier than traditional aggregate materials, and they are hard, stable, and resistant to abrasion (Collins and Ciesielski, 1994). These materials have been used for several years despite two drawbacks. First, mixing the materials provides an inconsistent product. Second, leachate from slag fills has sometimes clogged drains (Collins and Ciesielski, 1994). Used in asphalt pavement, embankment, and base applications, non-ferrous slags exhibit varying properties according to their parent ore and whether they have been air-cooled or granulated (Collins and Ciesielski, 1994). Their use has been limited relative to the other types of slag. The following engineering properties have been observed for blast-furnace slags: unit weight of 800 to $1940 \mathrm{~kg} / \mathrm{m}^{3}$, specific gravity of 2 to 2.7 , absorption of 1 to $6 \%$, hardness of 5.5 to 6 , CBR of 250 , internal friction $40^{\circ}$ to $45^{\circ}$, and abrasion of $40 \%$. Steel-mill slags: unit weight of 1600 to $1920 \mathrm{~kg} / \mathrm{m}^{3}$, specific gravity of 3.2 to 3.6 , absorption of $3 \%$, hardness of 7, CBR of 300 , internal friction $40^{\circ}$ to $50^{\circ}$, and abrasion of $23 \%, \mathrm{pH}$ above 11 contributes to corrosive properties. Non-ferrous slags: unit weight of 1360 to $3800 \mathrm{~kg} / \mathrm{m}^{3}$, specific gravity of 2.8 to 3.8 , absorption of 0.13 to $5 \%$, hardness of 7 , internal friction $40^{\circ}$ to $53^{\circ}$, and abrasion of $26 \%$.

\section{Kiln Dusts (Cement and Lime)}

Kiln dusts have been investigated essentially from a field implementation standpoint (Collins and Ciesielski, 1994). Unfortunately, they have performed poorly. The principal uses are in asphalt pavement and stabilized base applications (Chesner et al., 2002). In addition to the poor performance of these materials, there is some question as to the underlying processing mechanism. Specifically, cement kilns burn hazardous waste as fuel sources, and this must be addressed either to testing or monitoring before kiln dusts can be used in practice. In short, this material does not appear to be very promising. 


\section{Reclaimed Asphalt Pavement and Reclaimed Concrete Pavement}

Reclaimed asphalt pavement has been investigated for use in hot and cold mix asphalt pavement as well as base, stabilized base, and embankment applications. The research is clear that reuse of this material is approaching 100 percent, and the portion that goes unused each year is usually stockpiled and used the following year (Collins and Ciesielski, 1994; Chesner et al., 2002). Every state is recycling asphalt pavement in some capacity. Performance and implementation programs have followed suit, and as a result processing capabilities are well-developed. One problem with RAP is its inconsistency. Specifically, RAP is a product of constituent materials such as asphalt type, and stockpiles can often be contaminated with foreign soils and debris. Also, the parent pavements themselves vary in quality depending on how many times they were resurfaced or patched (Chesner et al., 2002). So it is that quality control must be maintained preferably at a local level to ensure uniformity in material properties. The following engineering properties were observed for reclaimed asphalt pavement: unit weight of 1600 to $2300 \mathrm{~kg} / \mathrm{m}^{3}$, CBR of 20 to 150 , maximum dry density of 1872 to 2000 $\mathrm{kg} / \mathrm{m}^{3}$, and optimum water content of 5 to $8 \%$. The large range in CBR is generally attributed to reasons mentioned above.

Reclaimed concrete pavement does not enjoy the same widespread use as reclaimed asphalt pavement. However, the potential for a higher quality product is definitely there. Reclaimed concrete pavement (material), or RCM, is used as a concrete additive and in base and embankment applications (Chesner et al., 2002). As is the case with other materials, RCM will produce consistent properties if it is well-processed and it comes from a consistent source. Problems arise from the use of recycled concrete from various sources. Aggregates from the concrete in footings and piles can contain foreign substances as compared to pavement concrete (Chesner et al., 2002). Also, different concrete types yield a product that has varying aggregate quality, size, and compressive strength. "Precast concrete generally has a smaller aggregate size, higher compressive strength, and less variation in strength and other properties than cast-in-place concrete" (Chesner et al., 2002). Finally, salty environments such as Florida ensure exposure of the 
parent concrete to high levels of chlorides. The following properties have been observed for reclaimed concrete pavement: specific gravity of 2 to 2.5 , absorption of 4 to $8 \%$, CBR of 94 to 148 , maximum dry density of $1984 \mathrm{~kg} / \mathrm{m}^{3}$, internal friction of $40^{\circ}$, and optimum water content of $7.5 \%$.

\section{Foundry Waste}

Foundry waste has been used in asphalt pavement applications and flowable fill. Edil and Benson (1998) and Abichou et al. (1998) investigated the use of waste foundry sand as hydraulic fill. The presence of up to $15 \%$ bentonite reduces the hydraulic conductivity dramatically (Edil and Benson, 1998). Additionally, waste foundry sand performed satisfactorily when it was used to construct embankments (Mast and Fox, 1998). Foundry waste incorporates furnace dust, arc furnace dust, and residue in addition to foundry sand. Special consideration must be given to the presence of large concentrations of trace metals in foundry dusts (Collins and Ciesielski, 1994). Foundry sand is a better alternative due to its greater availability and its status as a non-hazardous material. Even so, attention must be paid to contaminants such as stone and trash as well as to its fine, uniform gradation and leaching of some heavy metals and phenols (Collins and Ciesielski, 1994; Chesner et al., 2002). Depending on the foundry source, high concentrations of cadmium, lead, copper, nickel, and zinc are also possible (Chesner et al., 2002). The following engineering properties were observed for foundry waste: unit weight of $2590 \mathrm{~kg} / \mathrm{m}^{3}$, specific gravity of 2.39 to 2.6 , absorption of 0.42 to $0.46 \%$, liquid limit of 31 , plastic limit of 25 , CBR of 4 to 20 , cohesion of 7 to $15 \mathrm{kPa}$, maximum dry density of $1855 \mathrm{~kg} / \mathrm{m}^{3}$, internal friction of $33^{\circ}$ to $40^{\circ}$, water content of 0.1 to $10 \%$.

\section{Paper Mill Sludge}

Very little information is available on paper mill sludge although it has been cited in the literature as a covering for landfills (Quiroz and Zimmie, 1998). Its use was tested as a substitute for traditional landfill cover materials such as clays. It exhibits unique 
properties such as high water contents, high organic contents, low shear strengths, and high compressibility (Quiroz and Zimmie, 1998). Hydraulic conductivity is the design parameter of interest, and it is this value that decreases while shear strength increases as the material consolidates. To ensure smooth construction, low pressure equipment must be used to place and compact the sludge (Quiroz and Zimmie, 1998). In addition, researchers have pointed to the need to establish some mechanism of quality assurance since the paper mill sludge byproduct is sensitive to both paper production changes and changes in wastewater treatment processes (Quiroz and Zimmie, 1998). Another byproduct of the paper industry, spent sulfite liquor may have potential for soil stabilization. Perhaps this is a new material that warrants further investigation. The following engineering properties were observed for paper mill sludge: specific gravity of 1.88 to 1.96 , liquid limit of 285 , plastic limit of 94 , compression index of 1.24 , and extremely low permeability values (typically less than $10^{-8} \mathrm{~cm} / \mathrm{s}$ ).

\section{Carpet Fibers}

In general, carpet fibers performed inadequately when used for soil stabilization. They performed better as concrete reinforcement when added is doses of 2 percent (Collins and Ciesielski, 1994). However, improvement in flexural strength and toughness came at the expense of compressive strength. As soil reinforcement, carpet fibers are impractical especially in sandy soils where they tend to migrate to the surface (Wang, 1999). Also, even when mixed in concrete, a superplasticizer is required to increase workability to an acceptable level (Wang, 1999). Researchers have had bad experiences with carpet fibers, and their poor engineering properties and limited availability make them an undesirable recycled material. The following engineering properties were observed for carpet fibers: unit weight of $1724 \mathrm{~kg} / \mathrm{m}^{3}$, optimum water content of $16.5 \%$. 


\section{Mill Tailings}

In relation to many of the materials, mill tailings are extraordinarily abundant. As fine-grained waste from ore concentration processes, mill tailings are produced from the concentration of copper, iron, taconite, lead, zinc, and uranium ores (Collins and Ciesielski, 1994). They have been used in asphalt pavement, base/subbase applications, and as embankment and fill materials. Unfortunately, properties, especially grain-size distribution vary dramatically with methods of ore processing, percentage of solids in the slurry, and location of the material within the same tailing pond (Collins and Ciesielski, 1994). Other problems include "fineness, high impurity content, trace metal leachability, propensity for acid generation, and/or remote location" (Chesner et al., 2002). In addition, tailings from gold may contain cyanide, those from uranium may be radioactive, those from sulfide ores may contain arsenic, and those from taconite may contain asbestos (Chesner et al., 2002). The following engineering properties were observed for mill tailings: unit weight of 1600 to $2300 \mathrm{~kg} / \mathrm{m}^{3}$, specific gravity of 2.6 to 3.5 , maximum dry density of $2025 \mathrm{~kg} / \mathrm{m}^{3}$, internal friction of $28^{\circ}$ to $45^{\circ}$, optimum water content of 10 to $18 \%$, permeability of 0.01 to $0.0001 \mathrm{~cm} / \mathrm{sec}$.

\section{Phosphogypsum}

Phosphogypsum is a controversial material that has been investigated extensively in the past but is currently only cited in passing (Chesner et al, 1998; Chesner et al., 2002). As a local material, phosphogypsum stacks can be found almost exclusively in Florida. However, due to a 1989 EPA ban on the use of phosphogypsum, research has slowed dramatically (Collins and Ciesielski, 1994). As a result, special petitions must be made to EPA before this material can be used or researched (Chesner et al., 2002). Despite all this, experimental sections of phosphogypsum stabilized roads are still performing well in Florida and Texas (Collins and Ciesielski, 1994). Most construction difficulties were a result of excessive moisture, overstabilization, and poor mixing and sealing (Chesner et al., 2001). The future of phosphogypsum as a viable recycled material is in limbo. The following engineering properties were observed for 
phosphogypsum: unit weight of 1470 to $1670 \mathrm{~kg} / \mathrm{m}^{3}$, specific gravity of 2.3 to 2.5 , cohesion of 76 to $179 \mathrm{kPa}$, maximum dry density of $1670 \mathrm{~kg} / \mathrm{m}^{3}$, internal friction of $28^{\circ}$ to $47^{\circ}$, optimum water content of 13 to $18 \%$, variable compressive strength, and a relatively high permeability.

\section{Quarry Waste}

Quarry waste consists of screenings, settling pond fines, and baghouse fines, and they have been used as cement additives, and in asphalt pavement and flowable fill (Chesner et al., 2002). It is widely available and has been used in Arkansas, Florida, Georgia, Illinois, Missouri, and Vermont (Collins and Ciesielski, 1994). Consideration must be made to completely dewater the waste after reclamation and prior to use. In addition, researchers must be conscious of the variation in material properties that are the results of different aggregate types and producer sources (Collins and Ciesielski, 1994). Local officials can be assured of consistent engineering and environmental quarries only within the same quarry location.

\section{Waste Glass}

Waste glass was investigated for use in asphalt pavement, base, and embankment applications (Chesner et al., 2002; Collins and Ciesielski, 1994). Most glass recycling occurs through individual household sorting before it goes to material recovery facilities to further separate and grind it down. Attention is given to specifications that limit impurities such as ceramics, ferrous metal, paper, plastics etc. (Chesner et al., 2002). Such impurities negate the otherwise uniform properties that clean glass exhibits. The finished product can be processed to decrease both size and angularity make it suitable for additional applications. The following engineering properties were observed for waste glass: unit weight of 1120 to $1900 \mathrm{~kg} / \mathrm{m}^{3}$, specific gravity of 1.96 to 2.52 , hardness of 6 , CBR of 42 to 132 , maximum dry density of $1900 \mathrm{~kg} / \mathrm{m}^{3}$, internal friction of $51^{\circ}$ to 
$53^{\circ}$, optimum water content of 5.7 to $7.5 \%$, permeability of 0.06 to $0.2 \mathrm{~cm} / \mathrm{sec}$, and abrasion of $36 \%$. 


\section{Chapter Five: Database Design}

As was mentioned previously, before proceeding with the database design, a literature review was conducted to establish the recycled material research that had already been accomplished. Relevant sources of research including technical reports, archived publications, online resources, books, special publications, and conference proceedings were categorized and documented. This step served the dual purposes of supplying substance for the database and highlighting areas in need of further research. A commercially available software, Microsoft Access, ${ }^{\circledR}$ was used as the database management system (DBMS).

Identification of Tables and Fields

Although table organization and corresponding field headings are assigned at the discretion of the database designer, certain obvious choices exist. There is a table dedicated to the 24 recycled materials as well as one for their potential applications and one for the processing mechanisms and techniques that generate a usable product. In addition, tables exist for each of the following: performance (case study), case/process (engineering properties), chemical composition, metallic concentration, organic concentration, and leachate analysis. Some tables such as the Performance table serve as intermediate tables - linking the primary tables while simultaneously providing compulsory information, which in this case includes authors names, literature reference, and the state and year in which the research was performed.

The Materials table contains fields corresponding to the material's name, description, and availability. Consistent with each of the nine tables, there exists a field, IDMaterial, which is a unique numerical identifier, or primary key, to be used when generating relationships among tables. As mentioned previously, the primary key or ID 
is data type "autonumber," which increments automatically each time a new record is created. Each primary key field corresponds to at least one field of similar name that functions as a secondary or foreign key. Primary and foreign keys directly link two data tables together and indirectly link the entire set of tables into one continuous, organized compendium. In addition, the key fields establish the requisite relationships between tables and fields. A portion of the Material table is reproduced in Figure 5-1.

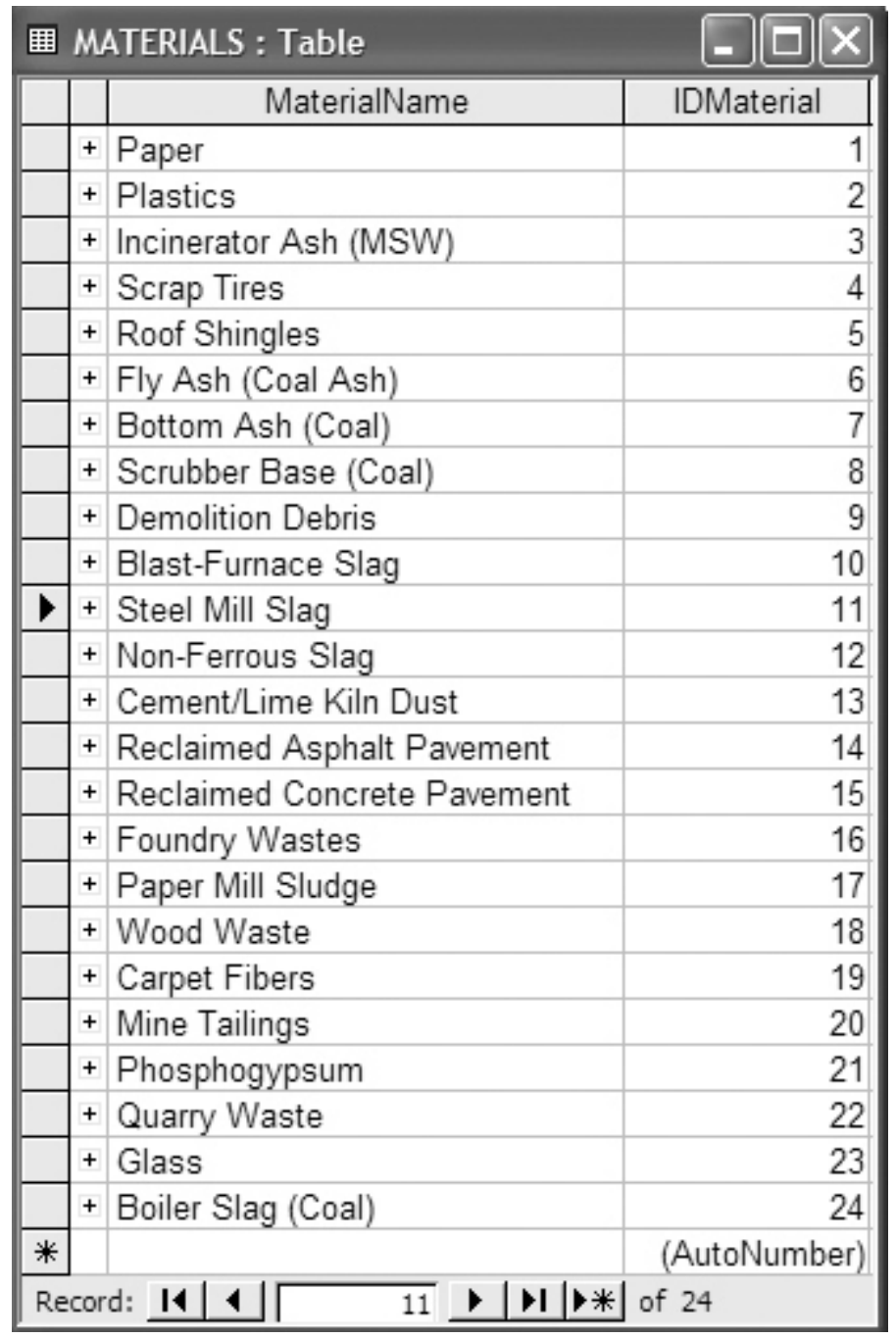

Figure 5-1: Part of the Material Table 
The Application table is composed of application titles and their descriptions. Like the Materials table, it has a primary key, IDApplication, which links it to the rest of the database. The Process table contains one primary key, IDProcess, and two foreign keys: IDMaterial and IDApplication in addition to a process description field and a cost per ton field. The IDProcess automatically increments each time a new, unique material/application combination is entered. The Performance table has one primary key, IDCaseStudy that uniquely identifies each case study and one foreign key, IDProcess. This table contains requisite fields to comprehensively cite each case study: Authors, Reference, Year, State, and a brief SummaryMemo that summarizes the purpose and findings of the research effort. The Case/Process table contains one primary key, IDCaseProcess that identifies each unique combination of a specific process (material and application combination) and a specific case study. It also contains two foreign keys: IDProcess and IDCaseStudy. This table also encompasses eighteen fields corresponding to eighteen engineering properties. The majority of engineering properties have a "high" field and a "low" field - allowing the user to enter a range of data values. The Chemical Composition table contains a chemical compound name, a foreign key (IDCaseProcess), and a field in which to cite the chemical compound's weight percentage. Similarly, the Metal Concentration table, the Organic Concentration table, and the Leachate table all share the same foreign key, IDCaseProcess. However, the Organic Concentration table also has fields for class (i.e. volatiles, semivolatiles etc.) and organic concentration listed in two different measurement units. The Leachate table summarizes data from four regulatory batch tests - TCLP, SPLP, EPTox, and ASTM D-3987.

\section{Developing Data Relationships}

Choosing a relational database model over a network or hierarchical model ensures that any two tables interact according to four general relationships: one-to-one, one-to-many, many-to-many, or no relation. This step is crucial because it directly affects the data that can be accessed and viewed by the user. In addition, relationships 
among data that exist in real life must be carried over into the database to ensure practicality. Proper relationships mitigate data redundancy and poor user access to data.

Table Relationships

A one-to-many relationship exists between the Material and Process tables and between the Application and Process tables. The first signifies that each material can be processed in one or more ways before it is used as an engineering material. For example, scrap tires can be shredded to a particular size before compaction or the process can involve a series of shredding, steel belt removal through magnetic separation, and grinding to meet crumb rubber specifications. However, each process has one and only one material associated with it. As another example, recycled plastic, an element from the Materials table, can be processed into composite recycled plastic piles/lumber or it can be cut into small strips before it is incorporated into geotechnical systems. The difficulty is in developing the processing mechanisms so that they are specific enough to avoid overlap with other materials and yet general enough to ensure practicality. This is more of an issue with the process description field that is included in memo format. Concerning applications, the one-to-many relationship means that each of the eight applications (i.e. embankment/fill, asphalt pavement, flowable fill etc.) can be associated with more than one process. To employ a material as an asphalt modifier, it may be reclaimed, crushed, and screened or it may be mechanically combined into pellet form. Each process is associated with only one application. So it is that for the purposes of the database, each process is actually a unique combination of a material and an application, and the process table links the other two while establishing the many-to-many relationship between them. Each of the materials can be used in one or several applications and each application can be fulfilled by one or more materials.

The Process table is paramount. Besides linking the aforementioned tables, it also has a many-to-many relationship with the Performance or case study table. Each process, or unique material/application combination is documented by one or several case studies, and each case study may contain information relating to several processes. For example, 
a particular study may document the use of roof shingles and bottom ash in stabilized base applications. Roof shingles and bottom ash in embankments may also be at least part of the research of a different study. The linking table between Process and Performance (case study) is the aptly named Case/Process table; it contains the engineering and environmental parameters required to completely characterize the material. This table contains a vast amount of data. For example, a single record in this table might contain all the engineering data documented by a single study on kiln dust used as road base.

The final four tables, Chemical Composition, Metal Concentration, Organic Concentration, and Leachate are the environmental properties tables. They are connected to the rest of the database through a one-to-many relationship with the Case/Process table. Again, for a single material envisioned for single application, documented in a single case study, there exist several chemical compounds with corresponding weight percentages. This relationship carries through to the presence of several trace metals, several organic compounds, and several leachate test results - all for a single case/process combination. Refer to Figure 1-4 from Chapter 1, which shows the database schema. Each table name is placed at the top in bold and each primary key is underlined. The lines delineate relationships among the tables with the ' 1 ' and ' $\infty$ ' representing the 'one' and 'many' relationships, respectively.

\section{Content Overview}

A more detailed examination of table headings and their corresponding fields is useful to understand how and where the data is inputted. Only the primary tables and those linking tables that contain important parameters are included in this discussion.

\section{Material Table}

Thorough review of the literature revealed 24 recycled materials suitable for this table. Although not encompassing every recycled material currently studied, these 24 
provide a satisfactory, representative sample about which there is sufficient research. The materials belong to one of three categories based on their origin. Collins and Ciesielski (1994) identified these categories as domestic waste materials, industrial waste materials, and mineral waste materials.

\section{Applications Table}

This table displays eight applications - how the materials functions as part of a highway or geotechnical system. The applications are as follows: embankment/fill, flowable fill, concrete additive, asphalt pavement, base/subbase, stabilized base, soil reinforcement/stability, and other. Typically, embankment/fill applications involve raising a roadway with compacted material, providing a bridge approach, or similar activities. Select fill or other soil is usually used but can be mixed with or completely supplanted by aggregate-like recycled materials. Flowable fill, a self-cementing slurry, is generally used as excess fill in hard to reach areas such as near utilities and pipes. Recycled materials can be used in place of its components - either as aggregate or cementitious material. As concrete additives, recycled materials function as mineral admixtures that improve the strength, workability, and resistance to sulfates of the concrete. These materials are also used as substitute aggregate and/or mineral filler in asphalt pavement applications.

In base and subbase applications, recycled materials take the place of aggregate materials and cementing materials, and they function as a load transfer mechanism between overlying pavement and the soil underneath. Used in stabilized base, recycled materials take the place of aggregates if the latter is unavailable and may improve the self-cementing properties of the stabilized base. Soil reinforcement/stability is really two sub-applications. The first involves mixing a marginal soil with doses of a recycled material that improves the mechanical properties of the soil. The second refers to stabilizing slopes with discrete elements such as recycled plastic piles. The "other" category exists for aesthetic applications, very specialized applications, or those that do not involve transportation or geotechnical criteria. 


\section{Process Table}

In addition to the aforementioned primary keys and linking fields, the process table is also composed of a description for each of the over 50 material/application combinations. Although each process is unique, many of the same actions are performed on the materials. These include shredding, screening, reclaiming, crushing, dewatering, stockpiling, and removing contaminant debris. Besides modifying them chemically, the recycled materials are often blended with other aggregate or fill to ensure uniformity or to meet gradation requirements. To process roof shingles that are to be used in asphalt pavement for example, debris must first be removed. Then the material is shredded, screened, stockpiled, and blended with other aggregate. Finally, it is moistened with water and added to the asphalt mixture. Concerning the database, the process description field is set to memo data type. This data type occupies more space than text but is essential in this case. A more detailed discussion of processes can be found in Chapter 4 .

\section{Performance Table}

This table provides the compendium of relevant lab and field case studies. It is connected to the rest of the database through the process table. The fields are: Authors, Reference, Year, State, and SummaryMemo. For example, a lab case study from the Geotechnical Testing Journal by Yang et al. (2002) analyzes the mechanical properties of scrap tires. Specifically, the unit weight, size, shape, cohesion, and friction angle of the material are documented. The reference information is inputted into the Performance table, and the engineering parameters are added to the table that lists properties. Therefore, the database user may choose a process or a case study or an engineering property, and is immediately granted access to the other two pieces of information that correspond to that choice. The result is an interactive compendium of data that enables 
the users to start with one table of data either because they choose to or because that is the only data to which they have access, and then move through the corresponding records in the other tables.

\section{Other Tables}

A linking table joins the Process table with the Performance table. It is necessary to model the many-to-many relationship that exists. The Case/Process table has the following fields: unit weight, specific gravity, shape, size, absorption, liquid limit, plastic limit, classification, hardness, CBR, cohesion, maximum dry density, internal friction angle, optimum water content, compressive strength, other properties, and general environmental notes. Environmental tables incorporate the major constituents that may have a detrimental impact on the environment. Obviously, very few case studies depict all or even most of the above parameters. This fact does not detract from the usefulness of the database.

Environmental parameters such as presence of trace metals, existence and composition of organics, leachate properties, and general environmental notes are also contained in tables that attach to the Case/Process table. Again, each case study may provide very little information concerning environmental properties or it may be more comprehensive in nature.

Using the Database

The completed tables are the compendium of recycled materials data. However, it is the interaction and manipulation of the data that gives the database its practicality. In the database management system, this is accomplished through the creation of forms, queries, and reports. 
Forms

Forms serve as filters so users can see data in an easily accessible format (Whitehorn and Marklyn, 2003). Unless the users are familiar with the database design and existing relationships between data sets, they cannot update it with new information. Typically, forms are the only method through which the user interacts with the data. For the recycled materials database, two sets of forms are created for each of the nine tables. As a result, the users can easily view existing information or they may add new recycled materials, new applications, new processes, new case studies, or new parameters to the database as the research is completed.

The forms for viewing existing data are created with functionality in mind. The user is not allowed to add to or edit information to the database in any of the nine forms through the 'view existing data' form set. This is accomplished through locking the forms to which the data tables are connected. It is a safeguard against misuse and/or data contamination that may result from making the database available. The authors of this report and the database designer can only be held responsible for the design of the database. The 'view existing data' form set is formatted with a yellow and green background so that the users develop an awareness of where they are at in the database. An example form from the 'view existing data' form set is shown in Figure 5-2. 


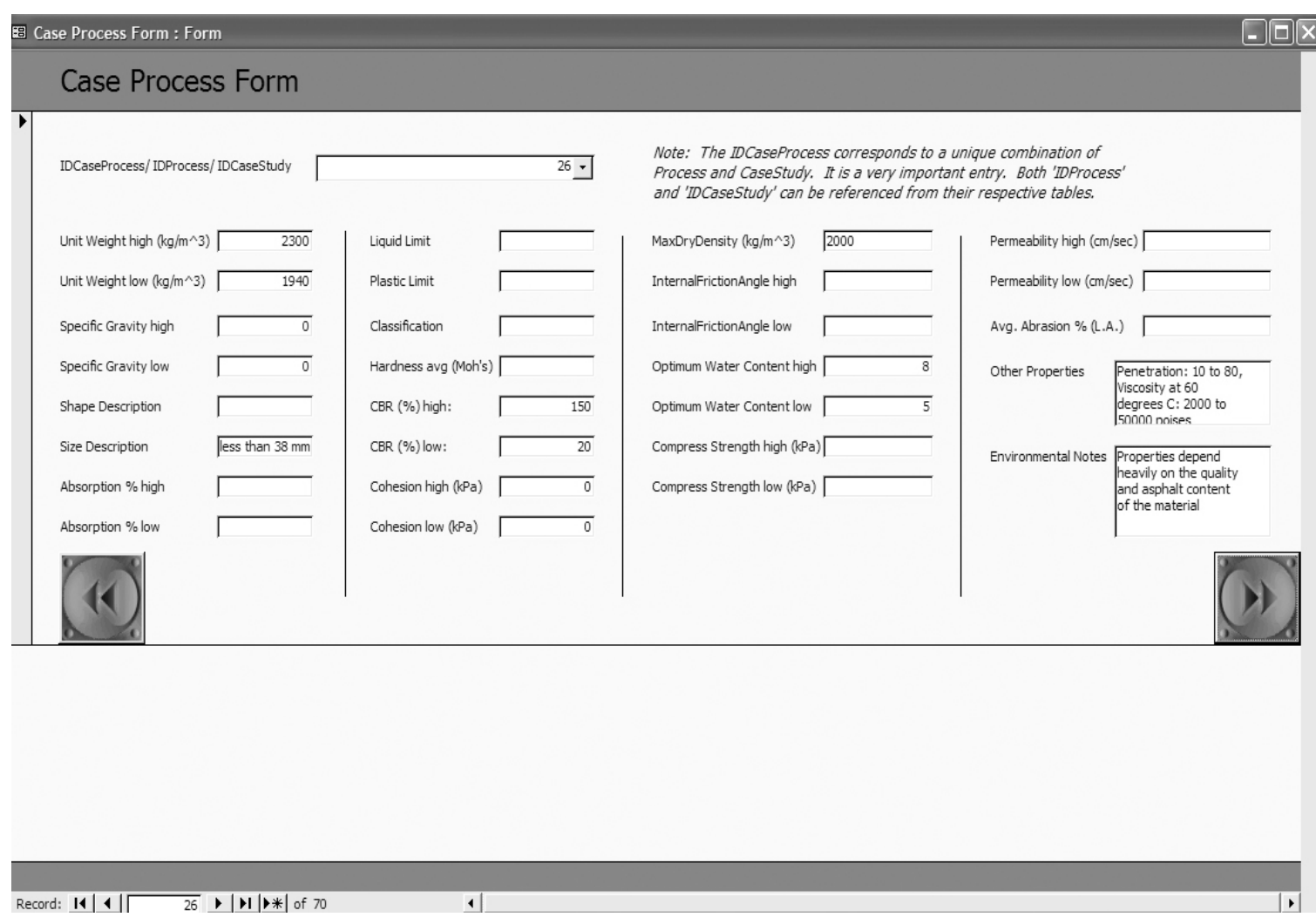

Figure 5-2: Case Process Form ('View Existing Data')

The forms for adding new data are blank. Each form updates and is formatted to automatically increment primary key autonumbers each time a new record is added. One drawback is that as the users move from form to form entering data, they must click the "save" button to update the information they have already inputted into the corresponding data tables. Failure to do so negates any efforts at data entry. The 'add new data' forms are equipped with a burgundy and gray background so that the users are aware they should be adding new data. A form of this type is reproduced in Figure 5-3. 


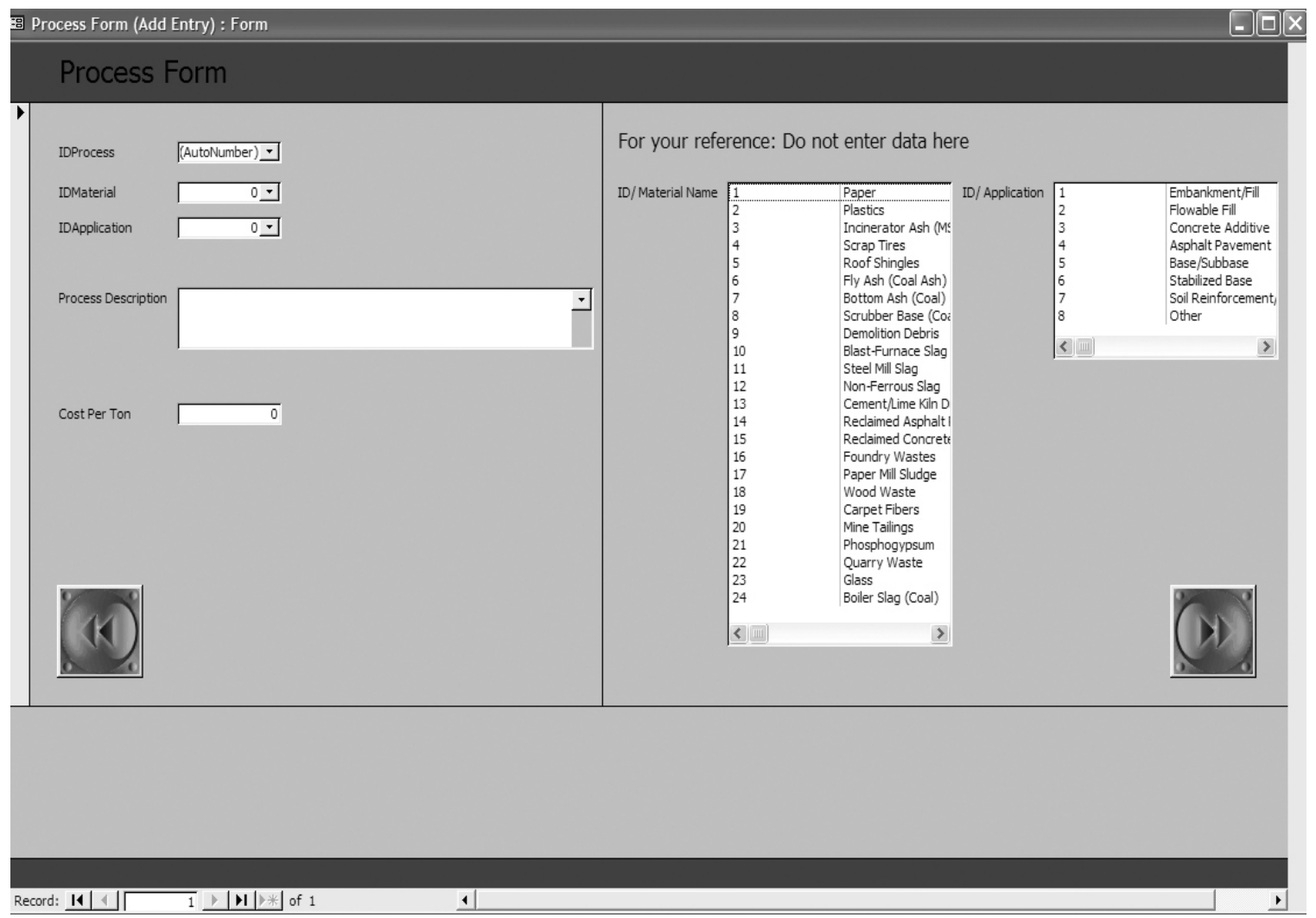

Figure 5-3: Process Form ('Add New Data')

Although not included in the database framework, forms may also be created from queries. A user can simply attach a form to a query. Each time the user types in a word, phrase, number, or other data in the appropriate field, the query finds the relevant information and summarizes it for the user. Connecting a form to a query merely improves the visual aspects of the user interaction with queries. It is equally functional to allow the user to create a custom query with the help wizard or design his own. There are too many features provided by the database management system to design for each and every one.

\section{Queries}

One of the purposes of queries is to find specific portions of data. They are questions that extract a subset of data displayed in the form of a summary table. 
However, they also have the potential to perform mathematical manipulation of existing data. General queries are created for some of the data subsets that attract interest. These include queries for each of the eight applications, queries for each of the twenty-four materials, queries for each of the over 50 processes, and queries for some of the more prolific authors of recycled materials case studies. In addition to the standard queries, the user has the option of creating custom queries. If for example, the user is only interested in a material or process that exhibits a certain compressive strength, a query may be used to display all the materials and processes that meet that criteria. The user may also create a custom query to avoid any process or case study that corresponds to a particularly troublesome chemical compound. Queries can be set up to search for incredibly detailed information or for more general lists. In addition to queries that simply select data drawn from multiple tables, there are four more types. Table 5-1 lists all query types.

Table 5-1: Types of Queries (Whitehorn and Marklyn, 2003)

\begin{tabular}{|l|l|}
\hline Query Type & Usage \\
\hline Select & Select fields/records from table according to specified criteria \\
\hline Parameter & Displays prompt boxes to supply query criteria \\
\hline Range & Selects fields/records which contain a range of values \\
\hline Group By/Crosstab & Displays summarized values (sums, averages) in a grid \\
\hline Action & Performs actions to change records or create new tables \\
\hline
\end{tabular}

In the given database, queries are created constantly to generate reports, view gaps in the data, and summarize information for presentations. An example query is created here for reference. The query assumes interest in all possible applications for coal fly ash. In addition, the assumption is made that the user wants to know the range of values for specific gravity as well as the high end values for both internal friction angle and permeability. Figure 5-4 shows the design view of the custom 'select' query. 


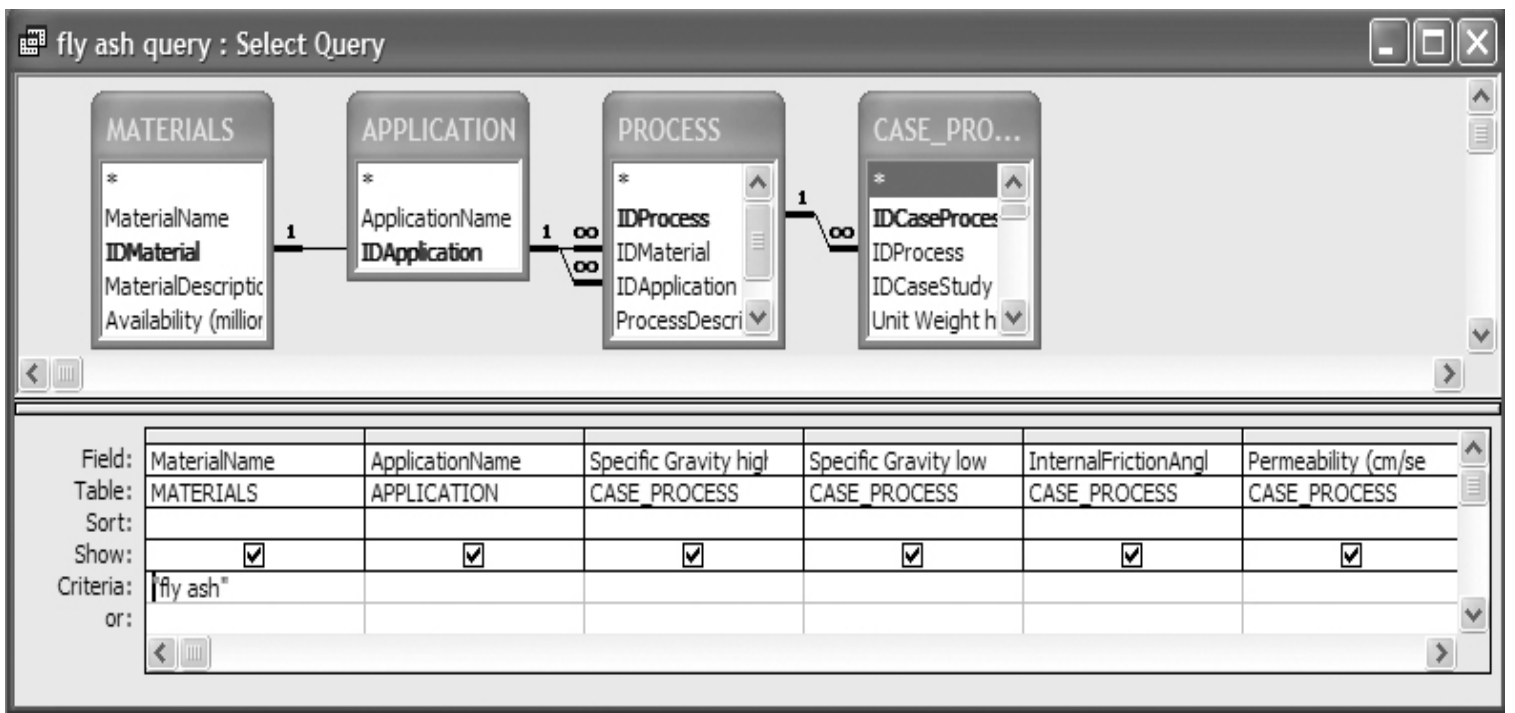

Figure 5-4: Fly Ash Query Design

The output is generated in the form of a table, which combines the fields of interest from the Material, Application, and Case/Process tables. The output can be used to generate a report or form. Figure 5-5 shows the output from the fly ash 'select' query.

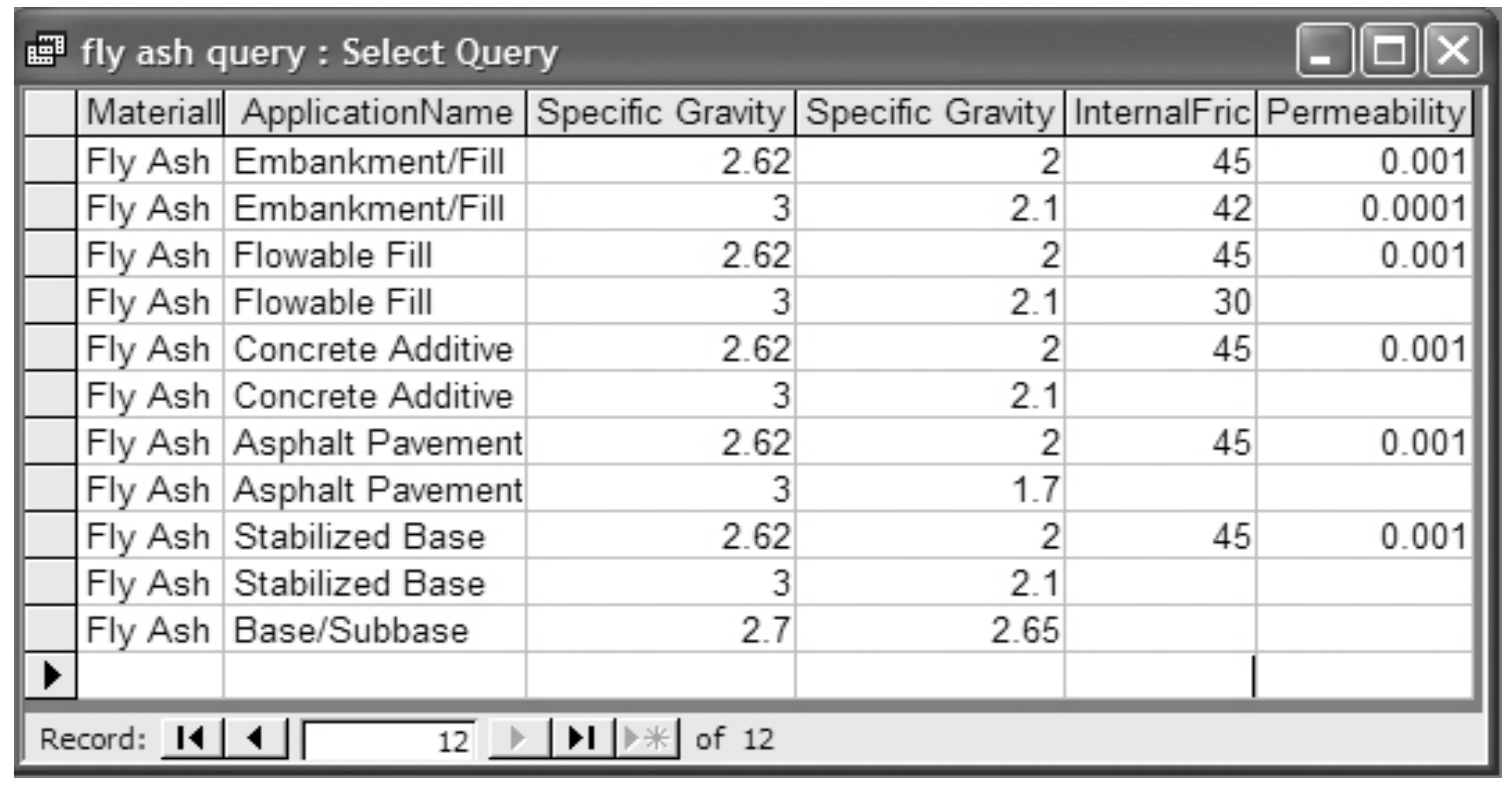

Figure 5-5: Fly Ash Query Output 


\section{Reports}

A report is simply a collection of summarized information that is acceptable for printing. Unlike forms, their purpose is not user interaction. Instead, reports prepare data for printing and presentation. To function properly, the database does not require their creation. However, the user can easily create custom forms from existing or custom queries to use in presentations or in hard copies of documents. One such report is created below. Figure 5-6 shows a portion of the report created from the 'select' custom query for fly ash. This time, the only information of interest is the material, fly ash, its applications, and range of specific gravity.

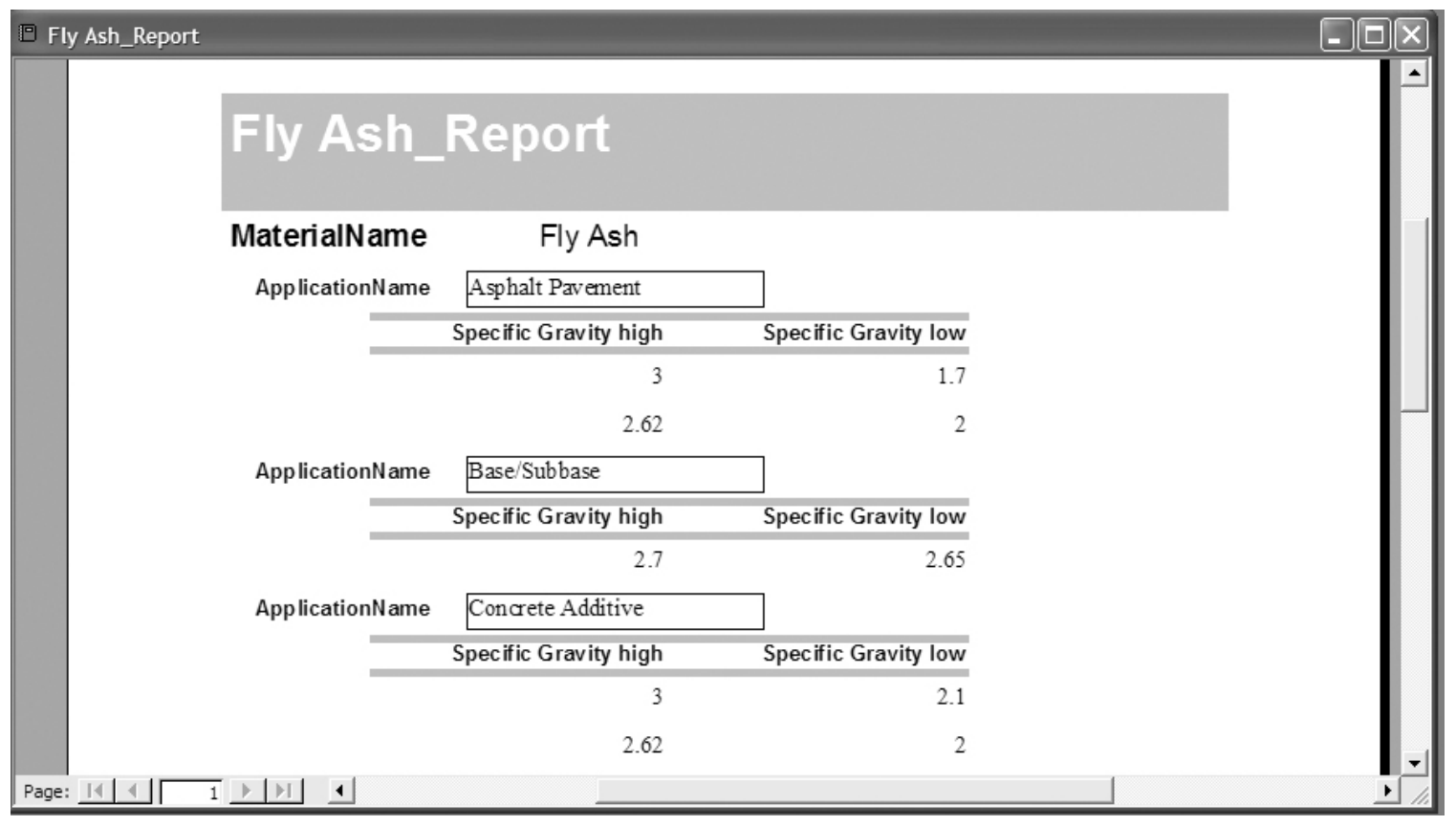

Figure 5-6: Fly Ash Custom Report

Interface

The interface is setup to provide an aesthetically pleasing backdrop wherein the user can view existing data or add new data. The importance here is to provide an easily 
navigable interface so that the user does not get lost. This is accomplished by linking components of the interface to produce a seamless whole.

\section{Navigating Existing Data Forms}

When the user opens the database, a switchboard opens that allows the user to choose between two options - 'View Existing Data' or 'Add New Data.' Choosing the first option takes the user directly to the first form in the 'view existing data' set - the Material form. The Material form window actually opens on top of the switchboard, concealing it from view. The default view of the first record for the material, Paper, is showing. The user can scroll through all the records in the Material table, viewing each field in from the 24 records that correspond to the 24 materials. The user may then move to the next form in the sequence, the Application form, by clicking on the next arrow and continue examining records or he may close the Material form by clicking on the back arrow. Each subsequent form window opens on top of the preceding form but may always be closed by clicking on the "Back" button. The final form in the sequence, the Leachate form, is equipped with an additional option of returning to the home or switchboard. The entire sequence is as follows: Material, Application, Process, Performance, Case/Process, Chemical Composition, Metal Concentration, Organic Concentration, and Leachate.

\section{Navigating New Data Forms}

If the user instead chooses the second option, 'Add New Data,' a second switchboard opens revealing four additional choices. The user may 'Add New Material,' 'Add New Application,' 'Add New Process,' or 'Add New Case Study.' Each choice

opens a different form that is separate from the 'view existing data' form set. These forms have burgundy and gray backgrounds, and their fields are initially blank. Choosing the first option will send the user to the Material (Add Entry) form into which the user can input a new material by typing it into the appropriate field (MaterialName). 
Here the primary key, IDMaterial, automatically increments to the next number - in this case 25 , and the rest of the fields within the form can be filled in by the user. A list box containing all existing materials is included for user reference. If for some reason the user enters a material that already exists, it will be possible to save the changes made to the form. This is because the property 'index: Yes (no duplicates)' in the field corresponding to material name has been selected. This is true for all fields where duplication would create confusion or otherwise slow the flow of data.

After entering the information required, the entry is saved by clicking on the 'save' button and the user navigates to the next form in the series, the Application (Add Entry) form where a similar process is followed. Upon continuing to the Process (Add Entry) form, a new process may be added. However, since a process is a unique material/application combination, a new process may be the result of adding a new material, adding a new application, adding both, or simply creating a new combination from an existing material and an existing process. To ensure consistency, the Process form is equipped with combo boxes, or pull-down boxes from which the user may select an existing IDMaterial and an existing IDApplication. The most recent of these values also shows up as the last entry in the choices within the combo box. When the user selects these values, a new IDProcess number automatically increments to create a new process.

The second switchboard has four options to help the user control data input. For example, the user may need to add just a new material, or just a new application. Perhaps the user may choose instead to create a new process from an existing material and an existing application. In this case, choosing the option at the second switchboard to 'Add New Process,' allows skipping the first two forms. The same is true for the Performance (Add Entry) form, which permits a user to enter new reference information from a recent case study. In choosing any of the four options, the user will eventually work his way through the entire sequence of forms - saving each new record throughout. A partial flow diagram delineating user navigation between forms is shown in Figure 5-7. 


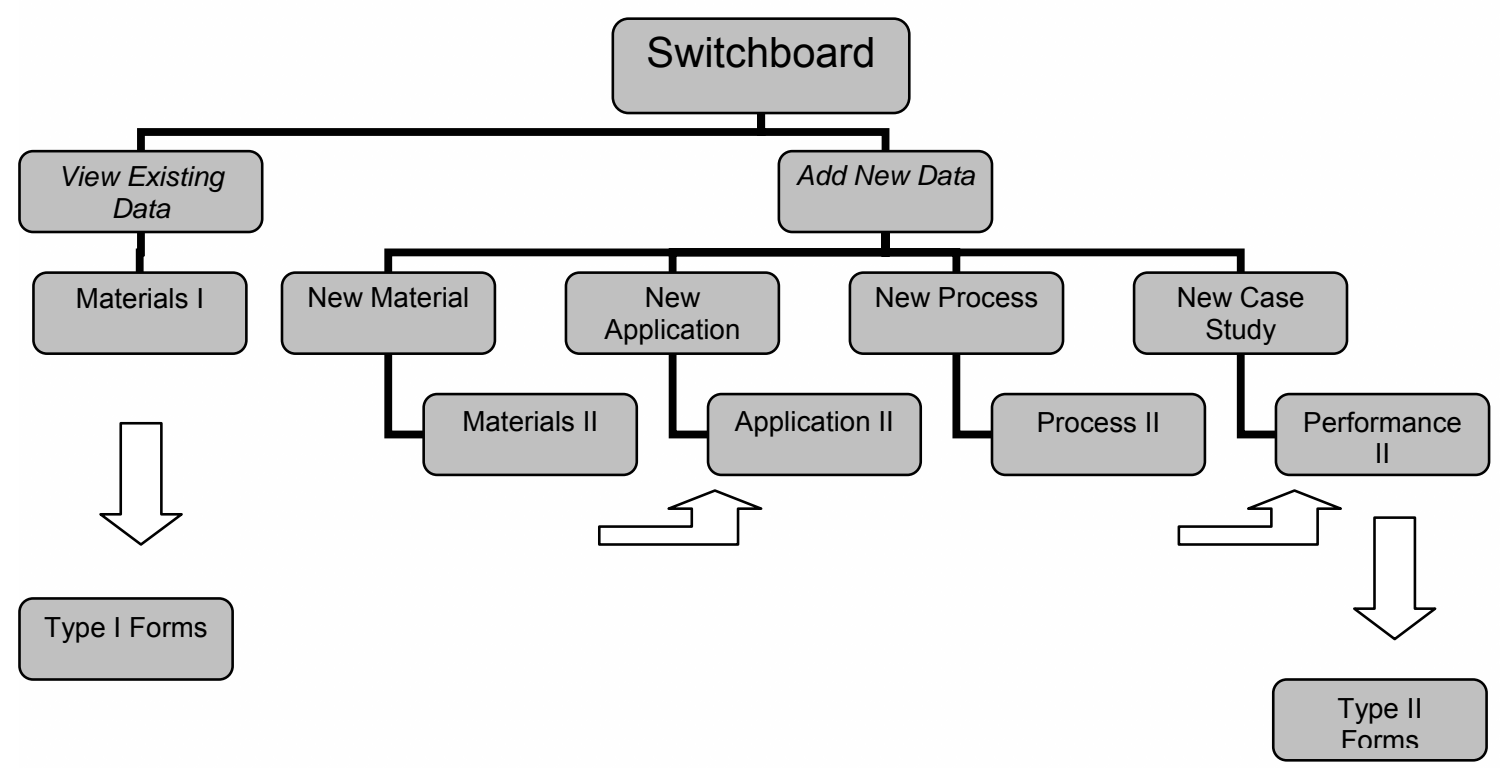

Figure 5-7: Interface Flow Diagram

\section{Modification}

It is impossible to design the database to cater to the needs of every engineering or research professional. The database is only a framework, albeit a robust one, which can be added to, improved, or even revamped. A database professional could certainly take advantage of features such as macros, scripts, or even create an improved interface through original code. On a more basic level, a designer might choose to add additional tables that organize pertinent recycled material data not included here. In addition, fields can be added within existing tables or removed at the discretion of the designer. It is envisioned that the relational database is the beginning - a first step in bridging the gap between academic research and engineering practice in recycled materials. 


\section{Chapter Six: Cost and Recommendations}

Cost

Overview

Quantifying the cost of recycled materials is a very difficult issue to address. This is the result of several factors. First, as a general observation, very little information is available regarding the cost of most recycled materials, which are cited in the literature. Researchers are much more concerned with evaluating engineering performance and even environmental impact of the materials rather than developing cost comparisons. Another problem with costs associated with waste materials is that they constantly fluctuate and change consistently over time. Over time, new taxes, environmental fines, restrictions, and inflation all have a progressive effect on costs. In addition, costs change as a result of improvements in recycling processes and variations in market conditions. For example, twenty years ago, very few tire-recycling firms even existed. As of the beginning of 2004 however, some 41 tire recycling facilities are located in Florida alone (DEP, 2003). The increase in firm competitiveness and productivity has driven down both direct and indirect costs. Another problem with quantifying costs stems from the large discrepancies in waste material cost and availability on both a national and a local level. Transport costs and premium costs associated with limited material availability can be greatly affected. Finally, cost analysis sometimes takes into account more subjective criterion such as cost to landfill and cost to the environment if the materials are not reused. In short, cost is difficult to quantify for researchers, engineering professionals, and database designers. 


\section{Considerations}

Comparison is a key issue in recycled material research. Waste materials must be compared to the traditional materials that they are replacing, and waste materials must be compared to each other. Perhaps the first consideration for the use of any material is adequate engineering performance. If the waste material functions adequately in the specified application, it can at least be considered for potential use. However, once this criterion has been met, the cost of the recycled material must be compared to established materials such as select fill, aggregate, etc. It is difficult to make the case for using a particular recycled material if the costs associated with it are higher than those of accepted materials. One possible exception occurs when materials are mandated for use through government legislation or bureaucratic regulation. In this case, cost is barely a consideration. However, this case will not be addressed here. Instead, recycled materials will be examined theoretically from a comprehensive consideration of all cost components.

\section{Cost Breakdown}

Although very few researchers have addressed cost in investigating the use of recycled materials, Chesner et al. (2002) develops cost considerations by borrowing from the economics of manufacturing. Specifically, three components are examined: cost of the material, cost of installation, and life-cycle cost. It is the opinion of the author that a fourth cost, environmental cost, should also be considered in the analysis.

\section{Material Cost}

The material cost is associated with what the buyer - in this case the engineering firm, contractor, or agency would pay to have the material on site and available for use. The seller would be the material supplier, recycling firm, or material handler. Equation 1 is proposed by Chesner et al. (2002) to express material cost: 


$$
C_{D P}=P_{R M}+C_{P R}+C_{S T}+C_{L D}+C_{T R}+P
$$

where,

$\mathrm{C}_{\mathrm{DP}}=$ Delivered price

$\mathrm{P}_{\mathrm{RM}}=$ Raw material price

$\mathrm{C}_{\mathrm{PR}}=$ Processing cost

$\mathrm{C}_{\mathrm{ST}}=$ Stockpiling cost

$\mathrm{C}_{\mathrm{LD}}=$ Loading cost

$\mathrm{C}_{\mathrm{TR}}=$ Transporting cost

$\mathrm{P}=$ Profit

It must be emphasized that the components of the equation are necessary only when there exists a significant difference in the cost in comparison to similar costs associated with traditional materials. For example, transporting may be necessary for select fill as well as for scrap tires. However, due to the large void ratio of scrap tires in relation to select fill, more truckloads may be required thereby increasing the cost.

Transporting, loading, and stockpiling costs are all self-explanatory. However, it must be mentioned that the raw material price can essentially have a positive or negative value. In general, if a recycler or processing firm sells the material, the raw material price will be positive, whereas if a manufacturing plant or production facility must otherwise dispose of the waste material for a fee, the raw material price will be negative (Chesner et al., 2002). Processing costs are those associated with refining a waste material so that it can be used. This involves shredding, crushing, screening, presorting etc. Processing costs are extremely variable depending on the material that is processed, processing requirements, and establishment of the recycling market. For example, economies of scale allow shredded tires to be produced at a lower per unit cost than several other materials that require markedly less processing. Profit is also highly variable. 


\section{Installation Cost}

The engineering firm or contractor may plan to subcontract the installation out or they may be interested in potential incurred costs as a result of installation. In addition, some materials require monitoring of both engineering systems and environmental impact. Some pre-testing of the material might also be necessary. Chesner et al. (2002) proposes Equation 2 to address such costs. Again, these component costs are only taken into account when there is a significant difference between the recycled material and the material for which it is substituting:

$$
C_{I}=C_{D R}+C_{C}+T_{R P} \quad(E q .2)
$$

where,

$\mathrm{C}_{\mathrm{I}}=$ Installation cost

$\mathrm{C}_{\mathrm{DR}}=$ Design cost

$\mathrm{C}_{\mathrm{C}}=$ Construction cost

$\mathrm{T}_{\mathrm{RP}}=$ Testing/inspection cost

\section{Life-Cycle Cost}

To further the comparison, it is important to consider the effect that the use of a recycled material in lieu of an established material has on maintenance or upkeep. This borrows from the economics of manufacturing in which the cost of a new machine must be compared to an older machine requiring yearly maintenance. Equation 3 proposed by Chesner et al. (2002) is basically an equivalent annuity calculated from a combination of maintenance costs, interest rates, and product life: 


$$
A_{E C}=C_{I} \times C R F(i, n)+C_{A M}
$$

where,

$\mathrm{A}_{\mathrm{EC}}=$ Annual effective cost

$\mathrm{C}_{\mathrm{I}}=$ Installation cost (Eq. 2)

$\mathrm{CRF}(\mathrm{i}, \mathrm{n})=$ Capital recovery factor (percent interest, $\mathrm{i}$, and product life, $\mathrm{n}$ )

$\mathrm{C}_{\mathrm{AM}}=$ Annual maintenance cost

Life-cycle cost is only an issue when recycled material use results in additional requirements in terms of maintenance and repair. For example, an asphalt pavement road may require supplementary maintenance techniques in addition to more regular servicing.

\section{Environmental Cost}

Although not included in the preceding cost analysis, environmental cost is very real and must be included for the sake of completeness. Unfortunately, environmental cost is much more esoteric - requiring subjective evaluation. It includes the potential environmental costs associated with not using a particular material. It might also include costs associated with mandated environmental cleanup as well as costs required to deal with problems of rapidly-filling landfills. No equation is proposed here to deal with this cost.

Database and Cost

From the database standpoint, it is not advisable to include cost in its current format. Currently, cost per ton is a field in the Process table. In other words, for each material/application combination, there is a total cost associated with it. However, this oversimplifies the cost issue as evidenced by the previous discussion. It has been proposed to include the cost in addition to the year in which the cost data or quote was obtained. Other suggestions include providing a local or source-specific framework in 
which to view the evolution of cost over time and by region. These topics are ambitious and might be better suited for a separate database. However, they represent some interesting directions for the research.

Recommendations

This section is meant not to present conclusions on the use of precise materials in specified applications. Rather, this information should be drawn by the reader of this paper and the user of the database. The focus is placed on more qualitative recommendations, suggestions for further recycled material research, and additional database feature propositions. In addition, a fundamental question from the research must be asked. Does the recycled material relational database adequately address the redefined problem presented in Chapter 1?

\section{General Recommendations}

From reading the literature and speaking with engineering professionals, it is apparent that a quality control mechanism must be in place if the goal of recycled materials implementation is to be achieved. Perhaps the most expeditious method to achieve it is through source control. By ensuring that a material comes from the same source and is processed in a consistent way, many of the variables associated with engineering performance and environmental impact can be at least partially controlled. The wide range of engineering parameters especially for unit weight, CBR, internal friction angle, permeability, and compressive strength emphasize the need to test materials at the local level from a controlled source using specified sampling procedures Once consistency can be established, and more importantly assured at the local level, the use of recycled materials will be greatly facilitated. High up-front costs associated with quality control through testing should lead to lower costs in the future. In addition, it is advisable to involve national and state environmental organizations such as EPA and DEP at every stage. Besides agency control of recycled materials, another option is to 
place the burden of quality control squarely on the sellers - recycling firms and materials generators. The responsibility of presorting, processing, testing, and possibility transport - all to achieve a quality product, will be handled by those profiting from the sale of the material.

\section{Additional Research}

As a result of this study and the database, certain gaps in recycled material research have surfaced. These gaps can be filled with appropriate laboratory and field testing to completely characterize the material properties and potential uses. It is suggested that three materials be investigated further: roof shingles (prompt and tear-off), paper mill sludge, and plastic. Little research has been done on both roof shingles and paper mill sludge, and plastic use thus far has been promising. Plastic should be investigated further in soil stabilization, and potential supplementary applications should be explored. Another avenue of research involves the development of construction guidelines and required field equipment so as to be able to actually build with recycled materials. Examples include guidelines and equipment to install discrete recycled material stabilizers such as plastic piles or to homogenously mix marginal soils onsite with property-enhancing waste material components or fibers. It may also be beneficial to develop candidate applications for the use of different recycled materials depending on site conditions, soil type, and other factors.

\section{Database Recommendations}

The addition of several components has been suggested and their incorporation into the database may be beneficial to both academics and engineers. The first is to bring some element of local availability and cost into the database. This would require investigating local market sources of each recycled material. In this way, a user would have access to a variety of pertinent information. For example, three different plants might sell a particular recycled material for a specified price with a given list of 
engineering properties and long-term environmental impact data. Access to this kind of information would be invaluable not only to design engineers and contractors, but also to state agencies and environmental organizations. A general database recommendation is to develop parameter or select queries to be connected to the interface through their own form set. Finally, the debugging process must continue, the interface can be improved, and wider access to the database can be achieved by making the database available online.

\section{Conclusion}

This study addresses the challenges of implementing a recycled material program. Its purpose is to bridge the gap between quality academic research on recycled materials and implementation of this research in engineering practice. The creation of a recycled material relational database resolves several issues. First, it provides a single resource that contains relevant data and case studies on the materials, their applications and processes, and the numerous environmental and engineering properties that characterize them. Information is organized through a seamless interface that consists of forms connected to the rest of the database with tables. Second, the relational model allows rapid sorting of data. Existing and customizable queries can be used to find subsets of data that are tailored to the user's interests. The information can in turn be used to implement a recycled material program. Finally, the user can amend existing data, update the database to keep pace with current research, or modify the design of the original database. In short, it is envisioned that the recycled material relational database will serve as a flexible, usable tool for professionals seeking to implement recycled material programs. 


\section{References}

Abichou, T., Benson, C.H., Edil, T.B., Freber, B.W. (1998), Recycled Materials in Geotechnical Applications, ASCE GSP 79, C. Vipulanandan, and D.J. Elton, Eds., pp. 86-99.

Aerotech Environmental Laboratories, (2004), Leaching Procedures. Accessed on June 15, 2004. http://www.palabs.com/Resources/splp_limits.asp.

Bosscher, P.J., Edil, T.B., and Kurako, S. (1997). "Design of highway embankments using tire chips." J. of Geotech. and Geoenviron. Eng., Vol. 123, No. 4, pp. 295-304.

Chesner, W. H., Simon, M.J., Eighmy, T.T. (2003). "Recent federal initiatives for recycled material use in highway construction in the United States." Beneficial Use of Recycled Materials in Transportation Applications, The Recycled Material Resource Center, T.T. Eighmy, Eds., pp. 3-10.

Chesner, W., Stein, C., Collins, R., and MacKay, M. (1998), National Cooperative Highway Research Program Waste and Recycled Materials Information Database. Accessed on January 7, 2004. http://www.rmrc.unh.edu/Resources/PandD/NCHRP.

Chesner, W., Collins, R.J., MacKay, M., and Emery, J. (2002), User Guidelines for Waste and Byproduct Materials in Pavement Construction. Accessed on January 15, 2004.

Collins, R.J., and Ciesielski, S.K. (1994), "Recycling and use of waste materials and byproducts in highway construction." National Cooperative Highway Research Program Synthesis of Highway Practice 199, National Academy Press.

Consoli, N.C., Montardo, J.P., Prietto, P.D.M., and Pasa, G.S. (2002). "Engineering behavior of a sand reinforced with plastic waste." J. of Geotech. and Geoenviron. Eng., Vol. 128, No. 6, pp. 462-472.

Department of Environmental Protection (2003), "Waste tires in Florida, state of the state." Accessed on January 17, 2004. http://www.dep.state.fl.us/waste.

Edil, T.B, and Benson, C.H. (1998), "Geotechnics of industrial by-products.” Recycled Materials in Geotechnical Applications, ASCE GSP 79, C. Vipulanandan, and D.J. Elton, Eds., pp. 1-18. 
Fahoum, K. (1998), "Utilization of lagoon-stored lime in embankment construction." Recycled Materials in Geotechnical Applications, ASCE GSP 79, C. Vipulanandan, and D.J. Elton, Eds., pp. 115-121.

Humphrey, D.N., Whetten, N., Weaver, J., Recker, K., Cosgrove, T.A. (1998), “Tire shreds as lightweight fill for embankments and retaining walls." Recycled Materials in Geotechnical Applications, ASCE GSP 79, C. Vipulanandan, and D.J. Elton, Eds., pp. 51-65.

Kim, A.G. (2003), CCB Leaching Summary: Survey of Methods and Results. Accessed on June 15, 2004. http://www.mcrcc.osmre.gov/PDF/Forums/CCB3/4-2.pdf.

Liu, H.S., Mead, J.L., and Stacer, R.G. (2000). "Environmental effects of recycled rubber in light-fill applications.” Rubber Chem. Technol., Vol. 73, pp. 551-564.

Loehr, J.E., and Bowders, J.J. (2000). "Slope stabilization with recycled plastic pins." Geotechnical News, Vol. 18, No. 1, pp. 41-44.

Mast, D.G., and Fox, P.J. (1998). "Geotechnical performance of a highway embankment constructed using waste foundry sand." Recycled Materials in Geotechnical Applications, ASCE GSP 79, C. Vipulanandan, and D.J. Elton, Eds., pp. 66-85.

O’Shaughnessy, V., and Garga, V.K. (1999). "Tire-reinforced earthfill. Part 3: environmental assessment.” Can. Geotech. J., Vol. 37, pp. 117-131.

Papp, W.J., Maher, M.H., Bennert, T.A., and Gucunski, N. (1998), "Behavior of construction and demolition debris in base and subbase applications." Recycled Materials in Geotechnical Applications, ASCE GSP 79, C. Vipulanandan, and D.J. Elton, Eds., pp. 122-136.

Quiroz, J.D., and Zimmie, T.F. (1998), "Paper Mill Sludge Landfill Cover Construction." Recycled Materials in Geotechnical Applications, ASCE GSP 79, C. Vipulanandan, and D.J. Elton, Eds., pp. 19-36.

Reid, R.A., Soupir, S.P., Schaefer, V.R. (1998), "Mitigation of void development under bridge approach slabs using rubber tire chips." Recycled Materials in Geotechnical Applications, ASCE GSP 79, C. Vipulanandan, and D.J. Elton, Eds., pp. 37-50.

Senadheera, S.P., Jayawickrama, P.W., and Rana, A.S.M. (1998), "Crushed hydrated fly ash as a construction aggregate." Recycled Materials in Geotechnical Applications, ASCE GSP 79, C. Vipulanandan, and D.J. Elton, Eds, pp. 167-179.

Tandon, V., Picornell, M. (1998), "The safe disposal of fly ash in pavement or earth structures not requiring high strength materials." Recycled Materials in Geotechnical Applications, ASCE GSP 79, C. Vipulanandan, and D.J. Elton, Eds., pp. 153-166. 
Vipulanandan, C., and Bashaeer, M. (1998). "Recycled materials for embankment construction." Recycled Materials in Geotechnical Applications, ASCE GSP 79, C. Vipulanandan, and D.J. Elton, Eds., pp. 100-114.

Vipulanandan, C., Weng, Y., and Zhang, C. (1998), "Role of constituents on the behavior of flowable fly ash fill." Recycled Materials in Geotechnical Applications, ASCE GSP 79, C. Vipulanandan, and D.J. Elton, Eds., pp. 137-152.

Wang, Y. (1999). "Utilization of recycled carpet waste fibers for reinforcement of concrete and soil." J. of Polym.-Plast. Technol. Eng., 38(3), 533-546.

Whitehorn, M., and Marklyn, B. (2001). "Inside Relational Databases." A book published by Springer. London.

Whitehorn, M., and Marklyn, B. (2003). “Accessible Access 2000.” A book published by Springer. London.

Yang, S., Lohnes, R.A., and Kjartanson, B.H. (2002). "Mechanical properties of shredded tires." Geotechnical Testing J., Vol. 25, No. 1, pp. 44-52. 